

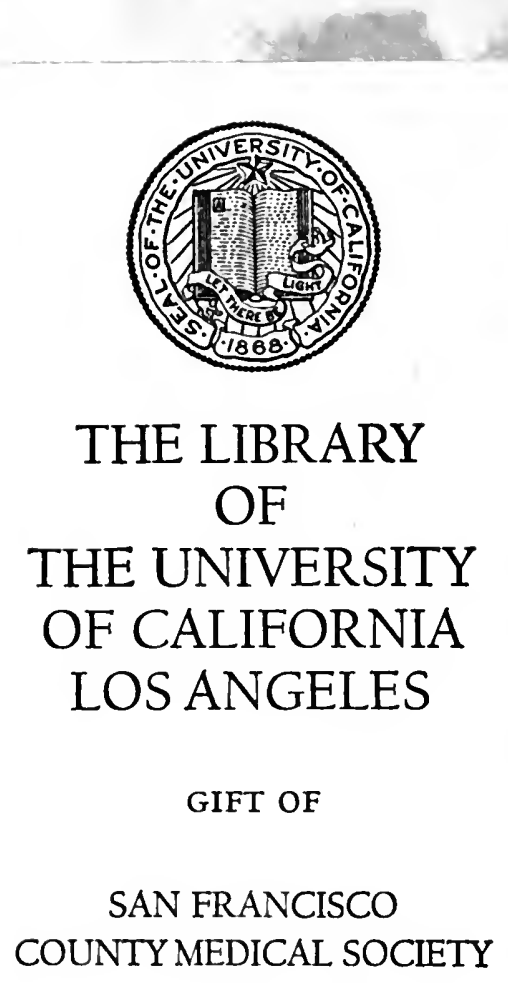




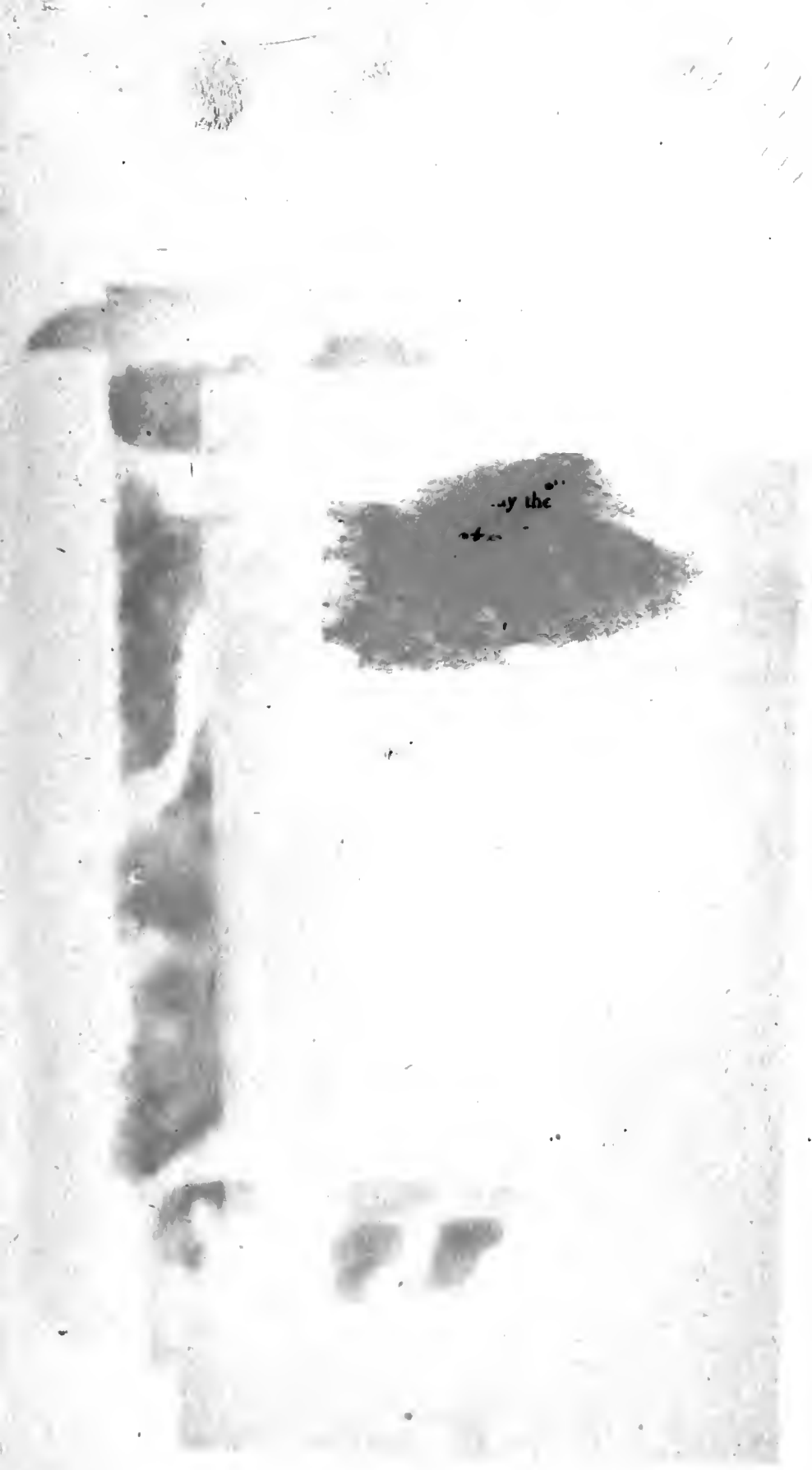


Digitized by the Internet Archive in 2007 with funding from

Microsoft Corporation 



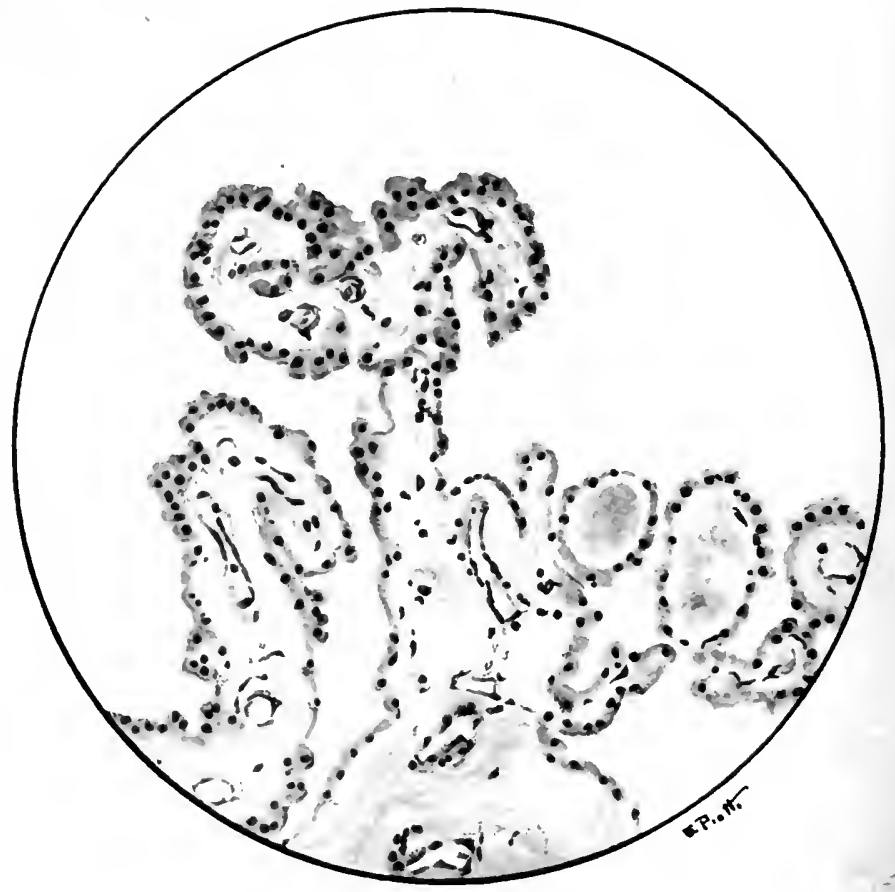

Choroid Plexus. 


\section{PHYSIOLOGY AND PATHOLOGY OF THE}

CEREBROSPINAL FLUID 


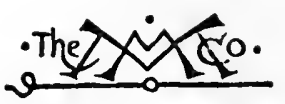

THE MACMILLAN COMPANY

NEW YORK BOSTON - CHICAGO - DALLAS

ATLANTA - SAN FRANCISCO

MACMILLAN \& CO., L.imiteD

LONDON - BOMBAY - CALCUTTA MELBOURNE

THE MaCMillaN CO OF CANADA, Lto. TORONTO 


\title{
Physiology and Pathology of the
}

\section{Cerebrospinal Fluid}

\author{
BY \\ WILLIAM BOYD \\ Professor of Pathology, University of Manitoba \\ Pathologist, Winnipeg General Hospital
}

田ew 撃ork

THE MACMILLAN COMPANY

1920

All rights reserved 
Copyright, 1920 ,

Bx THE MACMILLAN COMPANY

Set up and electrotyped. Published, June, 1920 


\section{Biomedieal}

Library

$$
\begin{aligned}
& \text { WL } \\
& 203 \\
& B 692 p \\
& 1920
\end{aligned}
$$

TO

MY TEACHER AND

CHIEF

BYROM BRAMWELL 

Cet enfant a de l'eau dans le tête, dit le vulgaire: cet enfant est hydrocéphale, dit gravement le médecin, répétant littéralement par un mot grec ce que dit l'ignorant dans sa propre langue. Mais quelle est cette eau? d'où vient-elle? Voilà ce dont les médecins auraient dû s'occuper.

MAGENDie. 



\section{PREFACE}

The object of this book is to present some of the fascinating physiological problems connected with the cerebrospinal fluid, and to show how they are related to the pathological problems which more directly concern the clinician. Not until the method of production and absorption of the fluid is completely understood can there be any hope of solving the age-long problem of the treatment of hydrocephalus; not until the details of the circulation of the fluid have been mastered, can intraspinal injections of drugs and sera be expected to fulfill the hopes of the therapeutist.

Any means which will facilitate the difficult diagnosis of diseases of the central nervous system is of value, and the cerebrospinal fluid, which bathes its deepest recesses and washes the very nerve cells and fibers themselves, is in truth a mirror which reflects every change taking place in that system. 



\section{CONTENTS}

\section{PART I}

I INTRODUCTORY

II Anatomical Considerations . . . . . . 6

III Origin and Destination of the Fluid . . . 14

IV The Circulation of the Fluid . . . . . . 23

$\mathrm{V}$ Functions of the Cerebrospinal Fluid • • • 29

VI Pressure of the Cerebrospinal Fluid . ' . 33

VII Lumbar Puncture • • . • . . • . . 36

VIII Physical Properties . . . . . . . . 4 I

iX Chemical Composition . . . . . . . . 49

X Cytology . . . . . . . . . . . . 60

XI Wassermann Reaction . . . . . . . 73

XII Colloidal Gold Reaction of Lange . . . 79

XIII Bacteriological Methods • . . . . . 86

PART II

SPECIAL

XIV Meningitis • • : • • • • • • •

Meningococcal meningitis . . . . . . . 92

Pneumococcal meningitis . . . . . . . 97

Streptococcal meningitis . • • . • . . . 99

Tuberculous meningitis . . . . . . . . IOO

Meningitis due to other organisms . . . . 104

Serous meningitis . . . . . . . . . I05

XV Syphilis of the Central Nervous System • . i io

Early syphilis . . • . . . . . . . . I I I

Cerebrospinal syphilis . . . . . . . . II3

Tabes dorsalis . . . . . . . . . . II5

General paresis . . . . . . . . . . II7

Juvenile general paresis . . . . . . . . 120 
XVI Organic Disease of the Brain .

Cerebral tumor

Cerebral abscess . . . . . . . . . . 124

Cerebral hæmorrhage . . . . . . . 126

Cerebral thrombosis . . . . . . . . . 127

Encephalitis . . . . . . . . . . . I27

Hydrocephalus . . . . . . . . . . I28

Concussion; shell shock . . . . . . . . I3I

Oedema of the brain . . . . . . . . . I3I

XVII Organic Disease of the Spinal Cord . . . $~ i 33$

Tumor of the spinal cord . . . . . . . I33

Syringomyelia . . . . . . . . . . I 35

Acute myelitis . . . . . . . . . . I35

Acute anterior poliomyelitis . . . . . . . I35

Subacute combined degeneration . . . . . I40

Multiple sclerosis . . . . . . . . . . I4I

Herpes zoster . . . . . . . . . . I4I

XVIII Mental Diseases . . . . . . . . . . 143

Manic-depressive insanity . . . . . . . I43

Epilepsy . . . . . . . . . . . . I44

Dementia præcox . . . . . . . . . . I44

Alcoholism . . . . . . . . . . . I45

Idiocy and imbecility . . . . . . . . . I45

XIX General Diseases . . . . . . . . . I46

Diabetes . . . . . . . . . . . . 146

Uræmia . . . . . . . . . . . . 146

Chorea . . . . . . . . . . . . I48

Mumps . . . . . . . . . . . . I49

Pneumonia . . . . . . . . . . . I5I

Sleeping sickness . . . . . . . . . . I5I

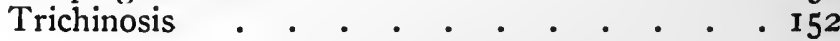

XX Therapeutics . . . . . . . . . . . . I55

Lumbar puncture . . . . . . . . . . . I55

Serum treatment of cerebrospinal meningitis . . I58

Tuberculous meningitis . . . . . . . . I62

Poliomyelitis . . . . . . . . . . . I62

Intraspinal treatment of neuro-syphilis . . . I63

Tetanus . . . . . . . . . . . . I70 


\section{LIST OF ILLUSTRATIONS}

\section{IN BLACK AND WHITE}

Diagrammatic representation of distribution of the cerebrospinal fluid ... . . . . . . . . . 8

Lumbar puncture needle in arachnoid sac . . . . . . I2

Cassidy and Page's Spinal Pressure Set . . . . . 34

The bony landmarks for lumbar puncture . . . . . 36

Mastic test in General Paresis . . . . . . . . 85

\section{COLORED PLATES}

Choroid Plexus . . . . . . . . . Frontispiece

Normal cell count . . . . . . . . . . . . 63

Meningococcal Meningitis . . . . . . . . 93

Pneumococcal Meningitis . . . . . . . . . 97

Streptococcal Meningitis . . . . . . . . . . . 99

Lymphocytosis in General Paresis . . . . . . . I15 

PART I

GENERAL 



\title{
PHYSIOLOGY AND PATHOLOGY OF THE CEREBROSPINAL FLUID
}

\author{
CHAPTER I
}

\section{INTRODUCTORY}

The fluids of the body have aroused interest and speculation from times immemorial. Observations on the blood and the urine are to be found in the earliest medical works, and the speculations as to their function and composition would fill a library of volumes. Although it was hardly to be expected that the same amount of interest should have been aroused by the cerebrospinal fluid, yet reference to the contents of the cerebral ventricles is made by many of the earliest writers. Galen, Vesalius, and Valsalva all note its presence, and it would have been remarkable if the existence of a watery fluid in the interior of the skull should have escaped such an accomplished observer as Aristotle. Cotugno in I 762 and Haller in I 766 both described the existence of a clear limpid fluid not only in the ventricles of the brain, but also in the space between the membranes and the convolutions.

Our modern interest in the fluid dates from the masterly observations and equally masterly description of Magendie in I825. It was he who first realized the intimate connection between the fluid in the ventricles and that in the subarchnoid space, and also the physiological possibilities of a fluid which comes into such close relation with the central nervous system. His description of the distribution of the fluid, and of the effects of varying intracranial pressure is of sufficient interest to bear quotation:

Entre la pie-mère et l'arachnoide se touve un liquide que je propose d'appeler cérébro-spinale; il existe chez l'homme et 
chez tous mammifères. Il sert à combler le vide qui existerait entre le cerveau et le crâne osseux; il se régénère avec rapidité, peut circuler à travers les ventricules cèrèbraux et les espaces sous-arachnoidiens du cerveau et de la moelle. Au moment de l'expiration le cerveau se gonfle; le liquide cérébro-spinale passe du crâne dans le canal vértèbral. Quand on augumente la pression du liquide, on produit des phénomènes de paralysie et, d'autre part, quand par une ouverture on provoque l'issu de ce liquide, le cerveau et la moelle n'étant protégés, il survient une débilité et une faiblesse générale de l'animal.

In I89I Quincke introduced the operation of lumbar puncture in the living subject, and an enormous impetus was at once given to the study of the fluid in various pathological conditions. Lumbar puncture was originally introduced for therapeutic purposes, as a means of lowering an abnormally high introcranial pressure. Soon, however, the diagnostic possibilities came to overshadow those of therapeutics, and the French school, led by Widal, Sicard, and Ravaut, showed in I9O I that very important and characteristic changes occurred in the cytology of the fluid in certain nervous diseases, notably those associated with syphilis. Constant changes in the fluid were also found in conditions of acute meningitis.

It was soon realized that just as an examination of the blood can afford valuable information regarding pathological changes in the tissues through which it circulates, so the morbid conditions affecting the central nervous system are in many cases reflected with a remarkable degree of accuracy by the ambient fluid which bathes its remotest recesses and receives the products of its metabolism. As the original somewhat coarse technique becomes more and more refined the diagnostic possibilities of spinal fluid examination become ever greater, and if such tests as the Wassermann and the colloidal gold are only the forerunners of a host of others, there is reason to hope that characteristic changes will ultimately be found in the great majority of nervous and mental diseases.

Already it has been established that indications of diagnostic importance may be afforded by the spinal fluid in other 
conditions than nervous affections. It will be seen later that in such general diseases as diabetes and uræmia there are important changes in the fluid. Even in the very early stages of syphilis before there are any clinical indications of involvement of the nervous system the spinal fluid may present a characteristic picture. In trichiniasis it is often invaded by the trichina spiralis before any somatic symptoms of the disease have made their appearance. Sleeping sickness is an example of a disease in which the final diagnosis depends on the demonstration of the parasite in the cerebrospinal fluid.

Great as have been the diagnostic advances in this sphere, the therapeutic possibilities are now beginning to attract even greater attention. The simple drainage of the subarachnoid space and the ventricles by lumbar puncture has proved of great value in a multitude of conditions, and the possibilities of the intradural injection of sera and drugs by the spinal and cerebral routes are just beginning to be realized.

\section{REFERENCES}

Haller: Physiologie in des Mensches. I766.

Magendie: Mémoire sur un liquide qui se trouve dans le crâne et la colonne vertébrale de l'homme et des animaux mammifères. C. R. Acad. des Sciences, Io Jan., I825.

Quincke: Die Lumbalpunktion des Hydrocefalus. Berl. klin. Wchnschr., I7 Sept., I89I.

Widal, Sicard et Ravaut: Cytologie du liquide céphalo-rachidien. Bull. et mém. Soc. méd. d. hôp. de Paris, I9or. 


\section{ANATOMICAL CONSIDERATIONS}

The cerebrospinal fluid occupies the ventricles of the brain, the subarachnoid space, and the central canal of the cord. Is the fluid in these three regions continuous? Is it affected in composition by the different tissues with which it finds itself in contact? How does it originate, and what is its destination? These questions cannot be answered without a consideration of the anatomical relationships of the cavities which contain the fluid, and of the histological constitution of the structures with which these cavities are lined, and over which the fluid has to pass.

\section{THE SUBARACHNOID SPACE}

The brain is covered by three membranes, the dura mater, the arachnoid mater, and the pia mater, and between these three membranes there are two cavities, the subdural cavity between the dura and arachnoid, the subarachnoid between the arachnoid and pia. The dura mater is a thick, tough, dense membrane of fibrous tissue consisting of two layers; an outer adherent to the wall of the cranial cavity and acting as a periosteum for that wall, and an inner covered by a sheet of endothelium. The two layers separate in places to enclose the venous sinuses of the skull.

The subdural space is bounded externally by the inner layer of dura mater, internally by the arachnoid, and both walls are covered by endothelium. The cavity is more potential than real, and contains a minute quantity of a lymph-like fluid. There is no communication of any kind between the subdural and the subarachnoid space. Colored fluids injected into the subdural space do not appear in the subarachnoid space, and in hrmorrhage into the subdural space the blood does 
not make its way into the subarachnoid space. The barrier appears to be complete and impenetrable.

When the skull cap is removed a number of small, rough, tuft-like bodies will be observed gathered in clusters along the line of the superior longitudinal sinus. These are the Pacchionian bodies. They consist of invaginations of the arachnoid carrying the dura in front of them, and are composed of spongy tissue continuous with the spongy areolar tissue which occupies the subarachnoid space. They are thus really extensions of the subarachnoid space. They project for the most part into the superior longitudinal sinus. Various functions have been attributed to the Pacchionian bodies. It has often been suggested that they represent the portal through which the cerebrospinal fluid passes from the subarachnoid space into the blood. It is certain, however, that any function of this nature which they may possess is shared by other structures, for they do not make their appearance till the third year, and are not present in any number until after the age of ten. Moreover they are not found in the lower animals. They increase considerably in number in old age.

The arachnoid mater is a thin non-vascular membrane, both sides of which are covered by a layer of endothelium. It forms the impermeable partition between the subdural and subarachnoid spaces. It clothes the brain much in the same way that a mantle clothes the body, that is to say it does not adapt itself closely to the folds of the convolutions, nor does it dip down into the fissures.

The pia mater is a delicate, highly vascular membrane, which is traversed by great numbers of blood vessels on their way to and from the brain. In spite of its great vascularity. however, it contains no capillaries, and in consequence it takes no part in the absorption of the fluid. Its relation to the brain is very different to that of the arachnoid mater. It may be compared to a closely fitting glove which adapts itself to every fold and fissure of the organ. The result of this difference in the two membranes is that the space which intervenes between them, the subarachnoid space, although in 
many places very narrow, in others is of considerable depth. The places where the increase in depth becomes marked are named cisterns, and are three in number. (Fig. I.)

The cisterna magna lies between the posterior surface of the medulla and the cerebellum, and is formed by a continuation upwards of the posterior part of the subarachnoid space of the spinal canal. It communicates directly with the fourth ventricle, for into it open the various foramina situated in the membranous roof of that ventricle. The arachnoid, instead of being closely reflected over the surface of the medulla and cerebellum, bridges across the interval between these structures, with the result that in this region the subarachnoid space develops into a veritable cistern.

The cisterna pontis, a prolongation of the anterior part of the spinal subarachnoid space, lies in front of the medulla, and is continuous round it with the cisterna magna. Thus this delicate part of the brain, containing as it does so many vital centers, is protected in a most efficient manner by a regular water cushion.

The cisterna basalis is formed by the araclinoid stretching across between the two temporal poles, is of large size, and comes into intimate relationship with the very important interpeduncular space, where many of the inflammatory conditions of the meninges show their most intense manifestations.

The cerebrospinal fluid within the cranial cavity may therefore be regarded as an expanse of water with rivers, rivulets, and a few deep lakes. This analogy must not, however, give rise to the conception of a mass of fluid in a motionless and stagnant state. There can be no doubt, from evidence which will be considered later, that the fluid is in a constant condition of motion and change.

It must not be imagined that the subarachnoid space is cmpty save for the fluid which it contains. Between the arachnoid and pia pass innumerable fine septa which subdivide the space into countless loculi all communicating freely with one another. These partitions are clothed by the endothelium which lines the opposed surfaces of the pia and 


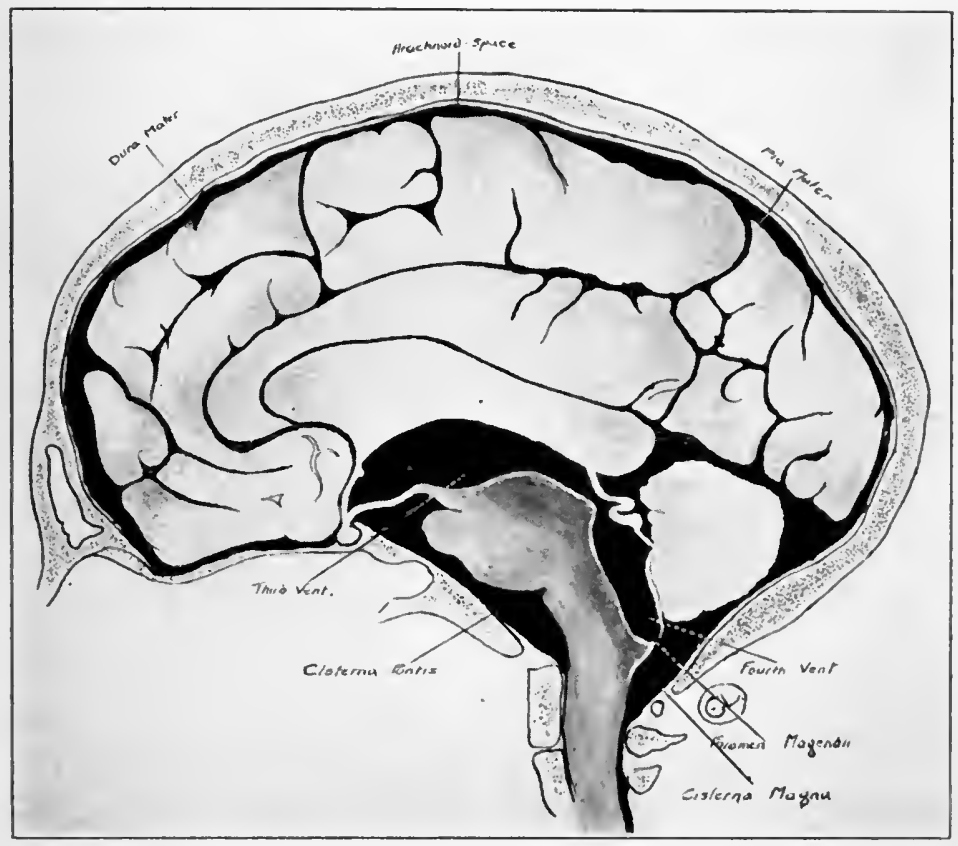

Fıc. I. Diagrammatic representation of distribution of the cerebrospinal linid 

arachnoid. The result is that the subarachnoid space is filled with a spongy tissue of the nature of areolar tissue, which is continuous with the spongy tissues already described as forming the chief part of the Pacchionian bodies.

\section{THE ARACHNOID VILLI}

The following account is largely taken from the very full and excellent description of these structures given in Weed's monograph. In the neighborhood of the great sinuses, especially the superior longitudinal sinus, finger-like projections of the arachnoid may be seen to penetrate into the lumen of the sinus, passing through the dura in order to accomplish this. These projections are too small to be seen by the naked eye. If the skull cap be removed in the manner usual at an autopsy they will be completely destroyed. In order to demonstrate them the brain must be hardened in situ, and the cranial vault removed piece by piece with the greatest care.

The villus is seen in most characteristic form at the point where a cerebral vein enters the sinus. The vein carries a sleeve-like prolongation of the arachnoid with it, the vein itself forming the core of the villus. At its commencement the villus presents a fine web-like tissue of interlacing strands similar to the spongy tissue already described as occurring in the subarachnoid space. There is, of course, an external covering of endothelial cells. Although the most characteristic structure is seen at the point of entry of a vein, it is by no means necessary for a villus to contain a vein. Indeed very large numbers of villi are apparently not in relation to any vein. As the vilius approaches the sinus its central structure becomes denser, the loose network disappears and its place is taken by a myxomatous material. At the same time in certain localities other than the superior sinus, notably in the region of the cavernous sinus, the endothelial covering becomes thickened, the cells no longer form a single layer, and may be piled upon one another. The dura mater gives way before the encroaching villus, which finally finds itself 
projecting freely into the sinus, in very much the same way that the chorionic villi project into the blood sinuses of the pregnant uterus.

What, then, is the relationship between the arachnoid villus and the Pacchionian granulation? Weed is of opinion that the granulation is merely a hypertrophic villus, thus becoming visible to the naked eye, and he regards the change as a pathological one, associated with the increasing age of the individual. It will be remembered that the Pacchionian bodies are found neither in children nor in the lower animals. The arachnoid villi, on the other hand, are met with at all ages, and in all the animals investigated, namely the cat, the dog, and the monkey. The arachnoid villus may, then, be regarded as an extension of the subarachnoid space into the cerebral sinuses. There are naturally no spinal arachnoid villi, as there are no blood sinuses, in the spinal canal.

The arachnoid villi are not the only examples of prolongations of the subarachnoid space. As the cerebral arteries pass into the brain substance they carry with them a fine sleeve-like sheath which accompanies the vessel until it becomes a capillary, at which point the sheath apparently encls as a cul-de-sac, becoming incorporated with the vessel wall. It appears again around the veins. Between the sheath and the vessel wall there is a space traversed by fine trabeculæ much after the fashion of those already described as occurring in the subarachnoid space. These perivascular spaces are not visible in the normal brain. Only under special conditions can they be brought to light. The spaces, first mentioned by Robin in 1858 , have been fully described by Mott and Weed. Both of these observers produced a condition of cerebral anæmia, Mott by ligaturing one vertebral and both cartoid arteries, Weed by exsanguinating the animal. Under these conditions a very evident space at once becomes apparent around the vessels. That this space is not a mere artifact produced by collapse of the vessel is evidenced by the presence of the trabeculix already described. The existence of such a space is also proved by the accumulation within it of in- 
flammatory cells - lymphocytes and plasma cells in general paresis, sleeping sickness, and acute poliomyelitis. The perivascular spaces are directly continuous with the subarachnoid space, as will be shown when the origin of the cerebrospinal fluid comes under consideration.

In addition to the perivascular spaces it is also possible to demonstrate similar spaces around the nerve cells in experimentally produced anæmia of the brain. These perineuronic spaces can be seen, in favorable sections, to communicate directly with the perivascular spaces, and thus eventually with the subarachnoid space. The fact that the nerve cells come in this manner to be bathed in the cerebrospinal fluid is one the importance of which it is impossible to overestimate.

There are still other prolongations of the subarachnoid space. The cranial and spinal nerves as they issue from the brain and spinal cord carry with them a sac-like prolongation of the arachnoid membrane for a varying distance. These perineural sheaths are particularly well marked in the case of the olfactory, the optic, and the auditory nerves.

\section{THE SPINAL SUBARACHNOID SPACE}

In the spinal canal the dura mater no longer presents two layers. The outer layer which acted as a periosteum for the cranial bones has now disappeared. The vertebre possess a periosteum of their own, and the dura mater forms a loose lining to the vertebral canal, the intervening space being occupied by areolar tissue and a few veins.

The arachnoid and pia mater are similar in every respect to those of the cranial cavity. The pia terminates as a definite membrane at the point where the cord ends, namely the lower horder of the first lumbar vertebra. In the child the cord ends at a lower level, reaching as. far as the body of the third lumbar vertebra.

The arachnoid sac is carried down as far as the first piece of the sacrum, and contains the strands of the cauda equina in addition to the cerebrospinal fluid. It is into this portion of the subarachnoid space that a needle may be inserted with 
perfect safety for the purpose of withdrawing a sample of the cerebrospinal fluid. (Fig. 2.)

\section{THE VENTRICLES OF THE BRAIN}

The ventricles of the brain in reality form one large cavity, consisting of various subdivisions which communicate freely with one another. The lateral ventricles open by the foramina of Monro into the third ventricle, and the aqueduct of Sylvius establishes a direct connection between the third and fourth ventricles.

In the roof of the fourth ventricle there are three openings, a central opening, the foramen of Magendie, and two lateral openings, the foramina of Luschka or Key and Retzius. Although the actual existence of these openings has been called in question in recent times there can be no doubt that a free communication exists between the fluid in the fourth ventricle and that contained in the part of the subarachnoid space which lies in immediate relation to the medulla and cerebellum.

The third, fourth, and lateral ventricles are lined throughout by the ependyma, a layer of cubical epithelial cells lying upon a somewhat dense and non-vascular fibrous tissue. The ependyma subserves the passive function of lining the ventricular cavities, and probably, in health at least, does not contribute to nor in any way alter the composition of the cerebrospinal fluid.

Lying free in each ventricle there are two highly convoluted vascular tufts, the choroid plexuses. These project into the ventricles carrying before them the lining epithelium in a manner which cannot but recall the tufts of Bowman in the kidney. They are produced by an invagination of the pia mater through the choroid fissure. The epithelial cells covering the tuft are differentiated for a special function, just as in the case of the kidney. They become larger and more columnar, and in many respects resemble those lining the alveoli of a secreting gland.

Changes similar to those seen in a secreting gland may be observed in these specialized epithelial cells under the influ- 


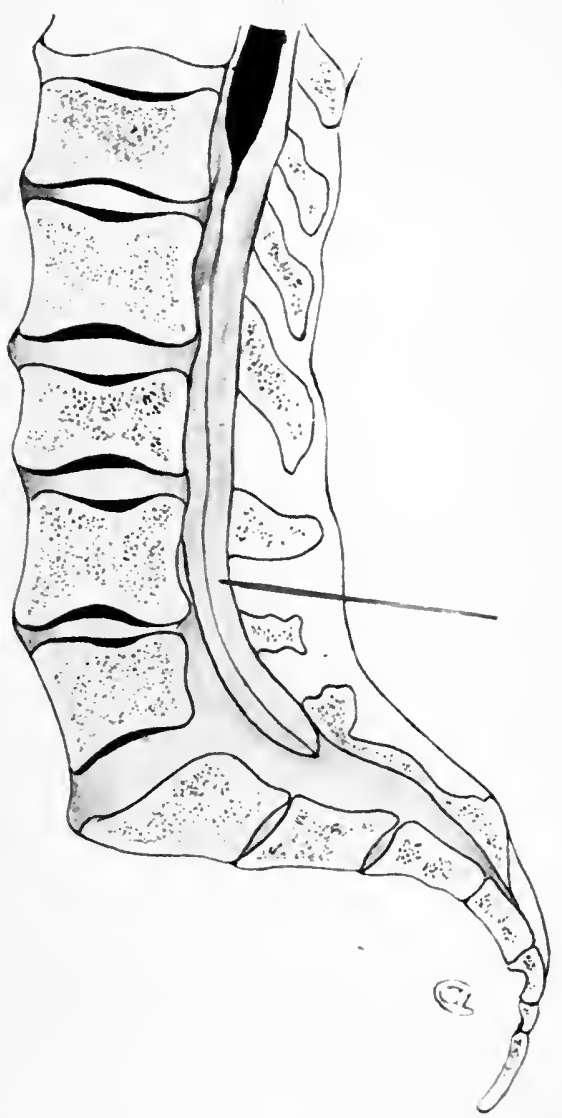

Fig. 2. Lumbar puncture needle in arachnoid sac. Termitation of cord at lower border of first lumbar vertebra. 

ence of stimulants. If the choroid plexus of an animal be examined immediately after the administration of ether it will be found that not only have the epithelial cells greatly increased in size, but a differentiation into two zones has taken place, and a number of hyaline droplets may be detected towards the free margin. Further, some of the cells show these changes in a more marked degree than others, a phenomenon also to be observed in a secreting gland. In short, the epithelial cells covering the plexus show every evidence of being in a state of active secretion. The choroid plexuses of the various ventricles may, therefore, be justly regarded as secreting organs. Mott considers that in view of the above facts it is now justifiable to speak of the plexus as the choroid gland. The importance of these observations on structure becomes apparent when the question of the origin of the cerebrospinal fluid comes to be considered.

\section{REFERENCES}

Mott, F. W.: The Oliver-Sharpey lectures on the cerebrospinal fluid. Lancet, I9Io, ii, July 2 and 9.

Weed, L. H.: Studies on the cerebrospinal fluid and its pathway. Jour. Med. Research, I912, XXXI, No. r. 


\section{CHAPTER III}

\section{THE ORIGIN AND DESTINATION OF THE FLUID}

\section{ORIGIN OF THE CEREBROSPINAL FLUID}

Endless discussion and controversy has taken place regarding the origin of the cerebrospinal fluid, and the most diverse views have at different times been expressed. Gradually, however, light is beginning to emerge from the darkness, and fact to take the place of theory. Until recently it was assumed, naturally, that the fluid had but a single source. Once that source was determined the problem would be solved. Now, however, it is recognized that there may be, and probably is, more than one source. This, of course, adds considerably to the difficulties of the problem, but in biology it frequently happens that an early simple explanation has to be repeatedly modified, till the charm of its original simplicity is entirely lost. We must be prepared, therefore, for a similar readjustment in our views concerning the origin of the cerebrospinal fluid.

The cerebrospinal fluid is contained in the two great cavities of the ventricular system and the subarachnoid space. Has the fluid in these two localities a common origin, or does a different mechanism come into play, depending on anatomical differences in the two regions?

That a considerable portion of the fluid is produced within the cavity of the ventricles has been proved incontestably. Such proof is partly clinical, partly experimental in character. The condition of internal hydrocephalus, in which the ventricles become distended by an enormous accumulation of fluid, is usually associated with some degree of obstruction to the outlets in the roof of the fourth ventricle:

If the aqueduct of Sylvius, leading from the third ventricle, 
be artificially blocked, as in the experimental method of Dandy and Blackfan, a mechanical internal hydrocephalus will invariably be produced.

Weed, by passing a cannula through the aqueduct of Sylvius, was able to withdraw fluid directly from the ventricles, thus entirely eliminating the surrounding tissues. After the preliminary increase in flow, the fluid continued for several hours to drop from the end of the cannula at the usual rate.

The only structures within the ventricles which could possibly be concerned with the production of the fluid are the choroid plexus and the ependyma lining the cavity. Although the choroid plexus had been frequently suggested as the source of the fluid, it was Petit and Girard in 1902 who first placed the theory on a firm foundation. These observers made an extensive and thorough series of investigations upon the structure of the choroid plexus in different classes of vertebrates, at the same time testing the effect of hypersecretory substances such as pilocarpine, muscarine, and ether. They found that during a period of increased production of fluid the epithelial cells covering the plexus showed changes very similar to those observed in an ordinary secreting gland. Mott, following a similar line of investigation, arrived at identical results. In a later paper he pointed out the strong similarity between the choroid plexus and the lachrymal gland, and considers that we are justified in speaking of the structure as the choroid gland.

Cushing has made direct observations upon the choroid plexus in cases where a porencephalic cavity communicated with the ventricles. The patients were under ether anæsthesia, a condition well calculated, as will be seen presently, to stimulate the production of fluid. In all these cases he was able to observe droplets of fluid exuding from the surface of the choroid plexus. In one case the vessels entering the plexus were ligatured, with the result that the secretion almost immediately ceased.

The most brilliant contribution is that of Dandy, who in a masterly paper proved that the choroid plexus is the sole source 
of the fluid, and that the ependyma takes no part in its production. By a most ingenious technic he succeeded in blocking the foramen of Monro on one side of a dog's brain, whilst on the other side he first removed the choroid plexus of the lateral ventricle, leaving the ependyma intact, and then blocked the foramen of Monro on that side. In the former case the ventricle became greatly distended with fluid, a condition of unilateral hydrocephalus, but in the latter it became shrunken and collapsed, containing not a drop of fluid, although still lined by the ependyma. It would be difficult to get a more beautiful solution of an apparently insoluble problem.

Is the fluid in the subarachnoid space identical with that of the ventricles? Does it merely represent the overflow from the ventricles which takes places through the openings in the roof of the fourth ventricle, or is there an additional source of supply outside the ventricles? It certainly is not identical in composition with ventricular fluid. It contains more albumin and less sugar. Both the globulin and the complement-absorbing substance in general paresis are more abundant in the spinal than in the ventricular fluid. The coloration of the fluid which occasionally occurs in jaundice is said to be more marked in the former than in the latter.

The fact that the extraventricular may differ considerably in composition from the intraventricular fluid, although suggestive, is by no means conclusive evidence of the existence of some mechanism for the production. of the cerebrospinal fluid additional to that of the ventricles. Much more convincing proof is afforded by the observations of Dandy and Blackfan on a case of internal hydrocephalus in which there was complete obstruction to the outflow from the ventricles. In this case, although only five cubic centimeters of fluid could be withdrawn by lumbar puncture, it was possible in a comparatively short time to recover another similar quantity. As this fluid could not have come from the ventricles, it must have originated from some extraventricular source.

If there is an additional source of the fluid it must either be the endothelial surface of the walls of the subaranchnoid 
space, or the perivascular prolongations of that space which have already been described. In this connection the observations of Spina are of importance. This observer produced a condition of high intracranial pressure by intravenous injections of suprarenal extract. On exposing the arachnoid mater he noted an exudation of clear points of fluid issuing from its surface. From this he argued that the direction of the flow was probably towards and not away from the subarachnoid space.

The great difficulty in investigations on a possible dual source of the cerebrospinal fluid is the separation of the ventricular from the extraventricular fluid. Weed's method of overcoming this difficulty by introducing a cannula along the aqueduct of Sylvius into the third ventricle has already been described. By this means he was enabled to make separate observations on the behavior of the fluids in the two spaces under different conditions.

Weed has further attacked the problem by means of his method of making subarachnoid injections of potassium ferrocyanide, hardening the brain in situ in formalin containing one per cent. hydrochloric acid, and examining for the presence of granules of Prussian blue. He found that although the granules penetrated to the farthest recesses of the perivascular spaces, there was no evidence of their passage into the vessels. The flow of fluid appears, therefore, to take place from the vessels into the spaces, and not in the reverse direction as suggested by Mott.

Finally, as Cushing has poined out, in cases where the intracranial pressure is markedly increased, where the convolutions are flattened against the surface, and where, therefore, the exit from the perivascular spaces tends to be obstructed, the spaces are found to be distended to an extent never seen in health, as if the fluid which they contained was being produced there and unable to escape. There seems to be good reason, therefore, to believe that the fluid in the subarachnoid sac is constantly being augmented by additions from the perivascular spaces of the arachnoid mater. These additions 
probably carry out with them the products of neuronal metabolism, owing to the close relation which exists between the perineuronal and perivascular spaces, so that a difference -between the subarachnoid and the ventricular fluids is to be expected rather than wondered at.

As our knowledge of the cerebrospinal fluid becomes greater it will possibly be found that various parts of the brain and its appendages make characteristic additions to the fluid. Cushing and Goetsch have already advanced evidence to show that the secretion of the posterior lobe of the pituitary gland is poured into the cerebrospinal fluid, and a recent case of my own lends support to this view. It cannot be claimed, however, that this matter has been conclusively proved.

\section{ABSORPTION OF THE CEREBROSPINAL FLUID}

There can be no question that the cerebrospinal fluid is being continually secreted. Very large quantities may be withdrawn, and be replaced within a short space of time. It has been estimated from observations on the absorption of dyes from the subarachnoid space and subsequent excretion in the urine that the fluid may be replaced four or five times over during twenty-four hours. As the total quantity of the fluid in man is probably somewhere about 120 cubic centimeters it is evident that a very rapid and extensive absorption of fluid must be continually taking place. In some cases of fracture of the base of the skull large quantities of fluid have been collected, as much as from one to two liters sometimes escaping in the course of twenty-four hours. Cases of cerebrospinal rhinorrhœa or escape of cerebrospinal fluid from the nose which occasionally occur afford striking ocular demonstration of this continuous production and outflow. In a case which came under my observation some years ago, a case in which direct communication had been established between the cranial and nasal cavities owing to destruction of the intervening structures by the eroding action of a tumor, a slow flow of fluid took place from the nose whenever the patient assumed the erect posture. This flow was observed 
over a period of many months and the total amount of fluid lost must have been enormous. By what channels, under normal conditions, does this constantly produced fluid make its escape?

The major part of the fluid undoubtedly passes into the blood. Leonard Hill, in his classical work on the circulation of the cerebrospinal fluid, found that when saline colored with methylene blue was injected into the subarachnoid space the dye appeared in the bladder and stomach in from ten to twenty minutes, whereas the lymphatics showed no trace of color for a much longer time. Lewandowsky similarly injected potassium ferrocyanide into the subarachnoid space and regained it from the urine in twenty minutes. But the problem of how the fluid gained access to the cerebral veins still remained to be solved.

The Pacchionian bodies, structures so evident when even the rough methods of the ordinary post-mortem examination are employed, were naturally the first to attract attention, and at first sight it appeared that these granulations from their anatomical structure were well qualified to act as a filter by means of which the fluid could escape from the subaraclinoid space into the cerebral sinuses. When, however, it was realized that the structures existed in neither early childhood nor in the lower animals it became evident that some other mechanism must be looked for. Cushing suggested that valvular openings into the sinuses might exist, through which the fluid could escape, but further research necessitated an abandonment of this view also. The brilliant experimental work of Weed is by far the most important contribution to the subject which has yet been made.

The technical procedure adopted by Weed has already been indicated. By hardening the brain in situ in a fluid containing one per cent. hydrochloric acid he was able to trace the granules of Prussian blue resulting from a preliminary antemortem subarachnoid injection of potassium ferrocyanide and iron ammonium citrate into the minutest ramifications of the subarachnoid space. The accuracy with which it was possible 
to follow the course of the injected fluid is evident from a study of the admirable plates with which his work is illustrated. This was not of course the first time that such injection methods had been employed, but much of the work of previous observers has been vitiated by the employment of abnormally high pressures in the process of injection. With such pressures it is quite possible for abnormal channels to be opened up and even formed. By using pressures only slightly above that of the cerebrospinal fluid, or still better, by the method of replacement whereby the injected fluid is made to take the place of an equal amount of fluid which has been withdrawn, IVeed was enabled to study the process of absorption from the subarachnoid space under normal conditions.

The outcome of the work was to prove conclusively the paramount importance of the arachnoid villi as a mechanism for the passage of the cerebrospinal fluid from the subarachnoid space into the venous circulation. In every instance the dark blue granules could be traced with the greatest ease from the subarachnoid space into the villus-like processes which project into the lumen of the sinus, and eventually into the sinus itself. In some instances the granules could be detected in their passage between the cells covering the villus. There was no evidence of any passage between the cells. Nor was there any evidence of absorption into the cerebral capillaries. These observations, therefore, lend no support to the view advanced by Mott that the major process of absorption takes place into the capillaries of the brain.

Several factors favor the flow of fluid from the subarachnoid space into the sinuses. The pressure in the veins is lower, so that the fluid tends to diffuse through into the blood. There is, in fact, a constant process of readjustment going on between production and absorption of the fluid, the object of which is to maintain a condition of accurate balance. Upset of this balance is a pathological condition which is characterized by the immediate appearance of symptoms of intracranial disturbance. The blood is far richer in crystal- 
loids and colloids than the cerebrospinal fluid, and this is a further factor in determining the flow of the fluid from the subarachnoid space into the cerebral sinuses.

But although drainage through the arachnoid villi into the great venous sinuses both at the vertex and base is evidently of the first importance, it does not follow that there are no other means of escape. The fact that there are no arachnoid villi and no venous sinuses corresponding to those of the cranium to be found in the spinal canal naturally leads one to look for some other possible mechanism. This subsidiary mechanism is to be found in the lymphatic system.

It has already been pointed out that definite extensions of the subarachnoid space can be demonstrated in the form of tubular sheaths which pass for a varying distance along many of the cranial and spinal nerves. These sheaths are especially well developed in relation to the olfactory, the optic, and the auditory nerves. These sheaths end in a definite cul-de-sac, beyond which injections of granular material such as carbon cannot pass. But when ferrocyanide solution is used the lymphatics of the neck will be found to be deeply stained. A similar result was obtained by Leonard Hill in his originai observations with methylene blue. It is evident then, that absorption can take place into the lymphatic system, but this absorption is much less in amount than that into the venous sinuses.

It still remains to be shown how the fluid finds its way from the subarachnoid cul-de-sac into the lymphatics of the neck. For long it has been known that a perineural space exists around the nerves which can be injected from the subaraclnoid space. Cotugno was the first to demonstrate the existence of this space by injecting it with air. It becomes very evident when the ferrocyanide method is employed. The blue granules of ferric ferrocyanide can be traced for some distance along the nerve in the perineural space. They then appear to enter a somewhat indefinite open reticular tissue from which they finally escape into the lymphatics which accompany the nerves. These relations can best be studied in the case of the 
olfactory nerve, where the various channels are large and well defined, but similar arrangements exist in relation to the other cranial and spinal nerves.

Although this accessory path is of relatively little importance in comparison with that into the venous circulation, yet in the case of the spinal subarachnoid space it comes to assume a position of greater importance, for in this region, as has already been pointed out, it is the only mechanism possible. In all of the spinal nerves absorption from the perineural spaces into the lymphatics of the anterior and posterior nerve roots can be demonstrated by the ferrocyanide replacement method. In those rare cases where the cranial is separated from the spinal subarachnoid space, and in which cerebrospinal fluid continues to be secreted into the perivascular sheaths, the lymphatic system of drainage must be regarded as of considerable importance.

\section{REFERENCES}

Boyd, W.: A case bearing on the function of the pituitary body. Jour. Am. Med. Assoc., I9I7, LXVIII, p. III.

Cushing, Harvey: Studies on the cerebrospinal fluid and its pathway. Jour. Med. Research, 1912, XXXI, No. I.

Cushing, Harvey, and Goetsch, Emil: Concerning the secretion of the infundibular lobe of the pituitary body and its presence in the cerebrospinal fluid. Am. Jour. Physiol., 1910, XXVII, p. 60.

Dandy, W. E. and Blackfan, K. D.: An experimental and clinical study of internal hydrocephalus. Jour. Am. Med. Assn. I9I3, LXI, p. 2216.

Dandy, W. E. and Blackfan, K. D.: Internal hydrocephalus. Am. Jour. Dis. Child. Dec. 1912, p. 406.

Dandy, W. E.: Experimental hyrocephalus. Ann. Surg., I9I9, LXX, p. I29.

Hill, Leonard: Physiology and pathology of the cerebral circulation. Churchill. London. 1896.

Lewandowsky: Zeitschr für Klinische Medicin, XL, p. 480.

Petit, A. and Girard, J.: Sur la fonction sécrétoire et la morphologie des plexus choroides des ventricules lateraux du systeme nerveux central. Paris, I9I2.

Spina, A.: Experimenteller Beitrag zur Kenntniss der Hypercmic des Gehirns. Wien Med. B1. I898, XXI, Nos. 16 and 17. p. 267.

Weed, L. H.: Loc. cit. 


\section{CHAPTER IV}

\section{CIRCULATION OF THE FLUID}

Is there a real circulation of the fluid? Is any movement that may take place merely one of ebb and flow, or does the fluid simply lie in stagnant pools in the great cisterns? All the analogies of biology are against the assumption that the fluid is in a stagnant condition. For it is not a mere means of lubrication, like the synovial fluid of the joints, nor is it nothing but a water cushion or buffer, as has often been suggested. It has an active part to play in the economy of the central nervous system, and for that purpose movement throughout its mass is essential. Little is known at present regarding the direction of this circulation or the factors which govern it, but it is becoming recognized that these are matters of the greatest importance in connection with the surgery of the brain and the administration of therapeutic remedies by the subarachnoid route.

The cerebrospinal fluid may in this connection be divided into two parts - the part above the tentorium cerebelli and the part below that membrane. From experimental evidence there can be little doubt that substances do not pass readily from the lower to the upper chamber. The fluid from the ventricles, escaping through the foramina in the roof of the fourth ventricle, reaches the subarachnoid space in the subtentorial region. Fluids injected below the tentorium only reach the cerebral cortex with difficulty. Thus Goldmann, injecting trypan blue in the lumbar region, found the greater part of the nervous system stained with dye, but the cerebral cortex remained unstained. Golla, using an improved technic, has been able to obtain slight staining of the cortical cells, but in, a much less intense degree than in the rest of the nervous 
system. He employed colloidal carbon, and allowed a few days to elapse before killing the animal. The black particles of carbon could then be demonstrated with great ease. Fluids injected above the tentorium, on the other hand, reached every part of the cerebral cortex.

As a result of these and other injection experiments it appears to be established that substances can pass with comparative ease from the spinal sac to the lower cranial chamber, but that in the upper cranial chamber the flow is for the most part from above downwards. The importance of these observations is obvious, and will be referred to again when discussing the administration of therapeutic remedies by the intraspinal route. They may serve in part to explain the efficacy of lumbar injections of salvarsanised serum in tabes dorsalis, and the much more disappointing results of the same treatment in general paresis.

It is a little difficult to understand where the downward flow from the cerebral cortex originates, seeing that the ventricular fluid escapes in the subtentorial region. A probable explanation is to be found in the accessory intramedullary source of supply provided by the perivascular spaces. This fluid streams downward to mingle with the fluid from the ventricles in the basal cisterns. It must further be remembered that under normal conditions the amount of fluid in the subarachnoid space above the tentorium is very small.

It has been suggested by Kramer that there may be an ascending current in the central canal of the cord. Injections of methylene blue were found to pass into the canal by a caudal metapore, and to ascend with the canal. The matter must still be considered sub judice, however, for the work of subsequent observers has not substantiated this hypothesis.

\section{FACTORS INFLUENCING THE FLOW OF THE CEREBROSPINAL FLUID}

If the choroid plexus is in reality to be regarded as a secretory gland, it is to be expected that some substances will exercise a stimulating effect upon it. In investigating prob- 
lems connected with the flow of the fluid and the allied subject of cerebrospinal pressure, it is necessary to bear in mind that several different factors may be involved in any given change. Unless this be done quite erroneous conclusions may be arrived at. For an increased flow or a heightened pressure might be due to increased production of fluid, or to a rise of arterial or venous pressure.

Of the various workers in this field Dixon and Halliburton have made the most notable contribution. By taking simultaneous records of the cerebrospinal pressure and the pressure in the great sinuses they were able to distinguish rises of pressure of vascular origin from those due to increased secretion of fluid. They found that certain substances act as true cerebral lymphagogues. Of these, those which had a truly specific action were extracts of choroid plexus and brain tissue. Normal cerebrospinal fluid produced no effect, but intravenous injections of fluid from cases of general paralysis and cerebra! disintegration were followed by an increased flow. They suggest that a hormone may be produced by the brain substance, and carried to the choroid plexus, where it stimulates the epithelial cells. This would explain the presence of an excitant in the fluid in cases of cerebral degeneration.

In addition to these specific stimulants they found other factors of great importance. Of these the chief was the presence of excess of carbon dioxide in the blood. The animals were kept under artificial respiration during the experiments, and the moment that a deficiency of oxygen or an excess of carbon dioxide was permitted in the inspired air, the fluid at once began to flow freely from the cannula. If anæsthetics such as chloroform or ether, or drugs such as pilocarpine or amyl nitrite, be employed, the result is the same. In such experiments, therefore, it is advisable to use morphine and urethane as an anæsthetic, combined with the use of artificial respiration.

This phenomenon of increased flow of fluid resulting from excess of carbon dioxide in the blood is readily understood. The cerebrospinal fluid is one of the means of producing a 
rapid excretion of carbon dioxide and when the carbon dioxide in the blood rises above normal it is natural that the process of excretion should be hastened. Analogies may be found in the increased flow of urine following injection of urea, and the cholagogue action of bile salts.

The conditions which favor an increased flow of fluid also tend to produce a rise of cerebrospinal pressure. For this pressure is largely independent of the arterial or venous pressure. The factors which influence it are the rate of production and the rate of absorption.

\section{PERMEABILITY OF THE MEMBRANES}

Many substances pass with ease from the cerebrospinal fluid into the veins, but very few can pass from the blood into the fluid. The epithelium of the choroid plexus presents an impenetrable barrier to the vast majority of substances which try to make this passage. By this rigid censorship it protects the delicate nervous structures from the action of harmful substances. Toxins are excluded. Tetanus toxin injected subcutaneously does not appear in the fluid. The specific agglutinin found in typhoid fever is also absent. Intravenous injections of dyes fail to reach the spinal fluid. Crystalline substances taken by the mouth or injected into the veins cannot be recovered from the fluid. The importance of these facts from the therapeutic standpoint is of course obvious.

The exclusiveness of the choroid plexus is not quite complete. Alcohol, chloroform, and acetone are allowed ready passage, and Crowe has shown that urotropin administered internally can be recovered from the cerebrospinal fluid. As a result of this last observation it has become the custom to give urotropin as an antiseptic in cases of meningitis. This is one of the instances, so often provided by the history of medicine, of an extensive practice being built up on the slenderest foundation. For the drug appears in the fluid in quantities so small that it can have no effect in staying the progress of a case of acute meningitis. Further Dixon and Halliburton and other workers have failed to detect any trace of for- 
maldehyde, to which the antiseptic action of urotropin is due. Any small traces of urotropin, however, which may be present may exert a very useful prophylactic influence, and render the fluid unsuitable for the growth of a few invading organisms. For this reason it is well worth while to give prophylactic doses of the drug in cases of fracture of the skull, wounds of the head, and before operating on cases of acute middle ear inflammation.

Formidable as is the obstacle to passage from the blood to the spinal fluid, many substances can pass in the opposite direction with remarkable ease and rapidity. Crystalline substances may be absorbed and produce their characteristic effect almost as quickly as when injected directly into the veins. Thus Dixon and Halliburton have shown that atropin injected into the subcerebellar cisterna of a dog will produce vagal paralysis in a minute, whilst with adrenalin the latent period may be as short as ten seconds. Pituitary extract is also rapidly absorbed.

Even more remarkable than the rapidity of absorption is the amount of fluid which can be absorbed. Anything up to a liter of normal saline may be run into the subcerebellar cisterna. of a dog, and be absorbed in the space of one or two hours. This enormous power of absorption becomes comprehensible, however, when the amount of cerebrospinal fluid secreted is considered. From observations on the absorption and excretion in the urine of phenolsulphonephthalein injected into the subarachnoid space it appears probable that the entire quantity of cerebrospinal fluid is completely renewed about every four hours. Granting that the average volume of fluid is somewhere about one hundred or one hundred and twenty cubic centimeters, this would give a total absorption of between six and seven hundred cubic centimeters in the course of twenty-four hours. The greater part of this absorption takes place from the cranial subarachnoid space, comparatively little occurring in the spinal part of the space. This again is a point for the therapeutist to bear in mind.

Colloids, on the other hand, are absorbed with great dif- 
ficulty or not at all. Witte's peptone and a foreign serum are proteins the presence of which in the blood stream can be recognized by their characteristic physiological action. Neither of these substances can pass from the cerebrospinal fluid into the blood. The reason for this difference in behavior undoubtedly depends on the size of the molecule. The large-sized molecules of the colloid are denied passage. This effectually disposes of any theory of valvular openings from the subarachnoid space into the cerebral sinuses.

\section{REFERENCES}

Crowc, S. J.: On the excretion of hexamethylenamin (urotropin) in the cerebrospinal fluid and its therapeutic value in meningitis. Bull. Johns Hopkins Hosp. I909, XX, p. 102.

Dixon, W. E. and Halliburton, W. D.: The cerebro-spinal fluid. Jour. Physiol. I9I3, XLVII, p. 215; I9I4, XLVIII, p. I28; 19I4, do. p. $317 ; 1916$, L, p. 198.

Kramer, S. P.: The circulation of the cerebrospinal fluid. New York Med. Jour. I9I2, XCV, p. 532. 


\section{CHAPTER V}

\section{THE FUNCTIONS OF THE CEREBROSPINAL FLUID}

The cerebrospinal fluid must have some important function to perform. That which is usually assigned to it is a purely or at least mainly - mechanical one. It is compared to a water jacket, an all-pervading medium which supports and protects the central nervous system, shielding it from the rude shocks and blows of the outside world, adapting itself to the varying conditions within the cranial cavity, accommodating the brain in the matter of space, ebbing and flowing in response to the demands of the changing volume of blood in the cerebral vessels, and in general subserving the useful though somewhat humble function of a stopper-up of gaps. But is it for this alone that the fluid exists? Is it for this that there has been created the complex system of the ventricles, the great stretch of the subarachnoid space with its cisterns and lakes, and the wonderful prolongations of that space deep down into the substance of the brain bringing even the individual nerve cells into intimate connection with the fluid? It seems about as reasonable to suppose that the blood fills the vessels that they may be distended to the proper extent, or that the chief function of the circulation is to warm the body. The whole unique constitution of the fluid,- the sugar for purposes of metabolism, the high content of carbon dioxide, the peculiar changes in the fluid in pathological states, - cries out against such a supposition. No doubt the fluid plays an important part in the mechanics of the cranial cavity; it must furnish a convenient mechanism for compensating changes in the cerebral volume, but in addition it must surely be concerned with the metabolism of nervous tissue.

The cerebrospinal fluid doubtless has many uses. Encasing 
and enveloping as it does the whole central nervous system, it cannot but act as a protection against sudden shocks. The medulla oblongata, the most delicate and vital part of the brain, is so surrounded by the cisterna magna and the cisterna pontis that it may be regarded as lying in a water bath. The cranial cavity is bounded by rigid and inexpandable walls. The only way in which the brain can possibly expand is for the cerebrospinal fluid to flow out of the cranial cavity into the spinal canal. That there is need for such a mechanism is easily proved by a few observations on the changes which may occur in cerebrospinal pressure. Such an act as coughing or crying at once causes the fluid to flow out of the skull. In such conditions as cerebral congestion or œdema the demand for such a mechanism is still more evident.

Owing to the peculiar constitution of the cerebrospinal fluid and the remarkable selective action of the choroid plexus, it is possible that the fluid plays an important part in protecting the nervous tissue from the action of harmful substances circulating in the blood. It has been shown that substances such as barium chloride, which prove fatal when injected into the spinal canal, may circulate in the blood in a concentration a thousand times greater before they produce injury to the brain. Salvarsan can be given intravenously in large doses without producing any toxic action on the brain, but even minute quantities may have a fatal effect when injected into the spinal canal. Bacterial and other toxins are in a similar manner excluded from reaching the nervous tissues.

Useful and important as these functions must be, there can be little doubt that the fluid is above all concerned with the nutrition of and the elimination of waste products from the elements of the central nervous system. It is for this reason that the carbon dioxide content of the fluid is so high. It is probably for this reason that the composition of the fluid may vary materially in different places. The composition of the fluid is itself highly suggestive. It contains a small quantity of sugar and a trace of albumin. The sugar provides the energy needed in the metabolism of the nerve cells and fibers, 
whilst the albumin provides nourishment for these structures. It is true that the albumin content is low, but it is probably sufficient for the purpose, for the wear and tear of the nervous tissue is not great. Halliburton has pointed out the remarkable similarity between the cerebrospinal fluid and Locke's physiological saline solution, which contains 0.9 per cent. sodium chloride and a small quantity of glucose. Locke's fluid is known to be an almost ideal fluid for nourishing the tissues and removing the products of metabolism. Mott estimates that the carbon dioxide content of the fluid is over fifty per cent. This again strongly suggests that the fluid plays the part of the lymph of the brain. At the present stage of our knowledge the matter is not susceptible of proof, but every analogy and probability points to the fact that the fluid has a metabolic as well as a mechanical function to perform.

\section{THE NATURE OF THE CEREBROSPINAL FLUID}

Two main views have been advanced as to the nature of the fluid. On the one hand it has been held that the fluid is a transudate, passing out from the blood vessels by the physical process of transfusion. Against this conception it is possible to bring a formidable array of facts. The fluid bears no resemblance in composition to that of other transudates occurring in the body, of which the most important is lymph. Although the fluid has been described by Mott as a lymph of the brain, it differs from lymph in one important particular. The blood serum contains about 6.5 per cent. of albuminous matter, and of this over 4.5 per cent. appears in the lymph. The process of filtration through the walls of the capillaries is accordingly a coarse one, for even the large colloid molecules of albumin are allowed to pass. In the cerebrospinal fluid, however, the protein is only present to the extent of .018 per cent. It is evident that here we are not dealing with a simple transudation uninfluenced by other factors.

On the other hand the fluid has been regarded as a secretion produced by the choroid plexus or choroid gland. For this view, which is at present the popular one, there is much to 
be said. Certainly the choroid plexus is intimately concerned with the production of the fluid. But are we justified in using the term secretion in this sense? In the secretions of the body such as the sweat, the bile, the milk, and the saliva, there is something added to the fluid secreted, some distinctive component the result of the vital activity of the cells engaged in the secretory process. What is there of this nature to which we can point in the case of the cerebrospinal fluid? Nothing is added or synthetised. It is merely a case of substances being held back.

Under these circumstances the most reasonable hypothesis seems to be that of Mestrezat, who regards the fluid as an "elective filtration," the result of dialysation through a membrane which has the power of holding back almost all substances other than those immediately necessary for the functioning of the nervous tissue. In this way the great class of albuminoid toxins are forbidden access to the nerve centers. Mestrezat classes the cerebrospinal fluid along with the aqueous humor of the eye and the endolymph of the internal ear as belonging to one family which he names the neuroprotectors. It must be admitted, however, that it is difficult to reconcile with this view the fact that the cerebrospinal pressure may be increased without a corresponding and causative increase in the pressure within the blood vessels. The process may be one of filtration in the sense that certain substances are held back, but the term is apt to create a false impression, for, under certain circumstances at least, the choroidal epithelium plays a much more active part than that of a mere restrainer. Under normal conditions the process is probably one of filtration, but when the choroid gland is stimulated to activity the process becomes one of active secretion.

\section{REFERENCES}

Halliburton, W. D.: The possible functions of the cerebrospinal fluid. Brit. Med. Jour., i916, II, p. 609.

Mestrezat: Le liquide céphalo-rachidien normal et pathologique Paris, 1912. 


\section{CHAPTER VI}

\section{PRESSURE OF THE CEREBROSPINAL FLUID}

It is seldom that in clinical reports we find an attempt to determine the pressure of the spinal fluid with any degree of accuracy. As a rule we have to be content with the information that the pressure is "normal" or "raised." Often no reference of any kind is made to it. And yet from the point of view of the physician and surgeon a knowledge of the pressure within the cranial cavity and of the conditions which may produce heightening of that pressure is of the greatest importance. For it is becoming increasingly recognized that increased or decreased intracranial pressure may be the chief factor in producing cerebral symptoms in widely differing affections. It has long been known that the headache, vomiting, and optic neuritis of cerebral tumor are directly due to high intracranial pressure, but only recently has it been realized that the convulsions ${ }^{*}$ in eclampsia, the coma in uræmia, and the tinnitus and giddiness in certain affections of the internal ear may be associated with a similar condition.

Many estimations of the normal cerebrospinal pressure have been made at different times, and the results obtained vary to an extraordinary degree, such widely divergent figures as 50 millimeters and 450 millimeters of water having been given. The reason for this enormous difference of opinion is no doubt twofold. On the one hand no standard instrument has been agreed upon. Each observer manufactures or improvises one for himself, so that it can hardly be wondered that the results vary. On the other hand the influence of incidental factors on the cerebrospinal pressure has not been sufficiently realized. Of these factors the two most important are gravity and venous pressure. A change from the horizontal to the erect 
position will often produce a very marked change in the cerebrospinal pressure. Anything which causes engorgement of the cerebral veins tends to raise the cerebrospinal pressure. Even the act of coughing and the movements of respiration affect that pressure. (Fig. 3.)

Of the various methods of estimating the cerebrospinal pressure, the simplest and the best adapted for clinical purposes is that of Cassidy and Page. The apparatus consists of a lumbar puncture needle provided with a cock at the blunt end, and rubber tubing a meter in length, to one end of which is attached a tapped nozzle which fits into the needle, and to the other end a simple glass tube $18 \mathrm{~cm}$. long and $1.5 \mathrm{~cm}$. in diameter. The patient lies in the recumbent posture, great care being taken that the cerebrospinal axis is horizontal. Normal saline the density of which is practically the same as that of water at $120^{\circ} \mathrm{F}$. is poured into the tubing, the tap on the nozzle being closed, till the glass tube is half full. A mark is made on the tube at the level of the fluid, or a wooden clip is used for the purpose. The needle is inserted into the spinal canal. Whenever a drop of fluid appears the tap is closed. It is important that only the minimum amount of fluid should be lost, otherwise the reading will be too low. This is a point to which sufficient attention has not usually been paid. The tubing is now connected with the needle and both taps opened. Minute oscillations of the fluid in the glass tube due to the respiratory movements ought to be seen, otherwise the readings are valueless. The glass tube is held directly above the needle at such a height that the fluid in it returns to its original level. The vertical height of this level above the needle is measured, and the result gives the cerebrospinal pressure in millimeters of water.

The pressure varies between 90 and ${ }^{5} 5 \mathrm{~mm}$., the average being about $120 \mathrm{~mm}$. A variety of conditions may cause the pressure to be raised. In all forms of meningitis it is increased, unless the openings in the roof of the fourth ventricle are blocked. The higliest readings are obtained in cerebral tumor. In a tumor of the cerebellum I have seen the fluid 


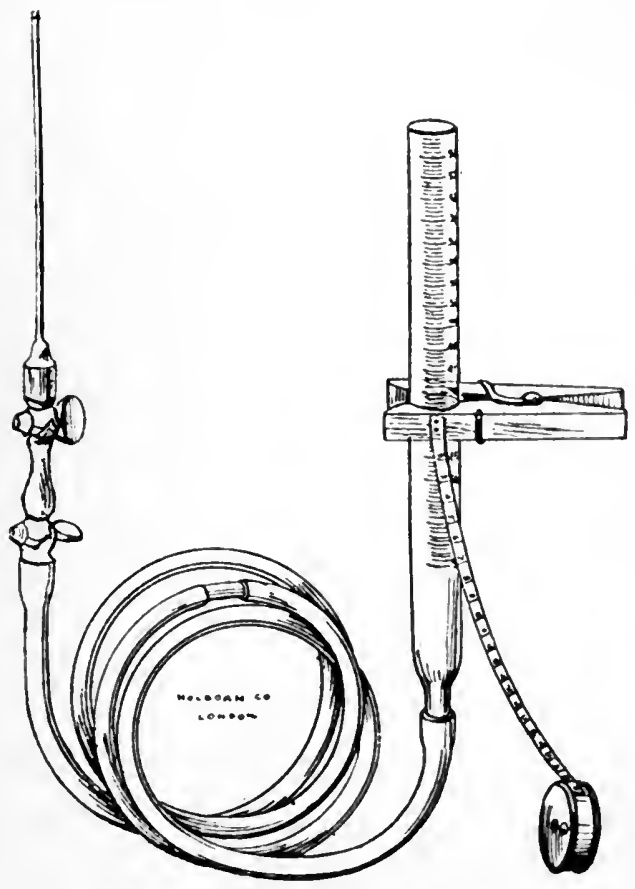

Cassidy \& Page's Spinal Pressure Set. 

spurt from one side of the bed to the other. It may be, however, that the high intracranial pressure forces the medulla into the foramen magnum, in which case the spinal pressure will show no increase. Most of the cases of general paralysis which I have examined have shown a pressure distinctly above the normal. Intracranial hæmorrhage is naturally associated with increased pressure. In children the raised intracranial pressure may be the most important factor in the case, and its reduction by lumbar puncture may directly lead to the cure of the condition. In conditions associated with general œedema, such as uræmia and eclampsia, there may be a high cerebrospinal pressure, the relief of which may lead to most dramatic improvement. The persistent headaches which form so troublesome a complication in some cases of anæmia can probably be traced to a disturbance - either a heightening or a lowering - of the intracranial pressure. The undoubted relationship which exists between the cerebrospinal fluid and the endolymph of the internal ear serves to explain how cases of Menière's disease have been improved and even cured by repeated lumbar puncture. From these and other facts it is evident that the pressure of the cerebrospinal fluid is of practical as well as theoretical interest, and well worthy of further study.

\section{REFERENCES}

Cassidy, M.A. and Page, C. M.: A method for determining the absolute pressure of the cerebrospinal fluid. Proc. Roy Soc. Med., London I9I I, IV, Pt. I. 


\section{CHAPTER VII}

\section{LUMBAR PUNCTURE}

The operation of lumbar puncture is now so well known and so widely practiced that it is unnecessary to discuss it in great detail. (Fig. 4.)

The patient may be sitting up or lying on one side. The most convenient site is the space between the fourth and fifth lumbar vertebræ, readily found by remembering that a line joining the highest points on the iliac crest passes through the spine of the fourth lumbar vertebra. The skin is sterilized with iodine. The best needle is one of platinum tipped with iridium. A common fault in lumbar puncture needles is to make them too thick. This greatly adds to the patient's discomfort. The needle should be provided with a stout stilette. A preliminary freezing of the skin with ethyl chloride is often advisable. A deep injection of eucain and adrenalin is useful in nervous patients. More useful, however, than any anesthetic is skill on the part of the operator. Those who have watched a tyro's unsuccessful efforts to enter the spinal canal will agree that it is advisable, if possible, to make the first attempts on the cadaver, or on a patient under a general anæsthetic. The chief thing to be learned is the difference between the resistance of the ligamenta subflava to the needle, and that of the vertebræ themselves. With the index finger of the left hand on the tip of the spine of the fourth lumbar vertebra, the needle should be entered about half an inch to one side of and a little below the spine. It must be pushed forwards, inwards, and a little upwards. The upward movement is important owing to the inclination of the laminæ. In children it is sometimes more convenient to enter in the middle of the line. A general anæsthetic will 


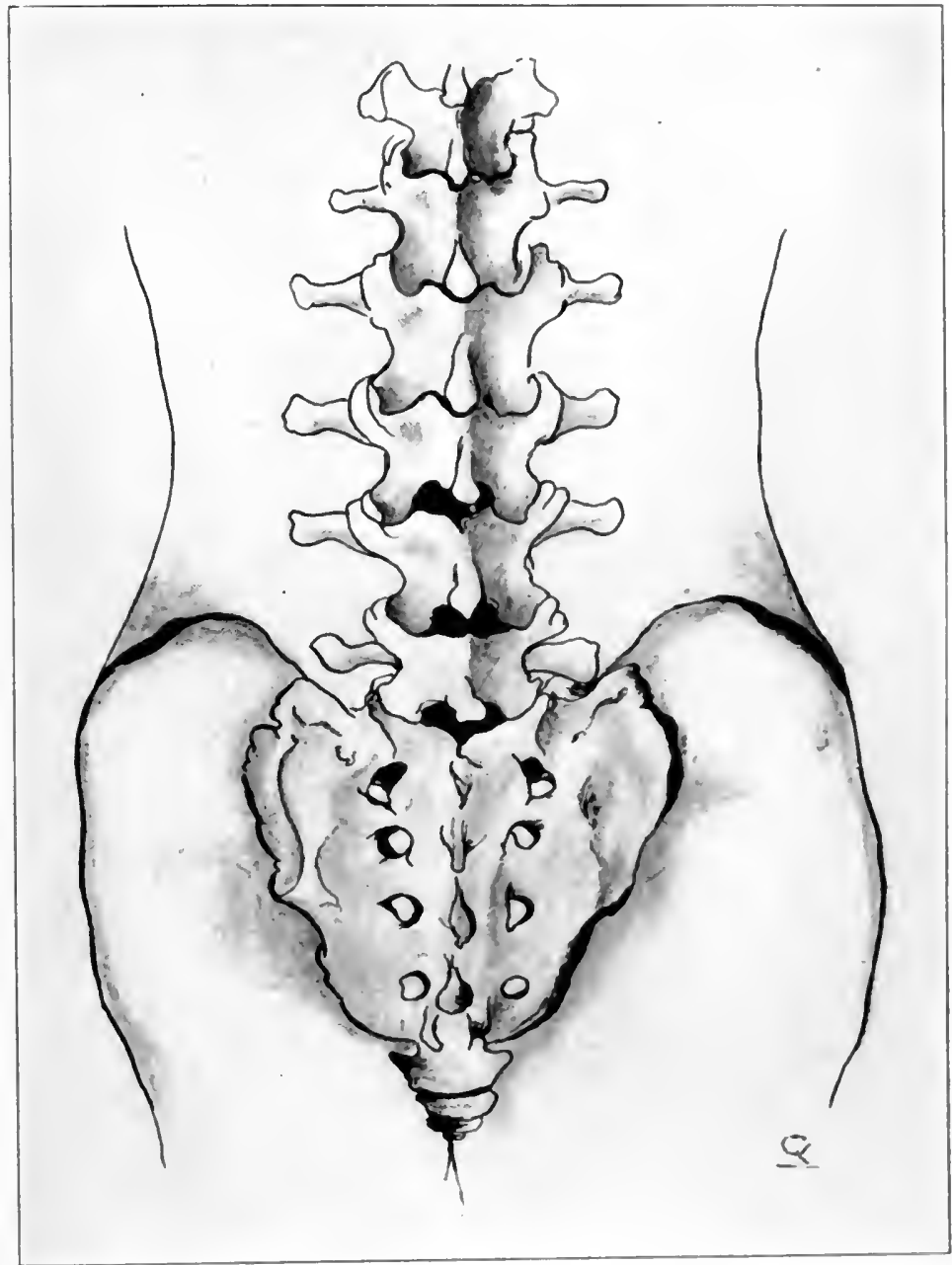

fivi. 4. The bony landmarks for lombar puncture 

sometimes be needed, especially in cases of meningitis with marked opisthotonos. In adults a general anæsthetic should be used in cases of tetanus.

The needle may enter the canal, and yet no fluid may be forthcoming. A stout stilette should be passed into the needle, as a shred of muscle may be blocking the lumen. If this is of no avail it is probable that the needle has not penetrated the arachnoid, but has merely pushed the membrane in front of it. In this case another puncture should be made in the space above. If the operator fails to enter the canal it is much better to withdraw the needle and try the next space than to continue blindly to prod the unhappy patient.

In rare cases it may be impossible to obtain any fluid the so-called dry tapping. Before assuming that such a condition exists it is always well to employ the two needle device. In addition to the needle already in the canal, another is introduced into the next space above, and coupled by a short length of rubber tubing to a glass cannula. A little warm sterile saline is poured into the cannula, and if the condition is really one of dry tap, that is to say if the lower needle is really lying unblocked in the spinal canal, the saline will flow freely from the latter needle. The only case of apparent absence of fluid in the lower part of the spinal sac which I have encountered was one of transverse myelitis.

Some of the most difficult cases on which to perform lumbar puncture are met with in asylums. Even in cases of acute delirious mania, however, one can almost always succeed, especially if the patient. be made to sit astride of a chair facing the back, and with his arms pulled well over the back, which should be as low as possible. In these cases it is always wise to use a platinum needle, for a steel one is very liable to break should the patient suddenly begin to struggle.

The quantity of fluid which may be or ought to be withdrawn depends greatly on circumstances. In the generality of cases from five to ten cubic centimeters may safely be taken off. For all ordinary purposes five cubic centimeters are amply sufficient, provided that the various tests are carried 
out in the proper order. In cases of meningitis it is advisable to withdraw large amounts up to thirty, forty, or fifty cubic centimeters, much depending upon the rate of flow. There is one class of case, however, in which too great care cannot be exercised. Most of the accidents and fatalities following lumbar puncture - and there is reason to believe that many such accidents and fatalities have not been reported - have been in cases of cerebral tumor, and especially tumor of the posterior cranial fossa. In these cases the intracranial pressure is invariably high, and if the spinal pressure be suddenly diminished by the withdrawal of fluids, there is great danger of the medulla being forced into the foramen magnum with consequent pressure on the vital centers which may be attended by fatal results. In a vascular sarcoma with thin walled vessels a sudden fall in pressure may be followed by a fatal hæmorrhage, in very much the same way as hæmorrhage from the vessels in the wall of a long-distended bladder may follow a too hasty withdrawal of urine.

It cannot be too strongly urged that lumbar puncture is not such an essentially harmless procedure as venesection. A fatality occurring in the course of a procedure which has probably - and naturally - been represented as of a trivial nature does not tend to establish the physician in the confidence of the relatives, nor in any way to enhance his reputation. If a tumor of the posterior cranial fossa has been diagnosed, the puncture must only be performed in the recumbent posture, without a pillow, and not more than two cubic centimeters should be withdrawn.

Schoenbeck has collected seventy-one fatal cases from the literature. In fifteen of these less than five cubic centimeters was withdrawn. In seven death occurred immediately after the puncture. In some it was delayed for several hours. In cases of cerebellar tumor he advises that the patient be kept in bed for 24 hours before and 24 hours after puncture.

The question of the after-effects of lumbar puncture is one which is not sufficiently emphasized by many writers. Indeed in many cases it is not even referred to. Amongst those au- 
thorities who do discuss the subject there is a somewhat remarkable diversity of opinion. For instance Chauffard and Boidin in a series of two liundred and twenty-three punctures record only three cases of vomiting and no other ill effects to speak of with the exception of slight headache. Nissl, on the other hand, met with headache, nausea, vomiting, and in some cases complete prostration in forty-eight out of one hundred and twelve cases punctured. Of seven doctors whom he punctured as controls, six developed severe symptoms. In a series of observations of my own upon one hundred and twenty asylum patients $I$ had to record marked after-effects in twenty-five cases, together with slighter sequela in a number more. The chief symptoms were headache, giddiness, nausea, and vomiting. Most of the patients were kept in bed for twenty-four hours after the puncture, and not more than eight cubic centimeters were withdrawn. The symptoms as a rule made their appearance soon after the patient got 11 , but were occasionally delayed for an hour or two. In one remarkable case a weakly and anæmic girl was kept in bed for five days. At the end of that period she got up and felt quite well, but seven hours later she had so severe an attack of headache and faintness that she had to retire to bed.

To what are we to ascribe these divergent and apparently contradictory results? I think that the most important factor is the type of case under investigation. In a general hospital if a lumbar puncture is performed on a patient the probability is that he is distinctly ill and is unlikely to leave his bed for many days after the puncture. Under such conditions it is unlikely that there will be any marked after-effects. Certainly in hospital patients I have never seen after-effects comparable in severity to those of asylum patients. In asylum practice, on the other hand, it is probable that the patient is merely put to bed for the purpose of the puncture, after which he is allowed to get up. Under such conditions disagreeable symptoms are much more likely to follow. But even in asylum work a further distinction can be made. The one class of case in which I never observed any unpleasant effects was the 
general paralytic; the explanation probably being the marked excess of fluid which is almost always present in this disease. If now a series of observations be made on general paralytics the results as regards after-effects will be very different from those in a series of ordinary mental cases. This, it appears to me, is the most reasonable explanation of the remarkable diversity of the reports in the literature. Speaking generally it may be said that the more normal the patient the more likely is he to suffer from after-effects, whereas cases of meningeal irritation and of increased intracranial tension feel better rather than worse as the result of the puncture. Occasionally the headache may be psychical in nature, for in one of my cases it occurred where no fluid was obtained.

\section{REFERENCES}

Chauffard, A. and Boidin, L.: Un an de ponctions lombaires dans un service hospitalier. Gaz. d. hôp., 1904, LXXVII, p. 725.

Nissl: Die Bedeutung des Lumbalpunktion für die Psychiatry. Centralbl. f. Nervenh u. Psychiat., I904, XXVII, p. 225.

Schoenbeck, O.: Die Gefahren der Lumbalpunktion. Arch. f. klin. Chir. I9I5, CVII, p. 309. 


\section{PHYSICAL PROPERTIES}

It cannot be said that the physical properties of the cerebrospinal fluid are very striking or of a specially positive character. Indeed, although much time and study have been devoted to them the results have not been remarkable either from the academic or the practical standpoint. To this statement, however, two exceptions must be made. Both the color and the pressure of the fluid are worthy of, and have received, careful consideration.

\section{COLOR}

The cerebrospinal fluid is a perfectly clear, limpid, colorless fluid, which in appearance cannot be distinguished from water. The slightest divergence from this condition of limpidity indicates a pathological condition, provided that certain possibilities are taken into consideration. For, before any conclusions regarding morbid conditions can be drawn, it is first essential to exclude the possibility that such a divergence from the normal may have its origin in the operation of lumbar puncture.

The chief conditions to which an alteration in the physical appearance of the fluid may be due are the presence of blood or leukocytes.

The fluid which first appears may be tinged with blood. This blood may come from one of two sources. It may be preëxistent in the fluid owing to cerebral hæmorrhage, fracture of the skull, or injury to the spinal column. Or it may come from a vessel which has been punctured at the operation. The tyro will frequently obtain blood in his earlier attempts. The expert who enters the canal with one quick push will be 
troubled in this way much more seldom. A frequent source of hæmorrhage is wounding of the plexus of veins which lies in the anterior wall of the canal. This accident may be avoided if the needle is not introduced too far after the ligamenta subflava have been pierced.

Even with the greatest care, however, the fluid which first issues may be blood stained. The first few drops should be discarded, and the rest of the fluid collected in two sterile test tubes. The second of these will contain little or no blood.

As a rule what may be called accidental blood may be distinguished from preëxisting blood by two simple tests. If the blood is accidental in origin the stream will usually rapidly clear, and there will be a marked difference between the tubes. Should a comparatively large vein have been opened, however. the second tube may contain a very appreciable quantity of blood. In this case the fluid must be centrifuged. If the blood is of recent origin, the red corpuscles will be drawn to the bottom and the supernatant fluid become perfectly clear. If, on the other hand, it has been in the spinal canal for any time it will have become hæmolysed, and centrifuging will produce little effect.

It must be realized, however, that the process of destruction of the red blood cells is one which takes some little time, and during the first day or two the cells may show little alteration.

The red coloration due to hæmolysis does not develop fully till the end of the first week, after which it gradually becomes fainter, till by the end of the fourth week it may have completely disappeared.

I have seen a case of fracture of the skull, examined within twenty-four hours of the injury, in which centrifuging removed every trace of blood, sufficient time for hrmolysis to be produced not having clapsed. The source of the blood was very evident, however, for it was so abundant and so intimately mixed with the fluid that it could not possibly have come from a wounded vein. In some cases the tinging of the supernatant fluid may be very slight, and it may only be 
detected when the fluid is compared against a white background with a specimen of clear water. It is important that this should be realized, for upon a determination of the presence of preexisting blood may depend the diagnosis and the question of operation.

Tinging of the fluid without turbidity is not in every instance due to cerebral or meningeal hamorrhage. Of recent years considerable attention has been devoted to a peculiar yellow or golden tinging of the fluid to which the name of xanthochromia has been applied. In this condition the fluid is perfectly translucent and free from turbidity, but of a color varying from a pale straw to a deep amber. This condition was first described by Froin in 1903, and was found by him to be associated with a remarkable increase in the protein content of the fluid. Fibrin is often present and spontaneous coagulation of the fluid may take place. Since that time a large number of cases have been recorded, and it is now recognized that the pathological condition in which this combination occurs most frequently is one of pressure on the spinal cord in which a portion of the subarachnoid sac is shut off from the rest of the space. In this condition, although the protein may be enormously increased, there is as a rule no corresponding increase in the cells of the fluid, which in many cases are normal in number. This last is the most characteristic feature of all. It cannot, however, be considered absolutely pathognomonic, for I have observed a case, with marked protein but no cellular increase, which at autopsy proved to be one of tumor in the pituitary region.

This phenomenon will be considered again in a later section. At present we are only concerned with the presence of coloring matter in the fluid. It is necessary to distinguish a true xanthochromia from coloration of the fluid or erythrochromia due to cerebral or meningeal hamorrlage. There are several respects in which the two conditions differ from one another.

In erythrochromia marked changes in the color of the fluid may be observed if a series of punctures at intervals of a few 
days be performed, and by the end of three or four weeks the color has almost or entirely disappeared. In xanthochromia the color, which is of a more golden tinge, may remain constant throughout a period of many months.

In erythrochromia well formed red cells or the shadows of such cells can be recognized under the microscope. No such cells are present in xanthochromia.

In erythrochromia the chemical, and in the early stages the spectroscopic, tests for blood pigment are positive. In xanthochromia they are invariably negative.

In erythrochromia it is common to find a marked increase in leukocytes, owing doubtless to the irritation of the meninges produced by the effused blood. In xanthochromia, as has already been mentioned, it is unusual to find any increase in white cells.

Finally, true xanthochromia is commonly met with as a late phenomenon in the complex known as the Nonne-Froin syndrome, of which massive coagulation of the fluid is one of the most characteristic features. This never occurs in erythrochromia.

When all has been said, however, there remain cases in which the coloration of the fluid is difficult to classify. In one case which I reported a marked yellow coloration suddenly appeared in the fluid of a case of acute meningitis which was being treated by repeated lumbar puncture. The fluid showed no traces of blood cells, but the color only persisted for a few weeks. There was no coincident increase in the protein.

The source of the coloring matter in xanthochromia must almost certainly be the blood, but what the exact mechanism may be, whether by minute hæmorrhages into the stagnant culde-sac or by some other means, is at present only a matter for conjecture. The prevalent view is that the color is due to capillary hæmorrhages, with very slow disintegration of the red cells, with a result somewhat analogous to the coloration met with in hæmolytic jaundice. Mestrezat states that by using refined methods he was able to demonstrate the presence of 
urobilin in such fluids. Certainly this cannot be done by using the ordinary tests for bile.

Jaundice. The fluid may be bile stained. It is sometimes stated that the cerebrospinal fluid escapes the universal tinging which is found in biliary jaundice. This; however, is only a partial truth. Whilst it is the case that the spinal fluid is less colored than any other of the body fluids, yet in many cases a careful examination will reveal a distinct yellowish tinge. The healthy choroid plexus presents an impenetrable barrier to the passage of the constituents of the bile, and especially of the bile salts, into the spinal fluid. In severe cases, however, the epithelium covering the plexuses may become so damaged that they allow the passage of at least the pigments of the bile into the spinal fluid. In no instance, however, does the coloration met with approach to that met with in the other body fluids. In one case of hæmolytic jaundice, in which the blood serum was highly charged with bile pigments, but the urine completely free, I examined the spinal fluid with great care for bile pigments, but was unable to detect the slightest trace.

Turbidity of the fluid indicates the presence of an abnormal number of cells. These cells may be:

I. Red blood corpuscles, derived from a cerebral or meningeal hæmorrhage, or from a vessel wounded by the puncture.

2. Polymorphonuclear leukocytes, which are present in enormous numbers in acute meningeal infections.

3. Lymphocytes. As a rule the presence of lymphocytes lends no turbidity to the fluid, and they may be present in considerable numbers without affecting its limpidity. When, however, the numbers are very high they may impart a distinct turbidity, or rather opalescence, to the fluid. In one of my cases of early general paralysis of the insane in which a very large cellular increase was present the appearance of the fluid was distinctly turbid.

Pressure. This has been fully discussed in Chapter VI.

Freezing point. The freezing point of a fluid is dependent on the quantity of dissolved substances which it contains, and 
thus affords an indication of the molecular concentration of the fluid. At one time it was hoped that valuable information might be provided by the determination of the freezing point of the cerebrospinal fluid, and numerous cryoscopic observations have been made with that end in view. It cannot be said, however, that these investigations have revealed much of importance. The normal freezing point is given by Mestrezat as -0.575 , but anything from $-0.5 \mathrm{I}$ to $-0.58 \mathrm{C}$. may be considered as being within the normal limits.

The electrical conductivity is another property of minor importance which has received some attention. It is sufficient to say that the fewer are the dissolved substances in the fluid, the poorer is its power of conduction.

The specific gravity varies little, being usually between I006 and $\mathrm{ioos}$.

Reaction. The ccrebrospinal fluid is faintly alkaline in reaction, owing to the salts which are dissolved in it. Cavazzani in I 892 asserted that the alkalinity was half that of the blood, a statement which has been faithfully transcribed by most succeeding writers. Of late much attention has been devoted to the alkalinity of the blood, and methods for its determination have been considerably simplified. The most convenient means of expressing the alkalinity of such a fluid as the blood is in terms of the hydrogen-ion concentration, which may very readily be determined by the method of Levy, Rowntree, and Marriott. This method is so eminently suited for such work on the cerebrospinal fluid that it has already been applied to that purpose by several workers.

The main difficulty that stands in the way of the colorimetric method for determining the hydrogen-ion content of the blood serum is the presence of coloring matter and protein. 'The first of these is not found in the cerebrospinal fluid. As for the second the amount of protein normally present is so small that it may be disregarded. If, however, a large amount of albumin is present it can be readily removed by dialysing the fluid through a collodion sac, one cubic centimeter being dialysed against three cubic centimeters of 0.8 per cent. 
solution of pure sodium chloride. The preparation of these sacs by the method usually recommended is one of considerable difficulty. Collodion is poured in and out of a small test-tube, the film which forms on the surface is allowed to dry, and is finally separated from the glass with the point of a knife. Unfortunately there is a great tendency for the bottom of the collodion sac to adhere to the glass, with the result that a tear occurs when the sac is withdrawn, and the sac thus rendered useless. I have found that a simple device will overcome this difficulty, and render the preparation of the sacs a matter of ease. Melted gelatin is poured in and out of the test-tube, and the film allowed to dry. Collodion is then poured in and out of the tube and also allowed to dry. The tube is filled with cold water to harden the collodion coat, and then placed in the incubator. The gelatin melts and the collodion sac can be removed intact from the test-tube.

If there is no excess of protein and no blood is present it is unnecessary to dialyse the fluid, for practically identical results are obtained with dialysed and undialysed specimens. To 3 c.c. of cerebrospinal fluid in a small test-tube Io by 100 mm. is added 0.3 c.c of a o.or per cent. solution of phenolsulphonephthalein. The color produced is compared with a standard set of tubes containing varying proportions of acid potassium phosphate, $\mathrm{KH}_{2} \mathrm{PO}_{4}$, and alkaline sodium phosphate, $\mathrm{Na}_{2} \mathrm{HPO}_{4}$. Such a set of tubes may be obtained from Hynson, Westcott, and Dunning, of Baltimore, or the solutions may be prepared in the manner described by Levy, Rowntree, and Marriott in their original paper.

The first extensive series of observations was that of Hurwitz and Tranter who found that the average hydrogen-ion concentration of the fluid was 8.I I, as compared with 7.6 to 7.8 for the average of the blood. Weston obtained similar results by the same method. Felton, Hussey, and BasqueJones, however, have pointed out one important source of error. They insist that the estimation must be made immediately after the withdrawal of the fluid, otherwise the rapid escape of the carbon dioxide in the fluid will materially 
increase the alkalinity. They observed the effect of exposing the fluid to the air, and found that in many cases an exposure of six hours would change the $\mathrm{pH}$ from 7.7 to 8.6. Using the method of immediate examination they concluded that the average $\mathrm{pH}$ of the cerebrospinal fluid equals 7.75 , and that the hydrogen-ion concentration of the blood serum and spinal fluid are approximately equal. They examined the fluid from a large number of cases of nervous disease, including epilepsy and syphilis of the nervous system, but found no appreciable alterations in the reaction.

Levinson has described another simple method of estimating the alkalinity of the fluid. He titrates the fluid against $\mathrm{n} /$ IOO sulphuric acid, using methyl red as an indicator. To one c.c. of spinal fluid, diluted with 20 c.c. of distilled water is added I drop of a 2 per cent. solution of methyl red, and the number of c. c. of $\mathrm{n} / \mathrm{IOO} \mathrm{H}_{2} \mathrm{SO}_{4}$ required to produce color changes is taken as the index. The normal fluid gives an index varying between 2.0 and 2.5 c.c. The alkalinity as tested by this method is considerably lowered in epidemic meningitis, ranging between 0.7 and 1.3 c.c., but in tuberculous meningitis there appears to be little change.

\section{REFERENCES}

Cavazzani: Contributions à la Physiologie du liquide cérébrospinale. Arch. Ital. de Biol. XXXVII, p. 30.

Felton, L. D., Hussey, R. G., and Basque-Jones, S.: The reaction of the cerebrospinal fluid. Preliminary report on hydrogen-ion concentration as determined by the colorimetric method. Arch. Int. Med., I9r7, XIX, ro85.

Hanes, F. M.: The spinal fluid syndromes of Nonne and Froin and their diagnostic significance. Am. Jour. Med. Sc., 1916, CLII, p. 66 .

Hurwitz, S. H. and Tranter, C. L.: On the reaction of the cerebrospinal fluid. Arch. Int. Med., I9I6, XVII, p. 828.

Levinson, A.: Studies in spinal fluid. Arch. Pediat., I916, XXXIII, p. $24 \mathrm{r}$.

Levy, R. L., Rowntree, L. G., and Marriott, W. Mck.: A simple method for determining variations in the hydrogen-ion concentration of the blood. Arch. Int. Med., 1915, XVI, p. 389. 


\section{CHAPTER IX}

\section{CHEMICAL COMPOSITION}

The cerebrospinal fluid is in many ways a unique fluid. Although taking its origin directly from the blood it differs diametrically from the serum in the remarkable simplicity of its chemical composition. That composition may be described in a word by saying that the fluid differs from distilled water in that it contains traces of a few salts, a trace of protein, a trace of sugar, a trace of urea, and is alkaline in reaction. There is a certain danger of being led by this simplicity of composition to neglect the chemical conditions in favor of the more obvious cytological changes which are met with in disease of the nervous system. In such disease, however, changes of the greatest importance may take place in the chemical composition of the fluid, and in this direction lies perhaps the greatest hope that eventually fuller light will be shed upon the nature of nervous diseases which are at present entirely obscure. One obstacle in the way of progress is the coarseness of some of the methods commonly employed. It is only when such tests as the Wassermann and the colloidal gold are applied to the fluid that we begin to realize the possibilities of chemical investigations on the fluid. It is inconceivable that the fluid which bathes the nervous tissues and which receives the products of their metabolism should be perfectly normal in such an essentially toxic condition as disseminated sclerosis, and yet because we can demonstrate no increase of cells or of protein content we are forced to call it so. There can be no doubt that as our methods of investigation become more and more refined and penetrating, chemical and biological changes will be revealed in the fluid which were never dreamt of in our philosophy. 


\section{PROTEIN}

Blood serum contains a large amount of albuminous material, of which the chief constituents are serum albumen and serum globulin, which are present in the proportion of 2.5 per cent. of serum albumen and 4.0 per cent. of serum globulin. For purposes of nomenclature it is convenient when dealing with the cerebrospinal fluid to include these two substances under the common term protein. Serum globulin may be precipitated by half saturating the fluid with ammonium sulphate (i.e. by adding an equal quantity of ammonium sulphate solution), or by fully saturating it with magnesium sulphate. If serum albumen is present it may be demonstrated in the filtered fluid by heating. It is removed by completely saturating the fluid with ammonium sulphate.

Investigations on the protein content of the cerebrospinal fluid have been conducted over a considerable number of years, and many and varied have been the results. It has been stated at different times that the fluid contains albumen, globulin, albumose, nucleo-protein, and various combinations of these substances.

It is now universally admitted that the most important constituent is globulin, which may readily be detected. Many authorities state that the normal fluid never contains true albumen, but undoubtedly in some cases when the globulin has been completely removed minute traces of albumen can be demonstrated. The quantity, however, is so small that for practical purposes it may be neglected. Mestrezat in one case estimated the amount of albumen as being .004 per cent.

Globulin is present normally to the extent of .02 to .03 per cent. It reacts readily to such tests as heat or the nitric acid ring test. In many pathological conditions it is increased in amount, and the detection of this increase is of the greatest importance. It is necessary, therefore, to employ a test which will give a positive result when the globulin is increased beyond the normal limits, but which will not react with the normal fluid. 
From time to time a multitude of tests have been devised and suggested for this purpose. Of these three may be highly recommended. Nothing is to be gained by describing the others in detail. Before applying any of the tests the fluid should if necessary be thoroughly centrifuged, so that any blood or pus cells may be removed.

The ammonium sulphate ring test of Ross and Jones has no equal for demonstrating the slightest increase in the protein of the fluid, but I have found that even in normal fluids, if the observations be made under the most favorable conditions, a positive result may sometimes be obtained.

The test is made as follows. A saturated solution of pure neutral ammonium sulphate is prepared with the aid of heat. Unless care be taken to insure that the solution is completely saturated the results will not be trustworthy. On to the surface of this saturated solution is poured 1 c.c. of cerebrospinal fluid, in the same manner as in the nitric acid test for albumen in the urine. A positive reaction is indicated by the appearance at the line of junction of the fluids of an extremely thin, clear-cut, white line, no thicker than a sheet of fine paper, and of a cobwebby appearance. An indistinct haze must always be regarded as indicating a negative reaction. In order that the faintest ring may be detected it is necessary that a suitable illumination and background be used. It is best to use an artificial light coming from the side and a black background. A black lined box in one side of which there is an opening for an electric light is an ideal arrangement. If a negative result be obtained with this test, employing the above precautions, there is no excess of protein present.

The original and classic form of the ammonium sulphate test is the Phase I test of Nonne and Apelt, which consists in the addition of an equal quantity of saturated ammonium sulphate solution to the cerebrospinal fluid. If turbidity appears within three minutes the test is positive. Phase II consists in the demonstration of the presence of albumen after all the globulin has been precipitated by ammonium sulphate. 
Noguchi's butyric acid test consists in the addition of 0.5 c.c. of Io per cent. butyric acid in normal saline to o.I c.c. of cerebrospinal fluid. The fluid is heated, o.I c.c. of a 4 per cent. solution of sodium hydrate is added, and heat is again applied. If the protein is increased there will appear in a few minutes fine flocculi, which gradually become coarser, and finally form a precipitate on the bottom of the tube. The test is a somewhat malodorous one.

The third and simplest of these tests is that of Pandy. The reagent is a Io per cent. solution of carbolic acid, which must be prepared with care. The solution, which is made up with distilled water, is well shaken and placed in the incubator for some hours. It is allowed to stand at room temperature for several days, and the clear supernatant fluid is then pipetted off. The test is performed by allowing a drop of cerebrospinal fluid to fall upon the surface of the reagent. It is usually recommended that the fluid should be allowed to trickle down the side of a watch glass containing the reagent, but a test tube viewed against a black background shows the reaction perfectly. A positive reaction is indicated by cloudiness or white precipitate as the drop of fluid passes through the reagent.

It will be seen that all these tests are essentially simple, as simple indeed as the corresponding tests for albumen in the urine. No complicated apparatus is needed, and they can be performed in the consulting room or by the bedside. To determine whether the cerebrospinal fluid contains an increased amount of albumen is as important, and in some cases much more important, than to decide a similar question with regard to the urine. If this fact were more generally recognized, what may be called bedside tests for the spinal fluid would undoubtedly become much commoner. The demonstration of albumen in the spinal fluid may settle a diagnosis of tuberculous meningitis, general paralysis of the insane, or tumor of the spinal cord. Although it may be possible to do as little for these conditions as for chronic Bright's disease, the question of prognosis is even more important. 
The protein content of the cerebrospinal fluid will be considered when the different diseases of the central nervous system are studied, but it may be well here to mention the conditions in which it may be increased.

A very great increase is present in acute meningitis, whether due to the meningococcus, the pneumococcus, or the streptococcus. In tuberculous meningitis there is a marked increase, although the fluid may appear perfectly normal to the naked eye. In syphilitic disease of the nervous system, in general paralysis, and in tabes dorsalis it is increased in the great majority of cases. Cases of brain tumor may show an increase, but as a rule they do not; no general rule can be stated. The condition in which the greatest increase may occur is pressure on the spinal cord, usually due to tumor of the cord. In a number of different types of insanity, in which there was no evidence of syphilitic involvement of the nervous system, I have found a slight protein increase. The chief of these were manic-depressive insanity, epilepsy, dementia precox, and congenital imbecility. These were only exceptional cases, however, and the increase was usually very slight.

The fact that albumen is present in pathological amount in a variety of conditions does not detract from the diagnostic value of the sign. The diagnosis may lie between meningitis and meningism, or tabes dorsalis and peripheral neuritis, or general paralysis and alcoholic insanity. In all of these instances the presence of albumen would at once settle the diagnosis. On the other hand the test would be of no value in distinguishing between disseminated sclerosis and hysteria, or between general paralysis and cerebrospinal syphilis.

\section{THE POTASSIUM PERMANGANATE INDEX}

It is a well known fact that water containing organic matter has the power of reducing a solution of potassium permanganate. This property has been utilized for the detection of organic matter of inflammatory origin in the cerebrospinal fluid. What is called the reduction index is the number of 
cubic centimeters of decinormal potassium permanganate solution which when boiled for ten minutes in a strongly acid medium are reduced by I c.c. of cerebrospinal fluid.

The test is performed as follows. To I c.c. of cerebrospinal fluid are added 50 c.c. of water, Io c.c. of $I$ in 4 sulphuric acid and ro c.c. of decinormal potassium permanganate, and the mixture boiled for ten minutes. To the mixture are added ro c.c. of decinormal oxalic acid, and the whole is titrated with potassium permanganate till the characteristic color returns. Below 2 is a normal index; from 2 to $2 . \dot{5}$ may be regarded as border-line cases, and above 2.5 as high. The higher the content of organic substances in the fluid, the greater will be the amount of potassium permanganate solution reduced.

The cases in which the test is most useful are those with a clear fluid and symptoms suggestive of meningitis, such conditions, for instance, as tuberculous meningitis or anterior poliomyelitis. There is no definite relation between the reduction index and the cell count. Hoffman and Schwartz record a case of cerebral tumor which closely simulated tuberculous meningitis; the fluid was opalescent, contained 330 cells per c.mm., the majority of which were lymphocytes. The reduction index, however, never went above the normal: There is a much closer relation between the index and the globulin, but the former has the advantage of being more readily expressed in figures.

All normal and non-inflammatory fluids give a normal reading. Borderline results are found in the early stages of inflammation of the brain and the meninges, and in serous meningitis. A high index signifies acute inflammation of the brain or meninges. The test is especially valuable in prognosis. In meningococcus meningitis if the prognosis is good the index falls after the injection of serum, even although the serum itself has a high reduction value. An index remaining persistently high, on the other hand, is a very unfavorable sign. 


\section{SUGAR}

The cerebrospinal fluid contains dextrose. That fact is undoubted, and yet it is remarkable how timidly many writers approach the subject. They appear to be afraid to make so startling an admission. The utmost length they are prepared to go is to admit that a Fehling-reducing substance is present in the fluid. The explanation of this unwillingness tn admit the presence of sugar in the fluid is probably traceable in many instances to Halliburton's statement to the effect that the Fehling-reducing substance was not dextrose but pyrocatechin, a pronouncement which appears to have been received with a remarkable degree of docility. Halliburton himself, however, has for some time revoked his opinion, and the pyrocatechin idea may well receive a decent burial. The sugar reduces Fehling's solution, is fermentable, rotates polarized light to the right, and when treated with phenylhydrazin gives crystals of glucosazone melting at $202^{\circ}-205^{\circ} \mathrm{C}$.

The normal cerebrospinal fluid reduces Fehling's solution to a slight but distinct extent. There may not be much color change in the solution, but if the tube be allowed to stand for a few minutes a reddish deposit will be found at the bottom. An excess of Fehling's solution should be avoided, and it is well to dilute the solution three or four times. Any excess of albumen present should first be removed by boiling, as it is apt to give a greenish precipitate which may be misleading. The amount of sugar present is so small that for its quantitative estimation special methods are necessary. The most convenient is that of Myers and Bailey for determining the sugar in the blood. To 2 c.c. of cerebrospinal fluid are added $0.2 \mathrm{gm}$. of dry picric acid and I c.c. of a 20 per cent. solution of sodium carbonate. The tube is placed in the water bath at $100^{\circ} \mathrm{C}$. for 20 minutes, and the canary yellow color produced is compared with a standard solution of picric acid in an Autenrieth-Königsberger wedge colorimeter.

Weston, in a series of observations on insane patients, found that the general average was 0.068 per cent., that of 
blood being 0.114 per cent. There were considerable individual differences, but the average of the different groups was very constant. These were as follows: manic-depressive insanity 0.07 II, epilepsy 0.0740 , imbecility 0.0723 , general paresis 0.0658 , dementia præcox 0.0604 .

The statement is generally made that in acute suppurative meningitis the sugar is markedly decreased or altogether absent. In tuberculous meningitis the diminution may be slight. These statements, however, lacked the sound foundation of a quantitative estimation expressed in figures, and as a rule one had to be satisfied with the assurance that the fluid did not reduce Fehling's solution well. Peirce, working in the laboratory of the Winnipeg General Hospital, and using a technic similar to that just described, although somewhat modified, obtained figures which bore out the contention that in acute suppurative conditions of the meninges there is a very marked reduction in the amount of sugar present. Mott states that the sugar is reduced in dementia præcox, but in a series of cases which I examined I did not find this to be the case. It will be noticed, however, that the lowest average in Weston's series was obtained in dementia præcox.

There is a very considerable increase in the sugar content in diabetes mellitus. With the onset of diabetic coma both diacetic acid and acetone are as a rule readily demonstrable. In cases in which the onset of diabetic coma is feared it is possible that the appearance of these substances in the spinal fluid may be an earlier and therefore more valuable prognostic sign than their presence in the urine.

The theoretical interest of the presence of and variations in the sugar in the cerebrospinal fluid is great. The cerebrospinal fluid has already been compared to Ringer's fluid, in which the function of the sugar is to provide nourishment and minister to the metabolism of the perfused organ. The sugar in the spinal fluid is undoubtedly intimately concerned with the metabolism of the nerve centers, and its presence or absence may be regarded as an index of the activity of the 
metabolism which is taking place. The data at our disposal are not yet sufficiently extensive to warrant us in drawing conclusions regarding the behavior of the cerebrospinal sugar in metabolic affections of the central nervous system, but this offers a promising field for future investigations. It is often asserted that a diminution of sugar occurs in general paralysis, but I have not been able to satisfy myself that this is the case.

The variation of the sugar content in the various forms of meningitis has a simple explanation. The meningococcus, the pneumococcus, and the streptococcus all possess the porver of readily fermenting glucose. In meningitis due to these organisms, therefore, the sugar is diminished or absent. The tubercle bacillus does not possess this power. Hence the sugar is as a rule little changed in tuberculous meningitis.

This varying behavior of the sugar may be of considerable value, both diagnostic and prognostic, to the physician.

It is one of the bedside tests which may settle the diagnosis for or against meningitis. With a frankly purulent fuid the need does not arise. But in early cases the fluid may be opalescent or even clear. In such cases a marked disappearance of sugar would point very strongly to meningitis.

In the matter of prognosis, again, it may be well worth while to test the Fehling reaction. In the course of a case of meningococcal meningitis treated by injections of serum, relapses in the clinical condition may occur. These may or may not be due to further activity on the part of the meningococcus. In the former case the sugar, which has begun to reappear with convalescence, will again disappear, and more serum must be administered. In the latter the sugar will remain unaltered, and serum is not indicated.

In anterior poliomyelitis the sugar is not at all reduced. This is one of the chief respects in which the fluid differs from that of tuberculous meningitis, as far as our present knowledge goes. The sugar of the spinal fluid should therefore always be tested in suspected cases of poliomyelitis. 


\section{UREA}

Urea occurs in the normal cerebrospinal fluid to the extent of 0.006 per cent. It is unique amongst the constituents of the fluid in that it increases with an increase in the urea content of the blood. Doubtless this is accounted for by the extreme diffusibility of urea, to which no check is placed by the epithelium of the choroid plexus.

In true uræmia, that is to say where there is a condition of renal impermeability to urea, the increase of the urea content of the blood is closely paralleled by a similar increase in the cerebrospinal fluid. Where, however, there is merely a retention of chlorides with a normal excretion of urea, such an increase is no longer found. Many cases of cardio-vascular disease, etc., are wrongly diagnosed as clinical cases of uræmia, and in such cases an estimation of the amount of urea in the spinal fluid is of great value both in diagnosis and prognosis.

The estimation of the urea in the blood is a little difficult. In the case of the spinal fluid it is perfectly simple. As the amounts in the two cases coincide so closely, it is evident that a valuable means is provided for determining the existence of a true urea retention, a means which will prove especially valuable in cases of coma of uncertain nature.

Canti found that in cases clinically diagnosed as uræmia those with a high cerebrospinal urea content all proved fatal, whereas those with a low urea content for the most part recovered. Mestrezat gives the figures in pure uræmia as varying between 0.098 per cent. and 0.634 per cent. Those below 0.3 per cent. were curable, those above 0.3 per cent. were all fatal.

The hypobromite method is sufficient for clinical purposes. Five c.c. of cerebrospinal fluid are mixed with 25 c.c. of 40 per cent. potassium hydrate solution, to which an ampule containing 2.2. c.c. of bromine is added. The results can be read in the usual way. The ammonium salts and other substances which interfere with the accuracy of this method in the case of 
the urine are of course not met with in the spinal fluid. For more accurate work it is best to use the urease method of Marshall. This is carried out in exactly the same way as in estimations of blood urea.

\section{REFERENCES}

Canti, R. G.: The urea content of the cerebrospinal fluid, Lancet, 1916, I, p. 344 .

Hoffman, W. O. and Schwartz, A. B.: The potassium permanganate reduction index of the cerebrospinal fluid. Arch. Int. Med., I9I6, XVII, p. 293.

Jones, E.: The protein content of cerebrospinal fluid in general paralysis. Rev. of Neurol. and Psych., 1909, p. 379.

Myers, V. C. and Bailey, C. V.: The Lewis and Benedict method for the estimation of blood sugar, with some observations obtained in disease. Jour. Biol. Chem., I9I6, XXIV, p. I47.

Nonne and Apelt: Über Fraktionerte Eiweissausfällung in der Spinalflüssigkeit, etc. Arch. f. Psychiat., 1907, Bd. XLIII, H, 2.

Pándy: Uber eine neue Eiweissprobe für die Zerebrospinalflüssigkeit. Neurol. Centralbl., I910, p. 915.

Weston, P. E.: Sugar content of the blood and spinal fluid of insane subjects. Jour. Med. Research, I9I6, XXXV, p. I99. 


\section{CHAPTER $\mathrm{X}$}

\section{CYTOLOGY}

The normal cerebrospinal fluid contains an occasional lymphocyte and sometimes an endothelial cell or two. In disease conditions, cells make their appearance in varying numbers. It is not only the number which varies. The cell type shows an equally great variation. Almost any blood cell may be present in addition to a considerable variety of tissue cells. Too little attention has been paid to the particular kind of cell present in different pathological conditions. How often do we read that a cytosis was found, a pleocytosis, an increased cell count, without a word as to the nature of the cells. Our present knowledge of diseases of the blood has been gained by a careful differential study of the various cells which may appear in disease. Similar study is needed in the case of the cerebrospinal fluid if we are to obtain a true conception of the pathology of many of the conditions in which it shows abnormal changes. This neglect is partly due to the fact that the usual methods of cell examination are inadequate for purposes of fine differentiation, and that the one really excellent method - that of Alzheimer - is somewhat cumbersome and tedions.

Examination of the cells of the cerebrospinal fluid must be both quantitative and qualitative.

\section{QUANTITATIVE EXAMINATION}

The French method. It was the investigations of Widal, Sicard and Ravaut in I9or upon the cell content of the spinal fluid which first drew attention to the clinical importance of the fluid, and it was therefore natural that their method, commonly called the French method, should have been used by the earlier workers. Latterly, however, it has fallen into disuse and almost into a disrepute which is certainly undeserved. For 
by it an idea as to whether a pathological increase in the cells is present may be gained quite as accurately as by the ordinary hæmocytometer, although not with the same accuracy as is given by the method of Fuchs and Rosenthal. Further, a reasonably good picture of the variety of cells present is afforded. The technic demands a reasonable amount of care.

Five cubic centimeters of spinal fluid are placed in a tapering centrifuge tube, which must be scrupulously clean, and centrifuged at a rapid rate - I 200 revolutions per minute - for half an hour. The fluid is decanted and the tube allowed to stand upon blotting paper in an inverted position for 3 minutes, so that only a trace of fluid remains in the tube. The tube is then returned to the upright position, and when not more than a drop of fluid has made its appearance at the bottom, the sediment is taken up into a fine capillary tube and blown out on to a glass slide. This is the part of the procedure which requires care and a certain degree of skill. The same capillary should be used each time. If treated reasonably its life will be a long one. Not more than a small drop of fluid must be allowed to collect at the bottom of the centrifuge tube, otherwise the sediment will be unduly diluted. The capillary should be twirled around the bottom of the tube in order that no sediment may be left adhering to the walls. Finally the fluid must not be blown out of the capillary all over the slide. Blow gently until a drop appears hanging from the end of the capillary. Then touch the slide gently with the drop, taking care that the latter does not spread out upon the slide. Unless this precaution is observed the count will be too low. The drop of fluid is dried in air, fixed in absolute alcohol for ro minutes, and stained.

The count is made by examining the slide under a magnification of 450 diameters - high power - and taking the average of a number of fields. It is advisable to count at least ro fields, and these should include both the margin and the center of the drop, for the cells tend to be collected more densely at the former than at the latter.

If details of the technic be attended to the French method 
will be found to give constant and accurate results. Some years ago I tested it in a series of observations on the cerebrospinal fluid of the insane. The patients were not receiving any special treatment and the condition of their fluid might therefore be regarded as reasonably constant. In a considerable number of cases the fluid was examined on several occasions and the results were remarkably constant. I am convinced that the variation would have been fully as great and probably greater with the ordinary hæmocytometer method. In addition the method provides a permanent preparation, and enables a differential count to be made.

Various modifications of the original French method, such as those of Nissl, and Fischer and Kafka, have been from time to time introduced, but they are not of sufficient importance to be considered in detail.

The counting chamber method. Useful as the French method undoubtedly is, there can be no doubt that the best all round method of cell estimation is the use of the special counting chamber of Fuchs and Rosenthal. Unfortunately in many instances the special chamber is not available, with the result that the ordinary Thoma-Zeiss apparatus is used.

The Thoma-Zeiss chamber is I $\mathrm{mm}$. square and $0 . \mathrm{Imm}$. deep. The total volume is therefore I/ro c.mm. The FuchsRosenthal chamber on the other hand is $16 \mathrm{~mm}$. square and $0.2 \mathrm{~mm}$. deep, with a resulting capacity of $16 / 5 \mathrm{c}$. $\mathrm{mm}$. or about $3 \mathrm{c} . \mathrm{mm}$. The number of cells counted is, therefore, very much greater, and the margin of error correspondingly less.

The cerebrospinal fluid which should be as fresh as possible is well shaken up so as to ensure a uniform distribution of cells. Using an ordinary white cell counting pipette, stain is drawn up to the mark $\mathrm{r}$, and cerebrospinal fluid to the mark I I. The staining fluid consists of :-

Methyl violet $\ldots \ldots$ o. I

Glacial acetic acid .... 2.0

Aq. dest. ......... 50.0 


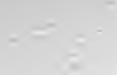

, 


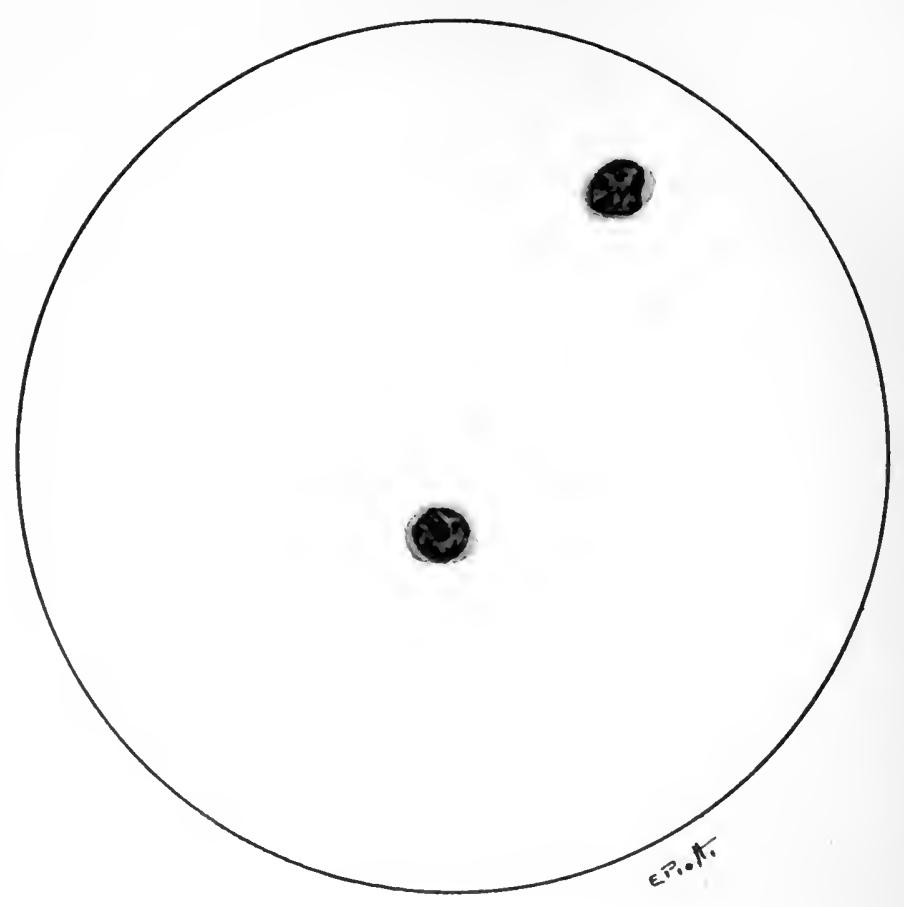

Normal Cell Count. 
After allowing the stain to act for a few minutes a drop of fluid is placed on the counting chamber and the cells are counted in the ordinary manner. This gives the number in $\mathrm{I} 6 / 5 \mathrm{c} . \mathrm{mm}$., and by dividing by three the number per c. $\mathrm{mm}$. is obtained. With practice a fair idea as to the type of the cell present may be obtained, for the cells have undergone none of the distortion which is liable to occur during the process of drying in the French method, but at first cell differentiation will be found a matter of considerable difficulty.

The Fuchs-Rosenthal method has received a thorough testing during the last dozen years, and it may safely be said that it is facile princeps among methods of cell counting. One of its great advantages is that the smallest quantity of fluid will suffice. This is a point of considerable importance in such conditions as tumor of the brain where the withdrawal of any large amount of fluid may be quite inadmissible.

Another great practical advantage is that it can be carried out at the bedside. Indeed the sooner the count is made after withdrawal of the fluid the better, as sedimentation occurs rapidly, and the cells are liable to adhere to the sides of the tube.

\section{THE CELL COUNT}

Whatever method be used, the interpretation of the findings is of primary importance. A normal and a pathological limit can be fixed, but between these two there comes a boundary zone in which the laboratory findings must be read in the light of the clinical facts. The numbers in the French and counting chamber methods correspond closely. From I to 5 cells per c. mm. or in an average field may be taken as normal. and anything above ro cells as abnormal. Between these there is the boundary or indefinite zone, in which a definite opinion can often not be expressed. In such cases it may be wise to perform a second puncture a day or two later.

The highest counts are obtained in acute suppurative meningitis, in which there may be many thousands of cells per c. $\mathrm{mm}$. Early cases of tabes dorsalis and general paresis may 
give a count of a hundred or more. As the disease progresses the count tends to fall and in advanced cases of paresis it may not be more than IO or 20. An ordinary case of tabes as a rule gives a count of under 100 , but often the figure is very much smaller. Active cerebrospinal syphilis especially the meningitic form is sometimes associated with an extremely high count, in some cases there being several thousand cells present. In that form of the disease, however, in which endarteritis is the chief feature there may be little or no pleocytosis. One of the most constant signs of tuberculous meningitis is a cerebrospinal lymphocytosis, often between 100 and 200 , but in some cases so low as to cause grave doubt regarding the diagnosis. In the earliest stages of poliomyelitis there is a constant pleocytosis, and a moderate increase may occur in encephalitis lethargica.

An increase in cells may thus occur in the following conditions: acute suppurative meningitis, tuberculous meningitis, acute anterior poliomyelitis, encephalitis lethargica, general paresis, tabes, cerebrospinal syphilis,- cerebral abscess, cerebral hæmorrhage, cerebral tumor (rarely and only when cortical), herpes zoster, mumps, sleeping sickness, cysticercus cellulose of the central nervous system, and in certain mental conditions which will be discussed later. From this brief survey it will be scen that a marked pleocytosis is a sign of great diagnostic value, but that borderline results must be accepted with caution, and are to be interpreted in the light of the clinical findings.

It is not, however, in diagnosis alone that observations on the cell count are of value. As an index to the success of treatment they are often invaluable. The pleocytosis is the first of the pathological signs to give way to treatment in cerebrospinal syphilis, and in meningitis the behavior of the cells may have great prognostic importance.

\section{CELL DIFFERENTIATION}

It has already been remarked that sufficient importance has not been attached to the differential study of the various kinds of cells present. This is largely due to difficulties of technic. 
The ordinary method of drying a film in the air and staining only gives differentiation sufficient, as a rule, to distinguish between the polymorphonuclear and the lymphocytic series of cells. It shows none of those cells upon the recognition of which depends future progress in such questions as the mechanism of meningitic inflammation and the origin of the new cells.

For this finer work of differentiation more refined methods are needed. In the Alzheimer method we have the method suited above all others for this particular purpose. It is not a bedside method, but if time and facilities are available, it is quite unequaled.

The principle of the method is to precipitate the albumen of the fluid with alcohol. The cells are drawn down with the precipitate, and the resulting coagulum treated as a tissue and cut in celloidin. The cells are instantaneously fixed in the fluid, with no opportunity for becoming dried and distorted, as in the French method. The resulting cell picture, if the section is a good one, is remarkable for its variety and clearness.

From 3 to 5 c.c of cerebrospinal fluid are mixed with an equal quantity of 96 per cent. alcohol as soon after withdrawal of the fluid as possible. If the albumen be much increased a dense cloud will form. If, however, there be no increase it is well to add a small amount of white of egg solution to the fluid in order to obtain the necessary precipitate. The tube is then centrifuged at a high speed for an hour, by the end of which time a firm circular coagulum will have formed at the bottom of the tube. Scattered throughout this coagulum are the fixed cells. The fluid is decanted, and the coagulum hardened with absolute alcohol, alcohol and ether, and pure ether. It is best to allow each of these reagents to act for 24 hours, but if time be a consideration a few hours may suffice.

When the ether has been decanted it will probably be found that the hardened coagulum has shrunk slightly from the sides of the tube, so that it is possible to detach it from the bottom 
by means of a platinum loop or a very fine glass rod. This manipulation requires care and varies considerably in difficulty. In many cases a mere tap on the bottom of the tube may suffice to remove the coagulum. In other cases, however, it is so soft that it is almost impossible to detach it without causing serious damage. I have found the greatest trouble in purulent fluids in which the coagulum although very large may be extremely soft. In such a condition as tabes, on the other hand, the coagulum is firm and compact and very easy to manipulate.

The detached coagulum is shaken out into the palm of the hand, and placed first in thin and then in thick celloidin. It should be left in each solution for at least three days, but may with advantage remain much longer. Finally it is mounted on a wooden block, covered with thick celloidin, and cut on a Jung microtome. The celloidin is removed with absolute alcohol and ether and the sections passed through 80 per cent. alcohol and distilled water into Pappenheim's pyronin-methyl green stain. This has the following composition:

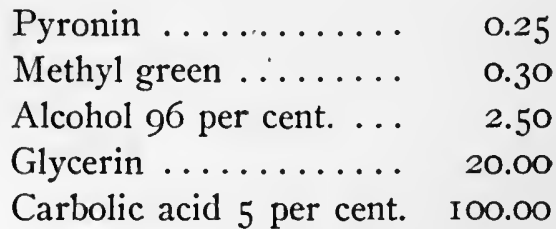

The sections are kept in this stain in the water bath at $40^{\circ} \mathrm{C}$ for 5 minutes. Excess stain is removed with distilled water. Differentiate in absolute alcohol till no more stain comes away. Clear in xylol and mount in balsam.

Pappenheim's stain is a difficult one to prepare, and I have found it preferable to work with the preparation supplied by Grübler. Unna's polychrome methylene blue gives an excellent picture, but with it the cells do not show some of the differential characteristics obtained with the Pappenheim stain. 


\section{THE NATURE OF THE CELLS}

With the French method it is not as a rule possible to do more than differentiate between the polymorphonuclear cell, the small lymphocyte and the large lymphocyte. By Alzheimer's method, however, cells can be distinguished which were not formerly known to occur in the cerebrospinal fluid. In such a condition as general paresis the variety of cells may be truly bewildering. Indeed there is a tendency, especially on the part of German writers, to multiply types and names to an extent which it is very improbable that future work will justify.

The lymphocyte is the most important cell in the spinal fluid. In health it is the only variety besides the endothelial cell which is found. In subacute and chronic inflammations of the meninges any increase of cells is mainly confined to the lymphocytes. Tuberculosis and syphilis afford examples of such conditions.

The typical lymphocyte is a compact little cell rather smaller than a red blood corpuscle. It consists mainly of a nucleus. The nucleus stains intensely blue with Pappenhein's stain and shows a very characteristic peripheral or clock-face concentration of the chromatic substance, although this appearance is not so marked as in the plasma cell. The cytoplasm is scanty, forming a narrow rim round the nucleus, and stains pink or red with pyronin. Some of the cells may be larger than a red blood corpuscle, and may then be called large lymphocytes.

In disease conditions associated with increase in the number of lymphocytes it is common to meet with cells which stain poorly. These are probably lymphocytes which are undergoing degeneration, and are no longer able to take up the basic stain. In a fresh case of meningeal irritation almost all the cells take up the stain in the normal manner. After a number of weeks have elapsed, however, large numbers of these feebly staining degenerating cells may make their appearance. They may be regarded as cells which have passed the hey-day of their youth, and are now in a condition of 
senility. In some cases of lymphocytosis the cytoplasm of certain of the lymphocytes is elongated in one direction, giving what has been called a tailed appearance to the cells. It is doubtful what importance should be attached to this peculiarity, or whether, as has been done, the cells should be placed in a separate group. The condition in which tailed lymphocytes are most abundant is new growth of the brain. In this condition they may outnumber the ordinary form of lymphocyte.

The endothelial cell can readily be distinguished from the lymphocyte. It is larger and the nucleus, which does not take on the intense stain so characteristic of the lymphocyte, is placed somewhat eccentrically and is usually indented or kidney-shaped, although in some cases it may be spherical. The nucleus does not show the clock-face arrangement of chromatin granules. It is probable that these cells originate from the lymph cells in the pia mater. In general paresis they are often present in considerable numbers, averaging about ro per cent. of all the cells. This figure may be more than doubled in post-mortem fluids (Cotton and Ayer).

Polymorphonuclear cells. - It is sometimes stated that the polymorph may occur in normal fluid, but I have never met with one, except in cases in which there was blood contamination. With Pappenheim's stain the nucleus alone is visible. In order to demonstrate the cytoplasm it is best to make a film and stain it with one of the Romanowsky stains. In acute purulent meningitis there may be enormous numbers of polymorphs, to the exclusion of all other cells. In tuberculous meningitis the proportion varies greatly, depending partly on the acuteness of the condition. As a rule they are greatly outnumbered by the lymphocytes, but occasionally the preponderating cell may be the polymorph. These cells are present in small numbers in general paresis. In acute exacerbations of the disease, and especially after convulsive seizures, there may be a marked increase, the proportion sometimes reaching 50 per cent.

The supremacy of the polymorph in acute meningitis only 
holds for the early and acute stages. As improvement sets in lymphocytes and endothelial cells make their appearance and eventually replace the polymorph completely. In one case of meningococcal meningitis the polymorphs at first numbered 96 per cent. After some weeks of serum treatment the number fell to 50 per cent. and when the patient finally recovered they had entirely disappeared, although there remained considerable numbers of lymphocytes and endothelial cells.

Plasma cells. - The plasma cell is larger than the lymphocyte and of very characteristic appearance. It is rounded or polygonal, often presenting a tailed appearance. The nucleus is as a rule markedly eccentric, stains intensely blue, and the clock-face arrangement of its chromatin is even more marked than in the lymphocyte. The cytoplasm which is coarsely granular stains an intense red with pyronin. Indeed Pappenheim's stain is specific for these cells.

The presence of plasma cells in the perivascular cellular infiltration in the brain in general paresis is well known, but they had never been found in the cerebrospinal fluid until the introduction of the Alzheimer method made it possible to demonstrate them in nearly every case. At first it was claimed that these cells were absolutely pathognomonic of general paresis, but this position can no longer be maintained. Rehm and Hough have found them in cerebral syphilis, and Henderson in tabes dorsalis and tuberculous meningitis. They are therefore not typical of any one condition, but they have never been found in the normal fluid.

Gitterzellen or lattice cells. - These are the largest cells found in the fluid, being at least ro times as large as a lymphocyte. The nucleus is large, usually eccentric in position, and does not stain very deeply. The cytoplasm is faintly stained and shows the characteristic vacuolation or lattice work. Perhaps the cytoplasm may best be described as being foaming in appearance. In some cases it appears to be converted into one great vascuole, and presents no structure whatever. These cells are never met with in the normal fluid. They are 
very characteristic of general paresis, but have also been found in tuberculous meningitis:

Phagocytes. - In a variety of morbid conditions it is common to find large cells with cell inclusions. It is difficult to know whether these cells deserve to be grouped in a separate class. It may well be that they are merely endothelial cells which have taken on a phagocytic function. The cell inclusions are generally degenerated lymphocytes or red blood corpuscles.

Fibroblasts. - A sharply defined and characteristic variety of cell is the fibroblast, which occurs in small numbers in syphilitic infections of the central nervous system. It is a narrow elongated cell similar in appearance to the fibroblast of connective tissue. The nucleus is elongated and stains somewhat faintly. The cytoplasm stains moderately deeply with pyronin.

Many other subvarieties of cells have been named and classified, notably by Szecsi, who speaks of microlymphocytes, microlymphoidocytes, lymphoidocytes, plasma daughter cells, etc. Until our cytological knowledge is more advanced, however, such minute subdivision only tends to confusion, and serves no useful purpose.

\section{ORIGIN OF THE CELLS}

No better example of the diametrically opposed views which are still held on many points regarding the cerebrospinal fluid could be afforded than the question of the origin of its cells. The two extremes are represented by Pappenheim, holding that all the cells come from the blood, and Szecsi, who maintains that they are almost all derived from the tissues.

As so commonly occurs in the history of science, it is probable that the truth lies midway between these extremes. It is obvious that certain cells must be hæmatogenous in origin. In a case of acute purulent meningitis the fuid is practically converted into pus. The enormous numbers of polymorphonuclear leucocytes which it contains can certainly originate from nowhere but the blood. In response to an acute irritant 
the vessels show the usual phenomena of inflammation, and emigration of leucocytes takes place just as in the case of acute inflammation elsewhere.

The same is true for eosinophil leucocytes. Cases have been described of cysticercus cellulosæ infection of the central nervous system in which there was a marked eosinophilia both in the blood and in the cerebrospinal fluid. Whatever be the true relation between infection by animal parasites and the appearance of an increased number of eosinophils, there is no reason to suppose that the eosinophils in the spinal fluid have been derived from any other source than the blood.

On the other hand it by no means follows that because certain of the cells undoubtedly originate from the blood, all the cells must have a similar origin. In order to recognize the importance of a histogenous source it is only necessary to examine sections of brain from such diseases as general paresis and sleeping sickness. In both of these conditions the perivascular space in the affected areas is crowded with cells, mainly lymphocytes and plasma cells. These have arisen from the fixed cells of the tissue in response to the action of a chronic irritant. They stand in intimate relation to the perivascular prolongations of the subarachnoid space. These tissue-derived cells have, therefore, the readiest access to the cerebrospinal fluid, and in conditions in which they undergo a pathological increase in number it would indeed be surprising if they did not make their appearance in the fluid. The endothelial cells are, I believe, derived from the endothelial lining of the perivascular lymphatics. The fibroblasts, again, are cells which can have but one origin, namely from the tissues.

In discussing this question, however, there is one point which must not be overlooked. Cells passing from the blood into the cerebrospinal fluid find themselves in a very different environment, and considerable changes of an adaptive or degenerative nature may occur in their morphology, so that they may lose all resemblance to their former selves. This is a point deserving of further investigation. 


\section{REFERENCES}

Alzheimer: Einige Methoden zur Finierung der zelligen Elemente der Zerebrospinalfiüssigkeit. Zentralbl. f. Nervenh. n. Psych. I907, N. 239.

Cotton H. A. and Ayer J. B.: The cytological examination of the cerebrospinal fluid. Jour. Nerv. and Ment. Dis. 1918, XXXV, p. 399 .

Fuchs and Rosenthal: Physikalische, chemische, zytologische und anderweitige Untersuchungen der Zerebrospinalflüssigkeit. Wein. med. Presse., 1904, N. 44-47.

Henderson D. K. and Muirhead Winifred: The differentiation of cells in the cerebrospinal fluid by the Alzheimer method: Rev. Neurol. and Psych. I9I3, XI, p. 195.

Hough W. H.: The cytological examination of the cerebrospinal fluid. Bull. No. I. Goven. Hosp. Washington, 1909.

Szecsi S.: Beitrage zu der zytologischen Untersuchung der Lumbalfüssigkeit, Monatschr. f. Psychiat. u. Neurol. 19I I, XXIX, p. 76.

Waterhouse R.: Cysticercus cellulosae in the central nervous system. Quart. Med. Jour., 19r3, VI, p. 469. 


\section{CHAPTER XI}

\section{WASSERMANN REACTION}

The theory on which the Wassermann reaction was originally based, namely, the Bordet-Gengou phenomenon, is comparatively simple. When an antigen, such as a microörganism or red blood cell, is brought into contact with its corresponding antibody in the presence of complement, union between these three substances takes place, and the complement is no longer free to enter into another combination.

Five substances are used in the test:- Complement and two sets of antigen and antibody. The antibody is commonly referred to as amboceptor. The first antigen-amboceptor complex may be called the reacting set, for to it the complement is added with the object of testing whether union of the three will occur. Should any of the three be absent no reaction will take place, and the complement will be free to enter into another combination. Of these three bodies in the test tube only one is unknown. The syphilitic antigen and the complement are supplied in every case, but the patient's serum may or may not contain the syphilitic amboceptor. If it does, union will occur, and complement will be bound. If it does not, complement will remain free.

In either case, however, no outward or visible sign will have occurred in the clear fluid in the test tube. An indicator must therefore be added. The second antigen-amboceptor set may be called the indicator set, for by means of it we may readily determine whether complement has been bound or still remains free in the tube.

The indicator antigen consists of the red blood cells of a sheep. The indicator amboceptor is the blood serum of a rabbit, which has been sensitized against the sheep's red cells 
by repeated injection. As long as there is no complement in the indicator set, no hæmolysis will occur, but when complement is added in correct proportion union and hremolysis will readily take place. In the indicator we have, then, a ready means of determining the presence or absence of free complement, and thus the presence or absence of the syphilitic amboceptor in the patient's serum.

In short, the complement is first given the opportunity of combining with the reacting set. It is then offered the indicator. The result of this second offer is shown by the presence or absence of hamolysis.

It is now known that the reaction is not a specific one for the spirochreta pallida, but is rather an indication that the serum examined possesses the property of entering into a firm combination with complement in the presence of certain substances of a lipoid nature, which may be used as an antigen. Although, however, the theoretical foundation has been cut away so that the reaction now hangs, as has been said, like Mahomet's coffin in the air, it has not on that account lost one iota of its practical value.

Many modifications have been introduced from time to time. mostly with the object of simplifying the technic. Simplicity, however, may be bought too dearly, when the price to be paid is loss of reliability. The Wassermann reaction is at present essentially a laboratory procedure, and there is as yet no indication that it is on the high road to become a method for the bedside or even for the office.

The only two valuable modifications of the original method are the substitution of an antigen of human heart reënforced with cholesterin for the original syphilitic liver, and the use of larger quantities of cerebrospinal fluid. McIntosh and Fildes in an exhaustive investigation of the subject in I9I3 showed that both for neurological and general work the cholesterinised heart antigen was superior to every other, and subsequent work has confirmed this estimate. This antigen consists of a mixture of 3 parts of alcoholic heart extract with 2 parts of a I per cent. alcoholic solution of cholesterin. 
The Wassermann test may be applied to the spinal fluid as readily as to the blood serum, but certain differences in the two cases must be taken into consideration. The spinal fluid is tested for the presence of syphilitic amboceptor. If such is present it is a proof that syphilitic infection of the central nervous system has occurred. Systemic syphilis not involving the nervous system produces no change in the spinal fluid.

When blood serum is used it is inactivated by heat, partly to destroy its complement, partly to remove non-specific substances, which sometimes give a false inhibition. Plaut in his Handbook says that the spinal fluid must also be heated. McIntosh and Fildes came to the conclusion from their work on the subject that the process of inactivation had little if any effect on the specific reacting substance, whether occurring in the blood or the fluid. In general paresis and tabes dorsalis the specific substance is the only one present, and the question of inactivation is not therefore of great importance. In active cases of cerebrospinal syphilis, however, other substances appear in the fluid which tend to make the reaction stronger. These substances are thermolabile, and therefore disappear on inactivation. It is true that the action obtained owing to the presence of these thermolabile bodies is in a sense nonspecific, but in practice this non-specificity may be disregarded. That is to say, an unheated fluid from a non-syphilitic case will never give a positive Wassermann reaction, and from the practical point of view that is all the specificity that can be desired. It is evident, therefore, that the test should always be performed on unheated fluid, and it is probable that if this precaution had been observed there would not have been the large number of negative results obtained by the earlier workers in cases of cerebrospinal syphilis.

The amount of spinal fluid to be used is a subject regarding which considerable discussion has taken place. McIntosh and Fildes recommend that only twice as much fluid as serum should be used. The largest amount of fluid which they use is 0.2 c.c. In I9II, however, Hauptmann introduced his "Auswertungsmethode," in which increasing quantities up to 
I.o c.c. of fluid are used. Although this practice has been severely condemned in some quarters, there can be no question that it represents a great advance in the application of the Wassermann test to the spinal fluid. For by means of it it is now possible to obtain positive results in the great majority of cases of cerebrospinal syphilis and tabes dorsalis, and all the work which has been done up to the present goes to prove that with careful technic, including titration of complement and amboceptor, there will be no non-specific results.

In my own work I employ five times as much spinal fluid as blood serum. It is very important, however, always to set up a control to which no antigen has been added, so that any nonspecific inhibitory action of the large amount of fluid may be readily detected. The method has its greatest use in the estimation of the effect of treatment. At the commencement of treatment the reaction may be positive with 0.05 c.c. then with O.I c.c. and finally there may be a negative result with I.O c.c. In such a case the physician feels that he really has produced some improvement in his patient. In many cases of neurosyphilis it will be found that no reaction is obtained with o.I c.c. or 0.2 c.c., but a well marked reaction with r.o c.c. In studying statistics of results it is very necessary, therefore, to know what quantity of fluid has been used. The large quantities are not of value in differentiating between different varieties of neurosyphilis, as between cerebrospinal syphilis and paresis. For such a purpose, only 0.1 or 0.2 c.c. should be employed. In every case, then, r.o c.c. of fluid should be used, but also decreasing quantities down to 0.05 or 0.25 c.c. Only in this way can a true and just estimate of the condition of the fluid be obtained.

\section{THE RESULTS OF THE REACTION}

Although the theoretical basis for the specificity of the reaction can no longer be maintained, each year sees the practical value of the test more thoroughly established. In the case of the serum there are certain conditions in which there may be ambiguity. The only conditions, however, in 
which a positive reaction has ever been found in a nonsyphilitic spinal fluid are leprosy and sleeping sickness, neither of which need be considered from the standpoint of ordinary practice.

The results of the test in the various forms of neurosyphilis will be discussed in a later chapter. A few general conclusions may, however, be stated. The reaction is extremely constant and very intense in the blood and spinal fluid in paresis. No other condition gives so strong a reaction in the fluid. It is positive in at least 96 per cent. of cases. Very rarely there may be a positive reaction in the fluid, but not in the blood, or vice versa. Tabes gives a lower proportion of positive results. With 0.2 c.c. of fluid not more than 60 per cent. will be found positive, although a few workers, such as McIntosh and Fildes, report higher figures. When r.o c.c. of fluid is used the results will nearly approach those of paresis, especially when both the blood and the spinal fluid are taken into consideration. For in tabes it is not at all uncommon to find that the blood alone or the fluid alone gives a positive reaction. In a suspected case, therefore, a negative result in the blood should always be followed by an examination of the spinal fluid. Cerebrospinal syphilis generally gives a positive reaction in the blood, but often a negative one in the fluid. Here again, however, the reaction will be more constant if the larger amounts of fluid are used. With 0.2 c.c. only about 30 per cent. of the cases are positive. Finally, cases of syphilis which show no evidence of involvement of the central nervous system may give a positive reaction in the spinal fluid if 1.0 or even 2.0 c.c. be used. In such cases the smaller quantities will always give a negative result. Although in these cases there is no clinical evidence of a syphilitic infection of the nervous system, pathological evidence is supplied by the presence of cellular and protein changes in the spinal fluid, and the characteristic histological lesions will be found at autopsy. 
78 PHYSIOLOGY AND PATHOLOGY OF THE CEREBROSPINAL FLUID

\section{REFERENCES}

Hauptmann A.: Die Vorteile der Verwendung grosserer Liquormengen ("Auswertungsmethode") bei der Wassermannschen Reaktion für die neurologische Diagnostik. Deutsche. Ztschr. f. Nervenh. I9I I, XLII, p. 240.

McIntosh J. and Fildes P.: The Wassermann reaction in its application to neurology. Brain, 1913, XXXVI, p. 193. 


\section{THE COLLOIDAL GOLD REACTION OF LANGE}

The colloidal gold reaction was primarily intended to show variations in the protein content of the cerebrospinal fluid, but it is considered apart from the other reactions for protein, partly because of the peculiar nature of the reaction, the exact mechanism of which is still undetermined, and partly because of the very special nature of the technic.

The reaction arose out of the researches of Zsigmondy, who in I90 discovered that solutions of proteins protect colloidal solutions of gold and other metals from being precipitated by electrolytes, the degree of protection being capable of being expressed numerically. Lange in 1912 attempted to apply this method to the cerebrospinal fluid in order to determine the amount of protein present. He found, however, that the protein not only did not protect the colloid, but actually facilitated its precipitation. Using a series of dilutions of spinal fluid containing an increased amount of protein he obtained a maximum reaction sometimes with one dilution, sometimes with another. The cases giving a maximum reaction with one dilution were found to fall into one clinical class, while those which gave a maximum reaction with another dilution fell into another clinical class. The reaction was not dependent on the quantity of protein present.

Thus the reaction is of value for differentiating one pathological condition from another, rather than, as was first cxpected, for making a quantitative determination of the protein.

The technic is one which demands a considerable amount of care, the chief difficulty being the preparation of the col- 
loidal gold solution. This, however, can be overcome if the requisite precautions are taken in handling the glassware and in preparing the distilled water.

Preparation of the Colloidal Gold Solution.- In a liter flask is placed 500 c.c. of fresh doubly distilled water. The flasks, of the best Jena glass, must be thoroughly washed out with strong $\mathrm{H} \mathrm{Cl}$, followed by distilled water, and sterilized by hot air for half an hour. All glassware used should be treated in the same manner. The distilled water must be prepared in a sterile all-glass condenser, and must not be allowed to come in contact with any rubber connections, nor allowed to stand more than a couple of hours. The preparation of the distilled water is the most important part of the technic, and unless the above precautions be taken a satisfactory solution will not be obtained.

The water is heated to $60^{\circ} \mathrm{C}$, and 5 c.c. of a 2 per cent. solution of potassium carbonate are added, followed immediately by 5 c.c. of a i per cent. solution of gold chloride. The solution is now rapidly heated with the aid of several Bunsen burners, and the moment the first bubbles appear the flame is removed, and 5 c.c. of a $I$ per cent. solution of formalin are added, the contents of the flask being rapidly rotated.

The gold is at once reduced to a colloidal state, and the colorless fluid changes to a deep cherry red. The fluid should be absolutely clear and transparent. The appearance of the slightest translucency or fluorescence indicates some fault in the preparation. After the fluid has stood for a few days there should be no bluish deposit on the sides of the flask. Finally the solution should be tested against the spinal fluid of a known general paretic, and ought to give the typical reaction in the "paretic zone," that is to say complete Ausflockung, in the first 4 or 5 tubes.

Technic of the Test.- A series of ro test tubes is set up. In the first tube place 1.8 c.c. of 0.4 per cent. salt solution. It is well to prepare this dilution freshly from a stock ro per cent. solution. In each of the other tubes place I c.c. of the 
salt solution. To the first tube is added 0.2 c.c. of spinal fluid, and thoroughly mixed, a I in ro dilution being thus obtained. Transfer I c.c. of fluid from the first to the second tube, thus getting a dilution of $\mathrm{I}$ in 20 . This procedure is repeated for each tube till a series of ro dilutions is obtained, ranging from $\mathrm{I}$ in $\mathrm{Io}$ to $\mathrm{I}$ in $5 \mathrm{I} 20$. To each tube is now added 5 c.c. of colloidal gold, and mixed with the fluid as rapidly as possible. The test may be read after 5 minutes, but it is better to allow the tubes to stand at room temperature 12. hours.

The result is expressed in figures or in the form of a curve, not merely as positive or negative. The red color may remain unchanged, or there may be complete decolorization due to complete precipitation of the colloidal gold. Between these two extremes there may be varying grades of blue and red to which a numerical value is attached as follows:

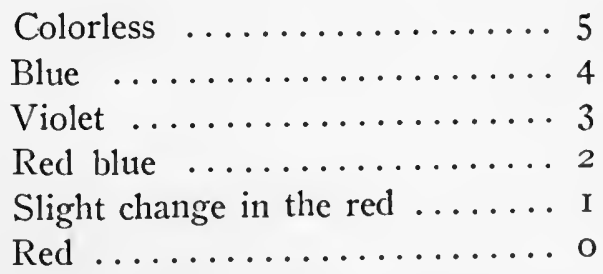

The color change, if any, may be most marked in the lower dilutions, in the middle dilutions, or in the higher dilutions. The position of the maximum change in the series of dilutions is of equal importance with the color change itself, and for this reason the result is best represented by a curve, or it may be expressed as a series of ro numbers in which the degree of change is represented by the numbers $o$ to 5 . Thus if no change occurred in any tube the result would be 0000000000 , whereas if complete reduction occurred in the first 3 tubes but no change in the remaining ones it would be 5550000000 .

If expressed graphically the following curves would be obtained: 


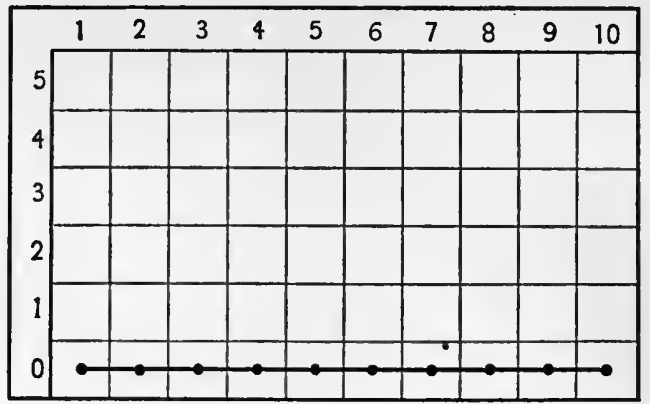

I. Colloidal gold curve. No reduction.

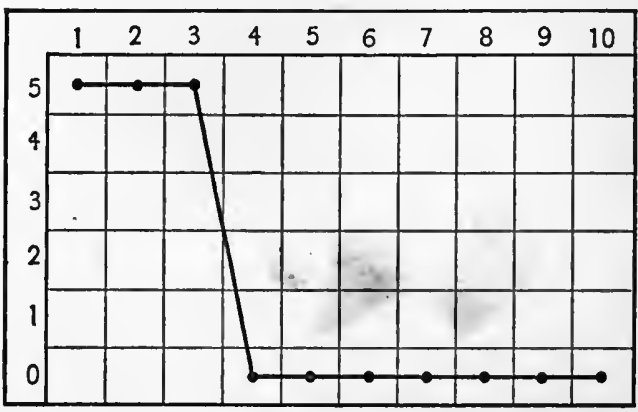

2. Colloidal gold curve. Reduction in first three tubes.

Two reactions occurring with sufficient frequency to merit the term characteristic have so far been found, the meningitic zone reaction and the paretic zone reaction.

In a typical meningitic reaction no change occurs with the low dilutions, but in the higher dilutions there may be marked precipitation. This phenomenon has been termed by Lange "Verschiebung nach oben," and is illustrated by the following curve :-

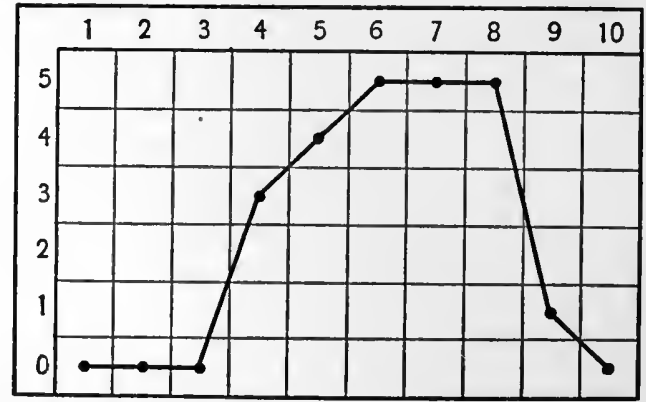

3. Colloidal gold curve. Acute meningitis. 
The paretic curve occurring in general paresis is the most important and characteristic of the reactions. There is complete precipitation in the paretic zone, namely the first 3,4 or 5 tubes, followed by an abrupt drop to zero. The following is a typical example:-

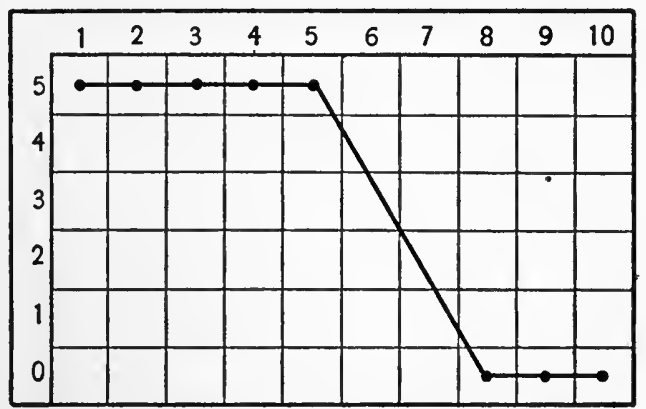

4. Colloidal gold curve. General paresis.

In tabes dorsalis and cerebrospinal syphilis if a reaction occurs at all it does so in the mid-zone, is moderate in degree, and is readily distinguished from that of general paresis. It may be that further work will make modification of these statements necessary, but at present there is every reason to believe that the colloidal gold test is a valuable means for differentiating general paresis from other syphilitic affections of the nervous system. In these other conditions the curve in the mid-zone has been considered sufficiently characteristic to earn the title "luctic curve." Grulee and Moody found a similar result in a series of cases of congenital syphilis.

It may thus be said that, speaking generally, a marked reaction in the first zone is extremely characteristic of general paresis; one in the mid-zone suggests nervous syphilis, and one in the end zone acute meningitis. Of these the least reliable are the mid-zone results.

The curve in general paresis corresponds closely with the positive Wassermann reaction in that condition, but that the two reactions are not dependent on the same substance has been demonstrated by Weston. 


\section{THE MASTIC TEST}

The colloidal gold test, although exquisitely sensitive, is undoubtedly a difficult one to carry out in practice. The gold chloride solution may be prepared five times, using exactly the same technic on each occasion with eminently satisfactory results, and yet the sixth attempt, carried out in precisely the same way, may result in complete failure.

On account of this difficulty several attempts have been made to employ other colloids which would be simpler to prepare. Of these the emulsion of mastic introduced by Emanuel for the purpose has proved the most succesful. At first the emulsion was too sensitive, for precipitation took place when it was mixed with salt solution, apart from the presence of a pathological spinal fluid. Cutting has suggested the addition of a very dilute solution of potassium carbonate to the saline, and certainly this prevents any precipitation of mastic except in the presence of a pathological spinal fluid. The test is still in its infancy, but controls made with the colloidal gold method lead us to believe that in the mastic test we have a simple and valuable method for estimating the effect of pathological spinal fluids upon colloidal solutions.

The test is conveniently performed as follows: A stock solution of Io gm. of gum mastic in IOO c.c. of absolute alcohol is made up, and may be kept indefinitely. Of this stock solution 2 c.c. is diluted with 8 c.c. of absolute alcohol and mixed rapidly with So c.c. of distilled water. To 99 c.c. of a 1.25 per cent. solution of sodium chloride in distilled water is added I c.c. of a 0.5 per cent. solution of potassium carbonate in distilled water.

In a series of 6 small test tubes place the combined salt and carbonate solution, I.5 c.c. in the first tube, and I c.c. in the other tubes. To the first tube is added 0.5 c.c. of cerebrospinal fluid, and then I c.c. is transferred from each tube to the next in the series in the usual way, the last cubic centimeter being thrown away. To each tube I c.c. of the prepared mastic 



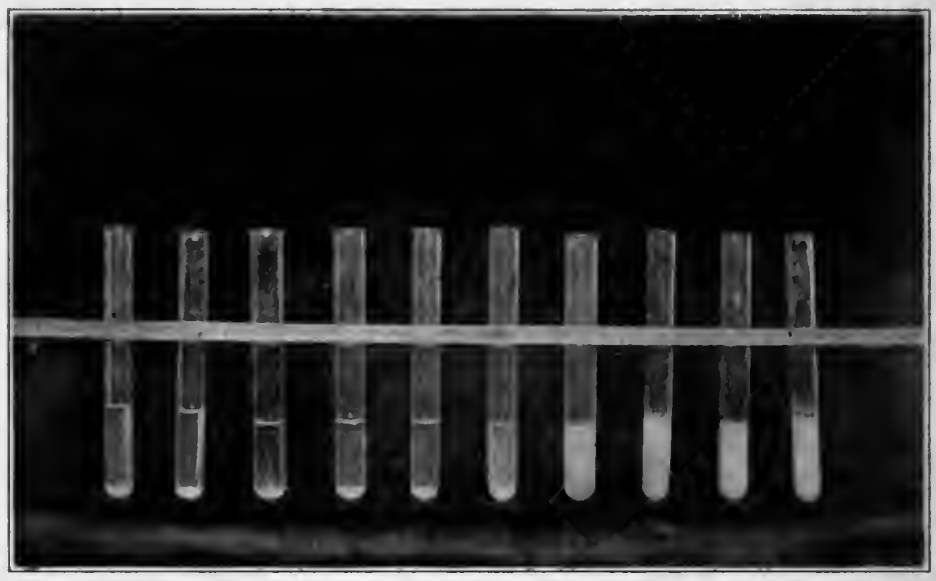

Fic. 5. Mastic test in General Paresis, showing precip.tation in first live tubics 
solution is added and well stirred, the tubes are incubated, and read next morning. (Fig. 5.)

In positive cases a complete precipitation of the mastic occurs in a given number of tubes, and the results are read in the same way as in the colloidal gold test. When precipitation is complete the fluid becomes perfectly clear, and there is a heavy white deposit at the bottom of the tube.

\section{REFERENCES}

Cutting, J. A.: A new mastic test for the spinal fluid. Jour. Am. Med. Assoc., 1917, LXVIII, p. I810.

Emanuel, G.: Eine neue Reaktion zur Untersuchung des Liquor cerebrospinalis. Berl. klin. Wchnschr., I9I5, LII, p. 78I.

Grulee, C. G. and Moody, A. M.: The Lange gold chloride reaction on the cerebrospinal fluid of infants and young children. Am. Jour. Dis. Child., 19! 5, IX, p. I7.

Lange, C.: Die Ausflockung Kolloidalen Goldes durch Cerebrospinalflüssigkeit bei syphilitischen Affectionen des Centralnervensystems. Ztschr. f. Chemotherapie, I912, No. I.

Miller, S. R. and Levy, R. L.: The colloidal gold reaction in the cerebrospinal fluid. Bull. Johns Hopkins Hosp., I9I4, XXV, p. I33.

Weston, Paul G.: The colloidal gold precipitating substance in the cerebrospinal fluid in paresis. Jour. Med. Res., I9I6, XXXIV, p. 107.

Zsigmondy: Ztschr. f. anal. Chem., I90I, XL, p. 697. 


\section{CHAPTER XIII}

\section{BACTERIOLOGICAL METHODS}

It is by no means necessary to make a bacteriological examination of every spinal fluid withdrawn. Where, however, it is intended to make such an examination - in cases where an acute bacterial infection of the meninges is suspectedspecial precautions must be observed in withdrawing the fluid. The needle and skin must, of course, be very thoroughly sterilized. The fluid should be collected in at least two sterile tubes.

Special care should be exercised to prevent contamination of the fluid at the point where it issues from the needle. It is best if possible to have a special needle carrying a stout stilette with an expanded extremity which is grasped by the hand when the puncture is being made, and is subsequently withdrawn. By this means the fingers do not come in contact with the point at which the fluid issues. Even more convenient is the form of needle in which there is a solid handle from which the continuation of the hollow part branches off in a gentle curve. If neither of these forms are available, the needle may be held in a piece of sterile gauze, and the first few drops of fluid allowed to escape before the collection is begun.

The fluid in one tube is centrifuged, and films made from the centrifuged deposit. If the fluid is at all purulent centrifuging will not be necessary. The films are stained with methylene blue and examined for microörganisms. In tuberculous meningitis a delicate skein usually forms which hangs down from the surface of the fluid provided that the latter is not agitated. The best method of detecting the tubercle bacillus is to spread this skein out on a slide and stain it by the Ziehl-Neelson method. 
In streptococcal and pneumococcal meningitis the infecting organism will usually be found in the direct smears. In meningococcal cases, however, none may be detected even after prolonged search, but if the fluid be placed in the incubator over night considerable numbers of meningococci may make their appearance. This device will also be found to give a larger number of positive cultures from fluids in which the organisms are present in very small numbers.

The second specimen of fluid is to be used for cultural purposes. Cultures may be made on blood serum or ordinary agar, but the best all-round medium is undoubtedly blood agar, recommended by Schottmüller, on which any of the organisms of meningitis will grow readily and in characteristic fashion. The tubes or plates should be incubated for at least 48 hours before a negative result is reported. Blood agar will be found especially useful when dealing with such a condition as influenzal meningitis. In doubtful cases of tuberculous meningitis in which no bacilli can be detected in the smears a guinea pig should be inoculated with the centrifuged deposit. The time required for signs of tuberculosis to manifest themselves in the animal may be shortened by first exposing it to the X-rays.

\section{REFERENCE}

Plaut, Rehm, and Schottmüller: Leitfaden zur Untersuchung der Cerebrospinalflussigkeit, I9r3, Fischer, Jena. 

PART II

SPECIAL 



\section{CHAPTER XIV}

\section{MENINGITIS}

The subarachnoid space is so thoroughly shut off from the general circulation, and so efficiently guarded from injurious agents which may be circulating in the blood, that hæmatogenous infection of the meninges is comparatively uncommon. In the immediate vicinity, however, are such cavities as the naso-pharynx, the sinuses of the nose and skull, and the middle ear, cavities either septic in themselves, or very liable to become so. Infection may spread from these areas to the meninges, all the more readily because of the various nerves passing from the inside to the outside of the cranial cavity, nerves which are accompanied by lymphatic vessels which form a natural route for an ascending infection.

The examination of the cerebrospinal fluid has thrown light upon many obscure conditions in clinical medicine, but it is in acute meningitis that it has proved of the greatest value, both as regards diagnosis and treatment. For no diagnosis of meningitis can be accepted nowadays unless the cerebrospinal fluid has been examined, and many an obscure case has only been shown to be really one of meningitis when a lumbar puncture has been done.

Almost every known pathogenic microörganism has been described as occurring in meningitis, but only four are found with any degree of frequency. These are the meningococcus, the pneumococcus, and the tubercle bacillus.

Although the vast majority of cases of meningitis are organismal in origin, it must be remembered that acute inflammation of the meninges may be due to a non-bacterial irritant. Thus Purves Stewart produced an inflammatory reaction accompanied by characteristic polynuclear leucocytosis in the 
fluid by the simple injection of sterile salt solution or a sterile emulsion of colored particles into the subarachnoid space. This is a fact of considerable importance in these days when all sorts and conditions of substances are being injected into the spinal canal. That the irritative effects of such injections may be by no means negligible is shown by the observations of Ingleton on the results produced by the intrathecal injection of antitetanic serum. The spinal fluid was examined before injection of the serum and again 2 hours later. In every case a well marked cellular reaction was observed, the cells averaging 400 per c.mm. with over 95 per cent. of polymorphs. In one case as many as I600 cells were present. The fluid was always found to be sterile. All cases coming to autopsy showed a definite aseptic meningitis of varying degrees of intensity.

\section{MENINGOCOCCAL MENINGITIS}

The diplococcus intracellularis meningitidis of Weichselbaum is the most common invader of the subarachnoid space. In appearance it closely resembles the gonococcus, but can be distinguished from that organism by its cultural characteristics and by agglutination and complement fixation tests. It occurs in pairs, the opposing surfaces usually being somewhat flattened. Occasionally it is seen in the form of tetrads. It is negative to Gram's stain.

In the spinal fluid the organism is mainly intracellular, being found within the polymorphonuclear leucocytes, but it also occurs free in the fluid. The mere fact that the cocci have been ingested by leucocytes does not prove that the organisms are being digested and are no longer viable, for it has been shown that living germs may be recovered from such leucocytes. It has been suggested that leucocytes may in this way act as carriers of infection from the nose to the central nervous system. The numbers vary greatly. The lencocytes may be crowded with cocci, presenting the appearance seen in a film of gonorrhœal pus. On the other hand a prolonged search may be necessary before a single pair can 


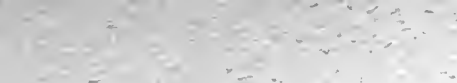




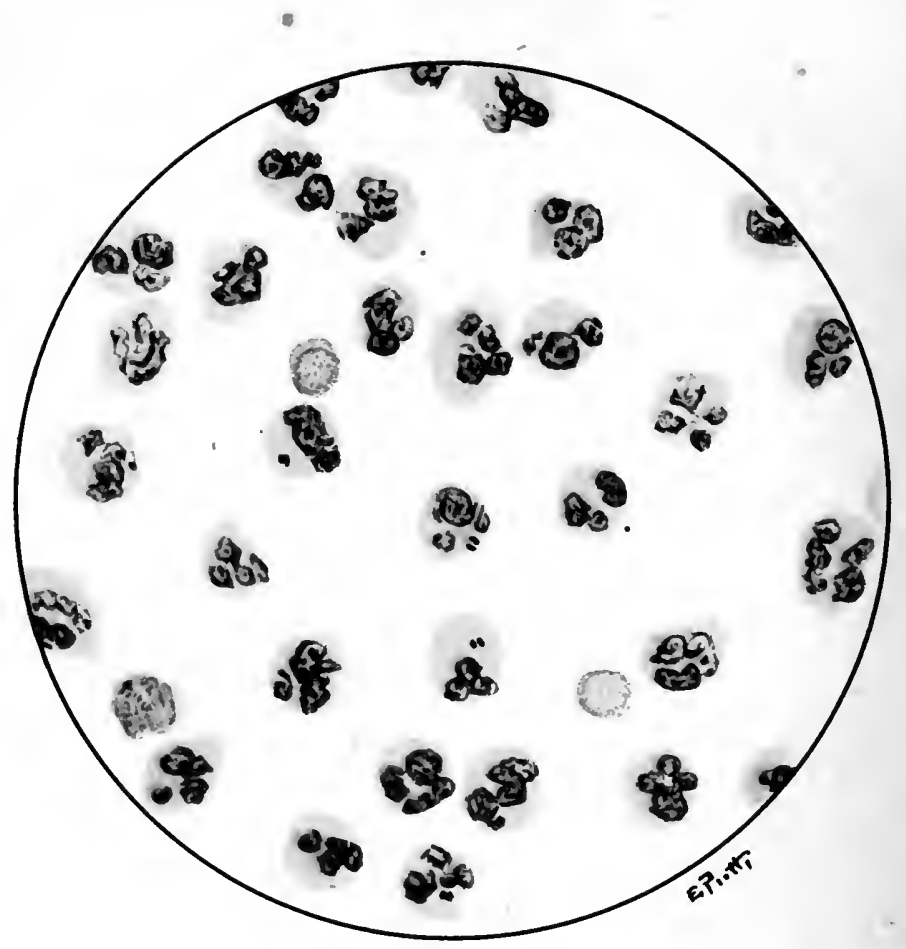

Meningococcal Meningitis. 
be discovered. A case of meningitis with purulent fluid in which no organisms can be found is probably one of meningococcal infection.

Although by no means a universal rule it will generally be found that the number of organisms bears some relation to the severity of the infection. In mild cases and in the chronic post-basic type the numbers may be extremely small. As improvement sets in the meningococci diminish in numbers, becoming more and more intracellular, and finally disappearing altogether. It must be remembered, however, that the findings in the fluid withdrawn by lumbar puncture may not always afford a true indication of the pathological changes present. Carnegie Dickson has reported cases in which the organisms gradually disappeared from the spinal fluid, without any corresponding improvement on the part of the patient. The explanation was afforded by post-mortem examination, where it was found that the communication between the ventricles and the subarachnoid space had been cut off. The fluid in the ventricles was extremely purulent, and contained meningococci in such numbers as to suggest the appearance of a culture of the organism.

On the other hand the presence of meningococci in the cerebrospinal fluid is not an incontestable proof that a condition of meningitis is present. For meningococcal meningitis is merely one aspect of the more general condition cerebrospinal fever, and the septicæmia may be so acute that the patient dies before meningitic changes have had time to occur. As Horder points out, "it is the cytology and the chemistry of the fluid, rather than its bacterial content, which determine the question whether or no meningitis is present."

Every effort to demonstrate the meningococcus in smears from the fluid should always be made, for in no condition is successful treatment so dependent on early diagnosis. When these efforts are unsuccessfu1, however, cultures are to be made on suitable media. Such media should contain some animal protein, since primary cultures do not readily grow on the ordinary laboratory media. One of the most suitable media 
for general work is blood agar, as recommended by Schottmüller. Nasgar (nutrose ascitic agar) has been extensively used by English workers.

The organism grows best at $37^{\circ} \mathrm{C}$., and growth fails to take place at a temperature below $25^{\circ} \mathrm{C}$. One of the readiest methods of distinguishing the meningococcus from the other Gram-negative organisms which occur in conjunction with it in the naso-pharynx is to keep the cultures at room temperature. Any Gram-negative cocci which grow are certainly not the meningococcus.

Although the meningococcus is accepted by most authorities as the sole and sufficient cause of cerebrospinal meningitis, the results of some recent workers are such that it is still necessary to keep an open mind on the subject. Hort in particular has recently published a series of papers in which he expresses the opinion that the disease is caused by a pleomorphic organism of which the meningococcus is merely one phase, and that not the infectious phase. The matter is still too indeterminate, however, to justify further discussion here.

It is at least certain that different strains of meningococci exist. Agglutination tests with antisera have definitely separated the para-meningococcus of Dopter from the meningococcus, and there is already sufficient evidence to indicate that the meningococcus itself can be divided into 3 or 4 types, just as has been done in the case of the pneumococcus.

Character of the Cerebrospinal Fluid.- The appearance of the fluid varies with the intensity of the infection, the stage at which lumbar puncture is done, and with other factors of which we have as yet imperfect knowledge.

The pressure is almost invariably raised, but sometimes not to any great extent. As high a figure as $650 \mathrm{~mm}$. of water has been recorded. In the chronic stage communication with the ventricle may become blocked, with a resulting low pressure of fluid.

The fluid may be opalescent, cloudy, or turbid. In the earliest stages, however, it may be quite clear. Amongst British 
soldiers in France I have on more than one occasion found the fluid clear one day, but quite turbid on the next. This lack of turbidity in the early stages must not, therefore, be allowed to lead one astray. As convalescence sets in the fluid gradually clears up.

Carnegie Dickson has pointed out one source of error which it is well to bear in mind. In a number of non-meningococcal cases (tuberculous and syphilitic meningitis) anti-meningococcal serum had been administered before the case was sent to the hospital. Lumbar puncture subsequent to admission revealed a fluid identical with that of meningococcal meningitis as regards turbidity of the fluid, overwhelming preponderance of polymorphs, etc. When the specimen of fluid withdrawn before admission was obtained an entirely different picture was presented. This "serum reaction" is similar to that already described as following the use of anti-tetanic serum.

The protein content of the fluid is invariably high. Globulin is greatly increased and albumen may be present in considerable amount. The protein usually exceeds 0.3 per cent. and may reach as high as 0.8 per cent.

The sugar is always diminished, and may be altogether absent. The disappearance of the sugar is mainly due to the fermentation action of the meningococcus upon glucose. I have examined the fluid from cases of cerebrospinal meningitis in which there were very few meningococci, and which gave a good reduction of Fehling's solution. By incubating the fluid over night the number of organisms was enormously increased, and there was a coincident disappearance of glucose from the fluid. Many authors minimize the importance of examining for sugar in meningitis. Personally I regard it as a useful bedside method which can be carried out by the physician at the time of the puncture. With a purulent fluid it is of course unnecessary, but in the case of a comparatively clear fluid it may well serve to help to differentiate an acute meningitis from other conditions simulating it. The behavior of the sugar may furnish valuable information re- 
garding the progress of the case. The sugar reappears about the fourth or fifth day in favorable cases, but disappears again if a relapse supervenes. It is sometimes difficult to distinguish between a true relapse and a reaction due to the use of antimeningococcal serum. In such cases sugar estimation is of great value, for in the serum reaction it will show no alteration.

The most striking feature of the cerebrospinal fluid in all forms of acute meningitis is the cytological change which is invariably found. The type of cell depends on a number of factors, such as the nature of the irritant, the intensity of the infection, and the stage of the disease. In cerebrospinal meningitis the polymorphonuclear leucocyte is the preponderating cell in the great majority of cases when first seen. From the few observations on record, however, it appears probable that the earliest cell to appear is the lymphocyte, but by the time that the ordinary case is seen by the physician the fluid is flooded with polymorphs, which may constitute go per cent. or more of the total cell count.

In a case in which lumbar puncture is performed every day for therapeutic purposes it is very instructive to watch the gradual change which comes over the cytological picture. In a case which is going to recover the polymorphs gradually diminish in number, their place being taken by large mononuclear phagocytic cells. The polymorphs lose their staining power and become disintegrated, and in the late stages of convalescence the large mononuclears also stain faintly, their place being taken by small lymphocytes. It is said that in post-basic meningitis the chief type of cell is the small lymphocyte.

In cases where no organism can be found the precipitoreaction of Vincent and Bellot may be tried. This is an indication not, probably, of antibodies but of autolysate of the meningococcus, produced by the disintegration of the bodies of the organisms. To a small quantity of antimeningococcal serum is added from so to 20 times the amount of cerebrospinal fluid, which has first been thoroughly centrifuged. The 



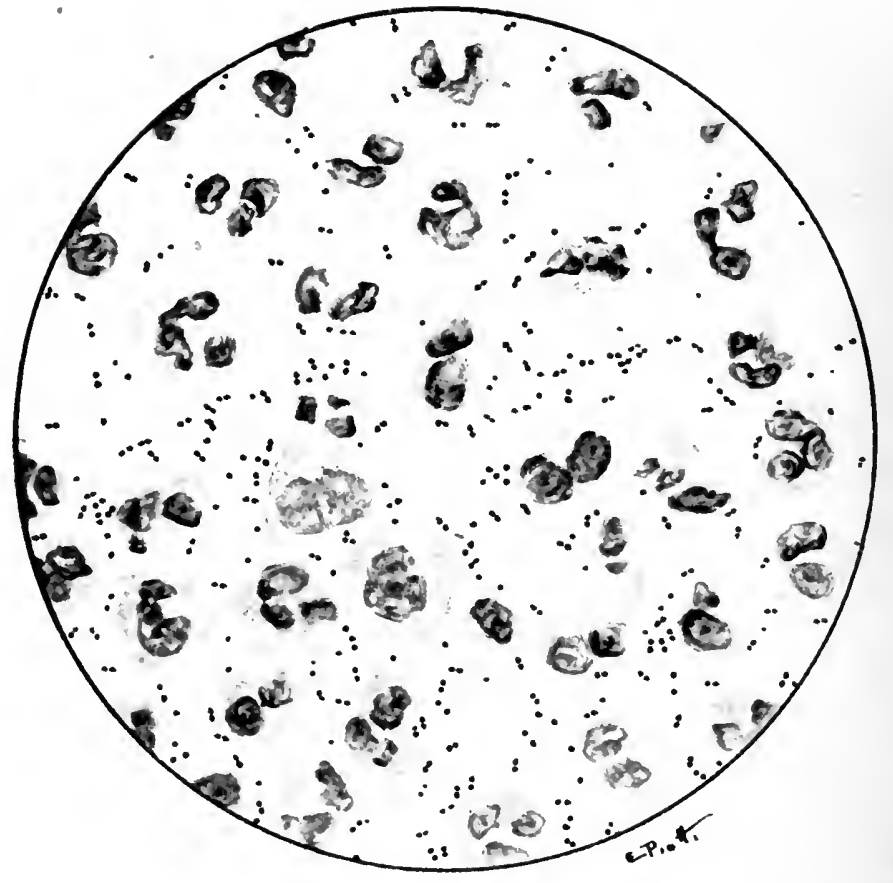

Pneumococcal Meningitis. 
fluid must be perfectly fresh. The tube is stoppered and placed in the incubator overnight. A turbidity or opalescence indicates a positive reaction. A control consisting of spinal fluid without serum should always be put up.

Another test for fluid in which no organisms can be found, but one of which I have no experience, is that of V. Grysez, quoted by Heiman and Feldstein. A guinea-pig is inoculated intraspinally with 0.5 c.c. of cerebrospinal fluid. A lowering of temperature of from $4^{\circ}$ to $8^{\circ} \mathrm{C}$. occurs in a short time, and death usually takes place in from 2 to 24 hours if the case is one of meningococcal meningitis.

\section{PNEUMOCOCCAL MENINGITIS}

Of the ordinary pyogenic organisms the pneumococcus is the commonest invader of the cerebral meninges, and pneumococcal meningitis ranks third, after the meningococcal and tuberculous forms, in order of frequency.

The infection may be primary or secondary. In the primary form no other focus of infection can be found, but the meninges, especially over the vertex, are the seat of a widespread, yellowish-green, purulent exudate in which large numbers of pneumococci are present. The disease in the suddenness of its onset and in the extreme gravity of its nature bears a resemblance to pneumococcal peritonitis. The symptoms often develop with lightning rapidity, and the changes in the cerebrospinal fluid are equally sudden, the whole character of the fluid sometimes undergoing a complete transformation in 24 hours.

In the secondary cases the primary focus may be found in a purulent otitis media, or in such a pulmonary condition as a localized empyema. The onset as a rule is not so acute, but the termination is the same as in the primary form.

Opinion varies as to the frequency of meningitis as a complication of pneumonia. West found no case in a series of 200, but Osler records 8 per cent. of cases at Montreal. Invasion of the subarachnoid space by the pneumococcus is, however, very much more frequent than the statistics regarding 
meningitis would lead one to believe. Rohdenburg and Vander Veer have established the fact that in a large number of fatal cases of pneumonia lumbar puncture will reveal the presence of pneumococci, although no meningitis may be present. In a series of cases examined irrespective of meningeal symptoms they found that in the cases which ultimately proved fatal pneumococci were obtained in culture in 87 per cent., whereas in cases which recovered only 34 per cent. were positive. The positive cases all gave a positive globulin reaction and an increased cell count. In only one case was the fluid purulent, and this was the only case with meningeal symptoms.

In pneumococcal meningitis the fluid varies to an even greatcr extent than in the meningococcal form. The pressure is raised, the quantity of fluid increased, the protein content greatly in excess, and the fluid may be highly purulent. On the other hand it may be so clear as to cause grave doubts as to whether a meningitis is present. I have withdrawn a fluid which to the naked eye was perfectly normal, but when a film was prepared from the uncentrifuged fluid it was found to contain large numbers of pneumococci. The case died a few days later of typical pneumococcal meningitis.

Films are to be made from the fluid, and stained with methylene blue and with Gram's stain. The predominant cell is the polymorph, which is usually present in large numbers. Occasionally, especially in the early stages, lymphocytes may be numerous. Cultures should be made on blood agar, but the most characteristic morphological appearances are to be observed in the organisms in the smears.

The spinal fluid often contains an increased amount of fibrin. In one case at the Winnipeg General Hospital the fluid, which was intensely blood stained, clotted into a solid jelly-like mass within to minutes of withdrawal. The clot was a scro-fibrinous one in which red corpuscles were entangled, and the phenomenon was certainly not due to the coagulation of blood already present in the fluid. Smears showed large numbers of capsulated diplococci, which on culture proved to be pneumococci. 



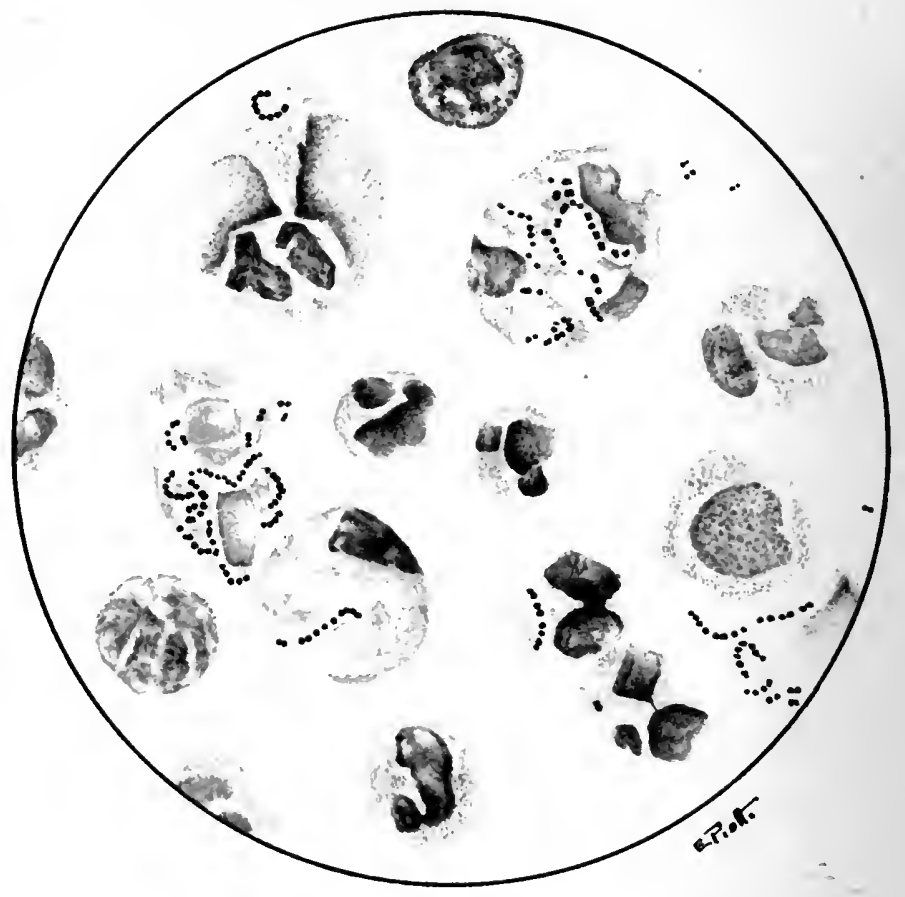

Streptococcal Meningitis. 


\section{STREPTOCOCCAL MENINGITIS}

Primary meningeal infection with the streptococcus is a rare occurrence. Secondary spread of an inflammatory process from the middle ear or from the sinuses of the skull is, on the other hand, comparatively frequent.

The pathologic findings in streptococcal meningitis are very similar to those in the pneumococcal form. It is rare to encounter a clear fluid. The polynuclear leucocytosis is usually very great. The organisms are present in the form of chains, mainly extracellular but some intracellular, and are readily recognized. If, however, they only occur in diplococcal form, cultural methods must be adopted in order to separate them from the pneumococcus.

Several varieties of streptococcus have been described as occurring in streptococcal meningitis. Of these the streptococcus hæmolyticus is by far the most frequent. It is actively hrmolytic, and on blood agar the colonies are rapidly surrounded by a clear zone where hæmolysis has taken place.

Next in frequency comes the streptococcus viridans. On blood agar it produces a green color, which, however, may be confused with a somewhat similar appearance sometimes scen in the case of pneumococci growing on this medium. Growth in blood serum offers a ready means of differentiation. In the fluid medium the streptococcus viridans grows in long chains of 20 or more elements, whereas the pneumococcal chains are never composed of more than 6 to 8 elements.

The streptococcus mucosus may be found in sporadic cases, generally secondary to purulent conditions of the middle ear. Schottmüller has described a number of such cases, which invariably proved fatal. The organism has also been found in one or two small epidemics in which the mortality was comparatively low - from 40 to 50 per cent. It is readily recognized by the characteristic capsule which surrounds the chains, and by the slimy growth which it produces in culture. On blood agar it forms a greenish color which may simulate that of the streptococcus viridans or the pneumococcus, but 
it may be differentiated from these organisms by growing it at $22^{\circ} \mathrm{C}$., at which temperature no color is produced.

Finally, the streptococcus putridus has been described in one or two cases, secondary to an infection by this organism elsewhere. It can be recognized by the characteristic odor of the cultures.

\section{TUBERCULOUS MENINGITIS}

Apart from epidemics of cerebrospinal meningitis, the organism most frequently responsible for acute inflammation of the meninges is the tubercle bacillus. Tuberculous meningitis is probably in every case secondary to some primary focus elsewhere, although in many cases it is extremely difficult to find such a focus. It may occur as part of a general miliary tuberculosis, or may be the only manifestation of the dissemination of the process. There may be widespread tuberculous infiltration of the meninges with abundant exudate especially at the base of the brain, or a few scattered tubercles along the line of the Sylvian vessels only discernible with the aid of a magnifying lens may be all that is revealed by the autopsy.

In view of these considerations it is natural that the condition of the spinal fluid should vary considerably in different cases. In the great majority of cases the pressure is raised, often very considerably so. It usually lies between 200 and $400 \mathrm{~mm}$; but in some cases may rise as high as 700 or even $800 \mathrm{~mm}$. A normal pressure cannot, however, be regarded as conclusive evidence against tuberculous meningitis. In the later stages occlusion of the foramina in the roof of the fourth ventricle may occur, with the production of a condition of internal hydrocephalus, and a consequent disappearance of the previous high pressure.

The fluid is, as a rule, clear or slightly opalescent. Only in exceptional cases is it distinctly turbid. The combination of a high cerebrospinal pressure together with a clear fluid is strongly suggestive of tuberculous meningitis.

When the fluid is allowed to stand for a short time a net- 
work or skein like a fine cobweb forms, which appears to be suspended from the surface of the fluid, and which waves to and fro as the tube is moved. This appearance is highly characteristic, although not absolutely pathognomonic of this condition. It differs from that seen in purulent meningitis, in which the coagulum is flaky and friable, and tends to adhere to the sides of the tube. It is essential for the formation of this clot that the fluid should be left undisturbed, as any agitation will prevent its appearance.

An increase in the protein content is a very constant feature of the fluid, although it does not reach the high figures found in the other forms of acute meningitis, varying as a rule between 0.1 and 0.3 per cent. In a few cases no increase can be detected. In such a case, however, if the fluid be examined on a subsequent occasion a positive reaction will probably be obtained. This is a test which is readily performed at the bedside, and it is wise to go armed with some I in 20 carbolic or ammonium sulphate solution.

The sugar is as a rule decreased, but not to the same extent as in the other forms of meningitis. In some cases it is present in normal amount.

Mestrezat, who tends to somewhat over-emphasize the importance of a purely chemical examination, maintains that diminution in the chlorides and increased impermeability to nitrates are two of the most characteristic features. He gives the normal chloride content of the fluid as 0.74 per cent., but finds that in tuberculous meningitis it varies from 0.5 to 0.6 per cent., a much greater reduction than is found in the meningococcal or pneumococcal forms. The permeability to nitrates is determined by giving the patient I gram of sodium nitrate for every 30 kilos of body weight, withdrawing the fluid 3 hours later, and estimating the amount of the salt present. In health from 0.8 to $\mathrm{I} . \mathrm{O}$ per cent. is obtained, in cerebrospinal meningitis 3.8 per cent., and in tuberculous meningitis from 4.3 to 8.5 per cent.

In ordinary routine work the cell count, both quantitative and qualitative, is one of the readiest methods of diagnosing 
the condition. No one feature is pathognomonic, but when the result is taken into consideration along with the other laboratory and clinical findings a correct diagnosis can be arrived at in the great majority of cases. The cells are almost always increased in number. This increase is moderate, averaging as a rule from 50 to 200 per c.mm., and never reaching the enormous figures met with in the purulent fluids of the other forms of acute meningitis. In very exceptional cases there may be no cellular increase.

The differential count varies, but the small lymphocyte is usually present in great excess. The centrifuged film often bears a close resemblance to that seen in tabes dorsalis. The same appearance is seen in films made from the pleural fuid in tuberculous pleurisy. Polymorphonuclear leucocytes may be entirely absent or only present in small numbers. Occasionally, however, they may equal or even exceed the lymphocytes in number. In a few such cases it has been found that a secondary infection was present, usually the meningococcus.

In specimens prepared by the Alzheimer method differentiation can be carried further, and cell forms may be observed almost as many and varied as in syphilitic infections of the meninges. Tailed forms and Gitterzellen may be present, and in particular large numbers of macrophages. Plasma cells have also been described.

It will be seen that although any of the above pathological changes may be met with in other conditions, yet when they are considered together and especially in relation to the clinical condition of the patient it will usually be possible to make a correct diagnosis. The only absolutely certain method, however, is the demonstration of the tubercle bacillus. This is by no means always easy, and a very prolonged search may be necessary before a single organism is found. The results of different authors vary from 50 to roo per cent., these variations probably depending on the care in technic and the amount of time spent in searching for the bacilli. Various methods have been suggested, but far the simplest and most satisfactory is to take the delicate cobweb which forms, spread 
it out as thinly as possible upon a slide, and stain with carbol fuchsin. If bacilli be present they will be found in the fibrin net-work.

In the event of failing to find any bacilli the enrichment method of Trembur may be used. The fluid is incubated for from 24 hours to several days, at the end of which time a great multiplication of the organisms may have taken place. The method is not successful, however, in every instance. It is of course essential that every precaution against contamination be adopted, otherwise the incubating fluid will speedily become turbid.

Finally, animal inoculation may be resorted to. The long period which has to relapse before the result of the inoculation can be determined may be greatly reduced by X-raying the guinea-pig previous to inoculation. This interferes so much with the resisting power of the animal, probably owing to the effect of the rays on the lymphoid tissue, that the usual period of 4 to 8 weeks may be reduced to about Io days. The centrifuged deposit of the fluid should be used for the inoculation.

A recent method of examining the cerebrospinal fluid in cases of suspected tuberculous meningitis is that of Kasahara. He only records 5 cases with 3 controls, and in only one of the controls (Hydrocephalus) was the fluid normal, but the results are so striking that I give them here, although I have had no opportunity of confirming them.

The method is dependent on the production of a focal reaction by the injection of tuberculin. The usual amount of cerebrospinal fluid is withdrawn, and from 0.01 to $0.002 \mathrm{mg}$. of Koch's old tuberculin diluted with normal saline to I c.c. is injected into the spinal canal. A second specimen of spinal fluicl is obtained 24 hours later, and the two fluids compared as to cytological and chemical reactions. In each of the five cases of tuberculous meningitis a most remarkable cellular increase was observed. The lymphocytes increased in one case from 50 to 900 , polymorphs appeared in considerable numbers, but the most striking feature was the behavior of the red cells. In every case large numbers of red cells made 
their appearance, in one case the number reaching 3200 per c.mm. The control cases showed no reaction, but, as has been already pointed out, far more extensive observations must be made before definite conclusions can be drawn. Kasahara does not record the clinical effect of the tuberculin injections.

\section{MENINGITIS DUE TO OTHER ORGANISMS}

The vast majority of cases of acute meningitis are due to the meningococcus, the pneumococcus, the streptococcus, and the tubercle bacillus. Occasionally, however, meningitis may be caused by one of a very large number of different organisms. These cases will be briefly considered. When a definite meningitis is present the usual cerebrospinal fluid findings are present, namely turbidity of varying degree, cellular increase especially amongst the polynuclears, marked globulin reaction, and diminution in the Fehling reduction. That is to say, the only distinguishing feature in these different forms is the presence of the infecting organism.

Staphylococcal meningitis is much rarer than might be expected. It may occur in a staphylococcal septicæmia, or may be secondary to infection following injury of the skull. The organisms are present in very small numbers, and can with difficulty be found in smears. If only found in culture contamination from the skin or the tissues of the back must be carefully excluded.

Meningitis may be caused by the typhoid bacillus. In many cases, however, the organism may be present in the fluid without causing a meningitis, just as it may occur in the urine without setting up a cystitis. Further, meningitic symptoms may be produced by bacilli circulating in the blood without a corresponding infection of the cerebrospinal fluid. In these cases lumbar puncture will reveal nothing more than a somewhat increased pressure. Meningitis due to paratyphoid bacilli has also been described.

Infection of the subarachnoid sac by the bacillus coli sometimes occurs. I have observed such a case in a girl of I2, 
who was suffering from blood infection with the same organism. Persistent headache with slight head retraction suggested the possibility of meningitis, but lumbar puncture revealed a clear fluid with no cellular and only a slight globulin increase. In the films were a number of Gram-negative bacilli, which on further investigation proved to be bacillus coli. The fluid was examined on more than half a dozen occasions, and the bacilli were present on each occasion until convalescence set in, when they finally disappeared.

Other organisms which have been described are the influenza bacillus, the bacillus pyocyaneus, the anthrax bacillus, Friedländer's pneumobacillus, the bacillus mallei, actinomyces, and a streptothrix. In general paralysis the spirocheta pallida has been demonstrated by injecting the spinal fluid into the testicle of the rabbit. I have examined Alzheimer preparations from such fluids by the Levaditi method, but have failed to detect any organisms. Trypanosomes are constantly present in sleeping sickness. In several cases of chorea the diplococcus rheumaticus of Poynton and Paine has been found in the spinal fluid. An appreciable quantity of toxin has been demonstrated in cases of tetanus; but no bacilli are present.

\section{SEROUS MENINGITIS}

In the varieties of meningitis discussed up to the present we have been dealing with inflammatory conditions of the meninges in which a definite inflammatory exudate is present, and in which the infecting organism is present in the cerebrospinal fluicl. In practice, however, cases are constantly being met with in which the symptoms are highly suggestive of meningitis, but the cerebrospinal fluid, which is invariably sterile, gives little or no support for such a diagnosis. Should such cases come to the autopsy table no evidence of meningitis can be found.

This condition has been described under many different names, and a considerable amount of confusion exists in regard to it. Schottmüller describes two separate conditions, 
circumscribed infectious meningitis and sympathetic meningitis. Kaplan speaks of non-micotic meningitis, and other authors use still different terms. The term serous meningitis or meningitis serosa is an old one, and if by it we understand all those cases in which there is meningeal irritation without a definite inflammation of the meninges it appears as satisfactory a one as can be devised. Whatever term is used it must be sufficiently elastic to include a considerable variety of conditions, for the condition is one which may appear in a number of widely differing morbid states. It is only natural, therefore, that the cerebrospinal fluid should present corresponding differences.

One of the most important causes of meningitis serosa is the presence in the neighborhood of the arachnoid sac of a focus of inflammation. This focus is situated most commonly in the middle ear, and on that account the condition is one of special importance to the aural surgeon. Any inflammatory condition of the skull may, however, give rise to it. A deepseated abscess of the brain may remain uncomplicated by a purulent meningitis for a considerable time, but symptoms of a serous meningitis may make their appearance at a much earlier date. At any time, of course, a serous meningitis may develop into a purulent meningitis, should the infectious process reach the pia mater. The meningitis in these cases is evidently toxic in nature, the toxins but not the organisms gaining access to the meninges. Very much the same phenomenon is seen in the case of a sub-diaphragmatic abscess, in which a non-purulent pleurisy is set up by the passage of toxins through the diaphragm.

Another great clinical group in which serous meningitis may appear as a complication is that of the infectious fevers, and other conditions in which bacteria and their toxins circulate in the blood. Thus the symptoms may arise in the course of measles, influenza, typhoid, pneumonia, and rheumatic fever. The symptoms of meningeal irritation not infrequently occurring in mumps should possibly be classed under 
this heading. Cases of sunstroke with high intracranial pressure probably furnish still another example. The condition often called meningismus may be included here. It is merely one variety of the general condition serous meningitis.

In many cases it is probable that the full force of the irritant falls not on the meninges but on the ependyma of the choroid plexus, the immediate result being a greatly increased production of cerebrospinal fluid, which may otherwise be perfectly normal. Quincke records several such cases in which hydrocephalus was associated with great thickening of the ependyma and degenerative changes in the choroid plexus, but in which the meninges showed no change. He also suggests that in some cases there may be a condition of angio-neurotic œdema of the choroid plexus, thus explaining the sudden onset which may occur on several occasions. This is one of those theories which it is as difficult to disprove as to prove.

During an epidemic of meningococcal meningitis amongst the British troops in France I encountered a number of cases which were apparently serous meningitis, of which the following is typical. The patient had been feeling ill for two davs. When I saw him he had marked signs of meningitis - headache, head retraction, pain in the back and neck, greatly exaggerated knee jerks, and a marked Kernig's sign. The temperature was $104.4^{\circ} \mathrm{F}$., the pulse 108 , and the blood showed a leucocytosis of 13,400 . The cerebrospinal fluid was under very high pressure, issuing in a forcible stream from the needle, but it was quite clear, showed no cellular nor globulin increase, and was sterile. The lumbar puncture at once relieved the symptoms of intracranial pressure in a remarkable way, and two days later the patient was convalescent. I came across several similar cases, in some of which a moderate lymphocytosis was present, but in no case were there any organisms in the fluid. Other cases from the same battalion with identical symptoms showed purulent spinal fluid containing large numbers of meningococci. The only conclusion possible is that in the first set of cases the organisms were circulating in 
the blood, but only the toxins gained access to the cerebral meninges. The prognosis in the two classes of cases was entirely different.

The symptoms are essentially those of increased intracranial pressure, of which the most constant is headache. The cerebrospinal pressure is invariably raised, sometimes to a marked degree. In very many cases the fluid is perfectly clear, and may present no other abnormality. The combination of a normal fluid under high pressure with the symptoms of meningitis is almost pathognomonic of serous meningitis. It is well to bear in mind, however, that in the very earliest stages of acute meningitis the fluid may occasionally show but little change.

It is in young children that the most important manifestations of serous meningitis are met with. A child may present all the symptoms of acute meningitis such as vomiting, rigidity, head retraction, Kernig's sign, and bulging of the fontanelle, but the spinal fluid may show no abnormality except extremely high pressure. In such cases withdrawal of a considerable quantity of fluid will be followed by remarkable and immediate clinical improvement. The symptoms may return in the course of a few days or weeks, but a second puncture will probably restore the child to a normal condition. The ependyma has apparently been stimulated to over-activity by some toxin circulating in the blood, with a resulting excessive production of cerebrospinal fluid, but when the excess of fluid has been removed a condition of equilibrium seems to be established, and the danger, undoubtedly great in these young patients, is averted. The condition is of great practical importance, and is not generally recognized. Almost all the cases which I have seen have been in children under one year of age. The most important single sign is fullness and bulging of the fontanelle. The fluid should be withdrawn until the fontanelle is depressed 


\section{REFERENCES}

Arzt and Boese: Uber Paratyphusmeningitis im Kindesalter. Weiner klin. Wochenschr. I908, No. 7.

Carnegie Dickson, W. E.: Cerebrospinal meningitis. Brit. Med. Jour. I9I7, p. 454.

Heiman and Feldstein: Meningococcal Meningitis. Lippincott, I9I3.

Horder, T. J.: Cerebrospinal fever. Oxford medical publications, I9I5, p. 52.

Ingleton, A. T.: Aseptic meningitis following intrathecal injection of antitetanic serum. Jour. R. A. M. C., XXVI, No. 2, p. 234.

Kaplan: Serology of nervous and mental diseases, p. 92.

Kasahara, M.: The specific diagnosis of tuberculous meningitis. Am. Jour. Dis. Child. I9I7, XIII, p. I4I.

Laroch, G. and Pignot, J.: Sugar in the cerebrospinal fluid in acute meningitis. Paris Medical, I9I7, VII, No. I5, p. 293. (Quoted in Jour. Am. Med. Assoc. I917, LXVIII, p. 1069.)

Osler: Practice of medicine, 7 th edition, pp. 336, 300, I8I.

Quincke: Meningitis serosa. Samml. klin. Vorte., Leipz. I893, No. 67. Inn. Med., 23, 655 .

Stewart, Purves: Diagnosis of nervous diseases. Arnold, 3 rd edition, p. 44I.

Trembur: Die Quinckesche Lumbalpunktion bie der Erkennung der Meningitis tuberculosa. Klin. Jahrbuch, I9ı, XXIV, p. 359.

Vincent and Bellot: Nouvelles recherches sur le precipito-diagnostic de la méningite cérébro-spinale. Bull. et mém. Soc. méd. des Hôp. de Paris, r9o9, XXVII, p. 952.

Warrington, W. B.: Intracranial serous effusions of inflammatory origin. Quart. Jour. of Medicine, I9I4, VII, p. 93.

West: Nervous phenomena in pneumonia. Clin. Journal, I908, XXXI, p. 364 . 


\section{CHAPTER XV}

\section{SYPHILIS OF THE NERVOUS SYSTEM}

In the recent history of clinical medicine no more remarkable revolution of ideas has taken place than in the case of the relationship of syphilis to the nervous system. John Hunter taught in I790 that syphilis never affected the internal organs, and in those days the paralysis which occasionally followed syphilis was usually attributed to the mercurial treatment.

We have for long known that certain pathological lesions of the central nervous system such as gummata, arterial degeneration, and some forms of meningitis are syphilitic in nature. It was also recognized that some relation existed between syphilis and general paresis and tabes dorsalis - diseases which were called para or metasyphilitic - but the exact nature of the relationship was by no means clear. Many authors refused to admit that syphilis was the sole etiological factor in these diseases, although they admitted that it played a very important part. Even so eminent an authority as Nonne said - "At the outset I desire to make it clear that progressive paralysis is not a specific syphilitic disease of the brain." The demonstration by Noguchi and Moore of the spirochæta pallida in the brain and cord in general paralysis and tabes, together with the evidence furnished by the Wassermann reaction in the blood and the spinal fluid, has swept away the last lingering doubt. It is now universally recognized that there is but one neuro-syphilis which may attack the meninges, the blood vessels, the nerve cells of the cerebral cortex, or the nerve fibers in the posterior columns of the cord. So much is generally granted.

Recent work has, however, thrown most important light on the question of the involvement of the nervous system in 
the earlier stages of syphilis. It is now recognized that it is not the case, as was formerly supposed, that nervous syphilis is necessarily a late manifestation of the disease. The whole tendency of the work of the past few years has been to throw ever earlier the period at which the nervous system may become infected, until we have reached the stage where cases are being reported in which the cerebrospinal fluid shows changes said to be characteristic at the same time as the appearance of the primary sore.

Although, however, it is wise to maintain a critical attitude regarding the significance of certain results, there is no room for donbt that the light thrown upon the whole subject of neuro-syphilis by these recent investigators on the cerebrospinal fluid is of the very greatest importance. It is certain that in the general systemic infection which marks the commencement of the secondary stage the nervous system not only is not exempt, but is in reality one of the parts of the body most frequently involved. In the present state of our knowledge we cannot say which of these cases will speedily clear up and which will develop into incurable parenchymatous syphilis, nor do we know the factors upon which this depends. Further work may, however, serve to elucidate these very important points. From the practical point of view, all cases showing changes in the spinal fluid should receive energetic treatment until the fluid has returned to normal, whether or not symptoms of nervous disease have been present. As Neisser said at the International Medical Congress in I9I3, no one should be passed as cured of syphilis until the cerebrospinal fluid has been examined and found normal, and those whose experience in the treatment of syphilis is most extensive will be most likely to agree with him.

\section{EARLY SYPHILIS}

The strong tendency at present is to place the possibility of svphilitic involvement of the nervous system at an ever earlier date. The old view that the nervous lesions were essentially late manifestations of the diseases occurring in the tertiary 
and post-tertiary stages has been replaced by the modern one that the central nervous system may be one of the first organs to be involved. Gregory and Karpas, Gowers, Nonne, and many others have published cases in which the nervous system became involved within a year of the primary infection. In a series of 22 cases of secondary syphilis Dreyfus found changes in the spinal fluid in $I 7$.

In these secondary cases the changes in the fluid usually noted are a moderate lymphocytosis and an increase in the globulin. In the majority of these cases the Wassermann reaction is negative, although it may be strongly positive in the blood. A positive Wassermann in the spinal fluid indicates a much more serious involvement of the nervous tissue than a mere pleocytosis and globulin excess. In all cases, however, it is well to accept the cellular and globulin changes as evidence of direct involvement of the nervous system, even with a negative Wassermann.

That cerebrospinal involvement in secondary syphilis is common is now universally admitted, but it appears that this involvement may be earlier still, for in a number of cases characteristic changes have been found in the fluid in the primary stage, although a positive Wassermann reaction has never been present. Wile and Stokes describe 6 primary cases, in 4 of which the spinal fluid was abnormal, one case showing a cell count of 200. Fruhwald and Zalozieki furnish even more striking evidence of early infection, for by injecting the cerebrospinal fluid into the testicles of rabbits they demonstrated the presence of the spirochrta pallida in both primary and secondary syphilis. In some of these cases there were nervous symptoms, in others there were none. This final confirmation of the diagnosis by the demonstration of the spirochrta pallida in the cerebrospinal fluid has now been made by a number of workers. Levaditi, Marie and Bankowski succeeded in finding the spirochætes in the centrifuged ventricular fluid of a case of general paresis, and Wile, who was successful with inoculation tests in over 60 per cent. of a series of 8 cases, including secondary syphilis involving the nervous system, 
tabes dorsalis, and general paresis, believes that the spinal fluid contains spirochætes at certain times in every case of neuro-syphilis.

\section{CEREBROSPINAL SYPHILIS}

This term, although admittedly unsatisfactory in the light of present day knowledge, has passed into such general usage that it is difficult to dispense with it. By it we include all forms of what Mott has termed interstitial syphilis, that is to say cases in which the parenchymatous elements of the nervous system are not primarily involved. The three principal types are the gumma, syphilitic endarteritis, and syphilitic menigitis or meningo-encephalitis.

The cerebrospinal pressure is as a rule above normal and a globulin reaction, sometimes very marked, is almost always present. A somewhat less constant feature is a cellular increase, which in the meningitic form may reach several thousand. Where the only lesion is an endarteritis, however, the pleocytosis may be slight or even entirely absent. The characteristic cell is the small lymphocyte. In cases of acute syphilitic menigitis, however, in which the reaction is very marked the spinal fluid may show considerable numbers of endothelial cells, and in some cases polymorphs form a noticeable feature of the cell picture.

Regarding the Wassermann reaction in this condition the results of different workers in the past have varied to a marked degree. The earlier German workers, using the original Wassermann technic, regarded a negative finding in the spinal fluid as the rule. Plaut found a positive reaction in only 6 per cent. of his cases, and even in these the reaction was regarded as the exception rather than the rule. The substitution of the more sensitive cholesterinised heart antigen for the syphilitic liver antigen of the original method, and the introduction of the use of larger quantities of fluid up to I.O or even 2.0 c.c., have resulted in a great change of attitude on this subject. McIntosh and Fildes, it is true, condemn the use of large quantities of fluid on the ground that non-specific 
reactions may be obtained, and claim that by using cholesterinised heart as an antigen they can obtain a very high percentage of positive results with the use of 0.2 c.c. of fluid.

Most workers agree, however, that the use of larger quantities is essential if a true estimate of the condition of the fluid in cerebrospinal syphilis is to be arrived at. In many cases a positive reaction will only be obtained when I.O c.c. of fluid is used, and there is no good reason to believe that such quantities will give a non-specific reaction. Sometimes a cellular and globulin increase will be found in cases of secondary syphilis even when no nervous symptoms are present. In such cases a negative reaction will invariably be obtained when 0.2 c.c. of fluid are used, but with r.o c.c. the reaction may be positive. It is obvious, therefore, that many positive reactions will be missed if only 0.2 c.c. of fluid are used. The endarteritic form of cerebrospinal syphilis may however give a negative reaction even when the full quantity is used. The Auswertungsmethode further provides a very useful indication as to the success of treatment and the progress of the case, for by it the gradually decreasing intensity of the reaction can be accurately measured. If a fluid gives a strongly positive reaction' with o.I c.c. at the beginning of treatment, and at the end 2.0 c.c. are necessary in order to obtain a positive result, it is evident that the therapeutic effort has been of some avail. Finally, in an untreated case the amount of fluid which it is necessary to use in order to obtain a positive reaction affords a very fair indication as to the nature of the lesion. If r.o c.c. or 2.0 c.c. are necessary the case is almost certainly one of cerebrospinal syphilis. In general paresis, on the other hand, a positive reaction will be obtained with 0.05 c.c. or even with less. Tabes dorsalis occupies an intermediate position.

The colloidal gold test will often show a reaction in the mid or so-called luetic zone.

In the difficult task of differentiating between general paresis and cerebrospinal syphilis the therepeutic test often 



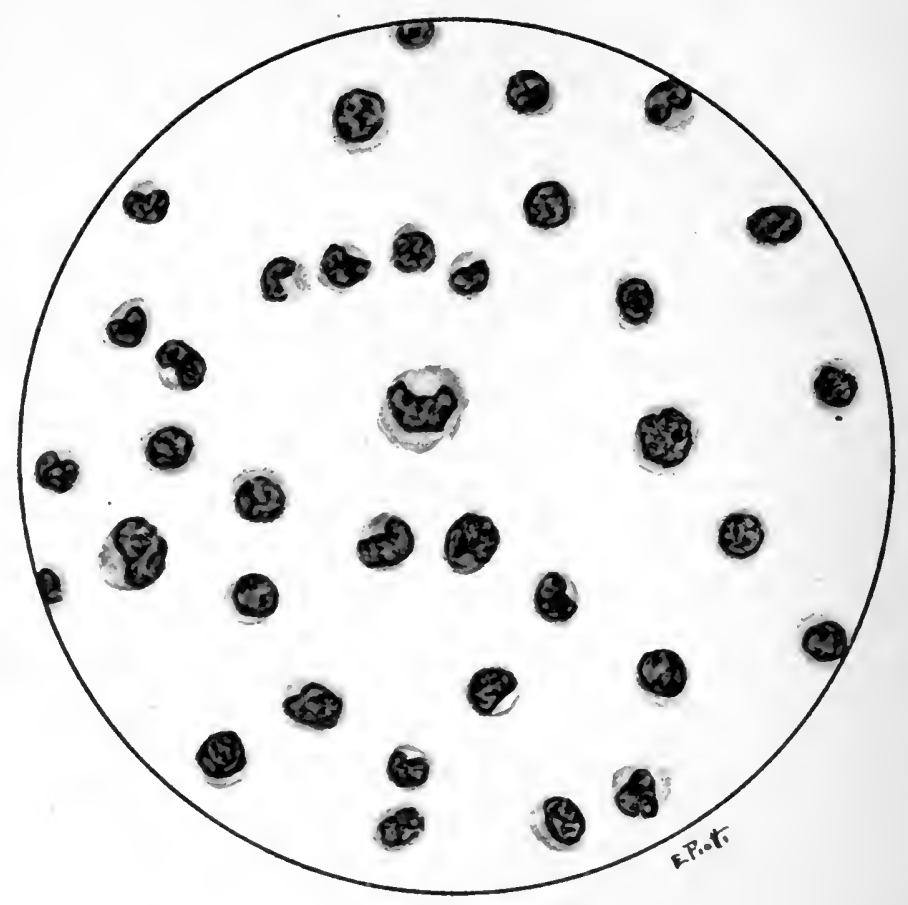

Lymphocytosis in General Paresis. 
yields information of great value. One or two intravenous injections of salvarsan will usually produce little or no effect on the spinal fluid in general paresis, although prolonged intraspinal injections by the Swift-Ellis method may ultimately cause considerable improvement. In cerebrospinal syphilis, on the other hand, the results of ordinary specific treatment are often remarkable, the change being most marked in the number of lymphocytes, which may fall to normal in a comparatively short time. Walker found that in cases of syphilitic meningitis in which endothelial cells were numerous these cells were the first to show a marked decrease in response to treatment, followed later by a fall in the small lymphocytes. The globulin reacts to a lesser extent. The Wassermann is the most resistant of the three reactions, but with intensive salvarsan treatment it also may be reduced or entirely abolished even when I c.c. of fluid is used. Occasionally, however, the Wassermann may respond more readily than the globulin. This may occur in any of the forms of neuro-syphilis.

\section{TABES DORSALIS}

As regards the condition of the cerebrospinal fluid tabes occupies a position midway between cerebrospinal syphilis and general paresis. The most constant feature is a lymphocytosis, moderate in degree, ranging from 60 to roo. Such an increase is present in about 90 per cent. of cases. In very old-standing cases the increase may be so slight as to leave room for doubt. Alzheimer sections show the chief type of cell to be the small lymphocyte. In many cases no other cell can be found. Large mononuclear or endothelial cells may occur, but I have never found plasma cells, although they are clescribed by some authors. In quiescent cases polymorphs are as a rule not found, but if the fluid be examined during or immediately after a crisis they may form a considerable portion of the cell count. At these times the total amount of fluid becomes much increased, and the globulin excess is also more apparent. The nature of such crises is not well un- 
derstood, but the changes in the spinal fluid, especially the appearance of polymorphs, are strongly suggestive of meningeal irritation.

Globulin is very constantly increased, but not to the extent seen in paresis. Fehling reduction is normal.

The results of the Wassermann test vary with different workers, depending no doubt upon the method employed. Most workers obtain positive results in from 50 to 70 per cent. of cases. Hauptmann by his "Auswertungsmethode" got a positive reaction in almost every case, whilst McIntosh and Fildes using 0.2 c.c. in a small series had 92 per cent. of positives. If quantities up to I.o c.c. be used, together with a cholesterinised heart antigen, a positive reaction will be obtained in from 80 to 90 per cent. of untreated cases, or even higher. The reaction in the blood is positive in about the same percentage of cases as in the fluid, but it is important to bear in mind that the reaction may be positive in the serum and negative in the fluid, or positive in the fluid and negative in the serum. For this reason it is essential in all cases to examine both the serum and the fluid. To sum up the position with regard to tabes, if a patient with suggestive physical signs has an increase in cells and globulin and a positive IVassermann in the spinal fluid or the blood or in both, there is ample evidence for a positive diagnosis. With a negative reaction in both blood and spinal fluid there may be some hesitancy, and the therapeutic test may have to be applied. The presence of pleocytosis and globulin increase, however, in a chronic case showing evidence of involvement of the nervous system may be taken as almost conclusive evidence of syphilitic infection.

The effects of ordinary intravenous - as opposed to intraspinous - treatment is much less marked than in cerebrospinal syphilis. Cases with a marked pleocytosis may show a very considerable reduction in the cell count, but it will seldom reach normal limits. The globulin increase is still more resistant, and the Wassermann reaction, except in cases where there is reason to suspect a large meningeal element, can rarely be con- 
verted from a positive into a negative. Some of the cases of tabes dorsalis and even of general paresis, however, treated at the Baston Psychopathic Hospital by Southard and Solomon by intravenous injections only have shown extraordinary improvement in the serology of their spinal fluids, every single pathological feature having returned to normal (personal communication).

\section{GENERAL PARESIS}

There is no condition in clinical medicine in which an examination of the cerebrospinal fluid is of greater importance than in general paresis, nor one in which the findings are more constant and characteristic. The differential diagnosis between general paresis in the early stages and neurasthenia, alcoholic insanity, cerebrospinal syphilis, and other conditions, is often one of extreme difficulty, and the help which the laboratory is able to provide may be welcome in the extreme. Absence of pain on lumbar puncture is a characteristic feature. I do not remember puncturing a paralytic who complained of discomfort at the time of the operation. Further, such patients are singularly immune from unpleasant after-effects.

The pressure may be normal, but as a rule it is distinctly raised. The total volume of fluid is increased, this being no doubt compensatory to the atrophy of brain tissue.

The fluid is almost always clear. In one case, however, with a phenomenal cell count - over 3,00o cells per c. mm.it was opalescent. Fehling reduction is prompt.

A cellular increase is the almost universal rule. Should a case fail to show such an increase when examined on several occasions the clinical evidence would need to be overwhelming before a diagnosis of general paresis could be accepted. The pleocytosis, together with the other positive findings, is dependent to some extent on the stage of the disease, and also upon the type. In a series of observations on asylum patients I found that the spinal fluid changes were much more marked in the early stages than when the patient had sunk into a condition of dementia in which he might continue to drag on a 
miserable existence for a number of years. Further, the acute type which rapidly passed through the various stages and ended fatally within a couple of years showed a similar intensity in the fluid changes as compared with those cases which pursued a more leisurely course during a number of years, although in these latter the cerebral lesions characteristic of general paralysis were present at autopsy. In ordinary cases the number of cells averages from 30 to 100 per c.mm. but as indicated above this number may be greatly exceeded. Polymorphs can usually be found in small numbers, but after a convulsive seizure they may appear in such large numbers as to equal the lymphocytes.

The small lymphocyte is the predominant type, but in Alzheimer sections every variety of cell known to occur in the fluid may be found. Of these the most important is the plasma cell. It used to be thought that these cells, so characteristic a feature in sections of the brain in this condition, were not present in the cerebrospinal fluid, but the Alzheimer method has shown that they are very constantly present, although only in small numbers. The presence of these cells in the spinal fluid is so characteristic as to be almost pathognomonic of the condition, but they have also been found in tuberculous meningitis. Endothelial cells, Gitterzellen, and "tailed cells" are also found. The exact significance and diagnostic importance of many of these cells is not known, but further studies may be expected to throw valuable light on this aspect of the subject.

A high protein content is a very constant feature, and the globulin reactions are positive in over 95 per cent. of cases. The total protein varies from 0.1 to 0.3 per cent. and the globulin test may give a positive reaction with a high dilution; indeed one of my cases gave a distinct reaction with a dilution of $I$ in I3. The protein increase is most marked in the early stages, tending progressively to diminish as the more chronic stages are reached. It is very seldom that the fluid of an untreated case will give a positive Wassermann if the globulin reaction is not positive. 
The Wassermann reaction is strongly positive both in the blood and the cerebrospinal fluid in at least 96 per cent. of cases; some workers obtain IoO per cent. of positive results. It is very rare for the reaction to be positive in the serum and negative in the fluid. In very chronic cases the serum may give a negative reaction while the fluid still remains positive. The reaction in addition to being extremely constant is characteristically intense. It will always be obtained with 0.2 c.c. and often with the whole series of dilutions. There is no other condition which approaches general paresis for the intensity of the reaction.

It will thus be seen that in general paresis the "four reactions " of Nonne are most characteristically present, namely a positive Wassermann reaction in the blood, cellular increase, globulin increase, and a positive Wassermann reaction in the spinal fluid. All four reactions will be found in at least 96 per cent. of cases.

Less effect is produced by treatment on the condition of the spinal fluid that in any of the other nervous manifestations of syphilis. The pleocytosis may become less marked, but the globulin and Wassermann reactions often resist all therapeutic efforts. With combined intravenous and intraspinal injections of salvarsan, however, if sufficiently long continued, the fluid may in many cases be reduced to a normal condition.

To the four classical reactions of such proved value in the diagnosis of general paresis must now be added a fifth. For the colloidal gold reaction of Lange not only is as characteristic as any or all of the classic four, but it serves to differentiate general paresis from other syphilitic nervous conditions with a sureness which cannot be claimed for any of the other tests.

The typical paretic curve has already been described in discussing the reaction. Complete precipitation is obtained in the paretic zone, that is to say in the first 3 , 4 , or 5 tubes. The curve then drops with varying degrees of abruptness to the zero line, in a manner described by Kaplan as step-ladder. The reaction is very constant, being present in at least 95 per 
cent. of cases. Its intensity bears no definite relation to the amount of protein in the fluid. This is somewhat remarkable, as the test was originally introduced with the object of obtaining a quantitative determination of the protein present. The Lange test closely parallels the Wassermann reaction, but in a few cases it may give a positive result when the Wassermann reaction is negative. It is certainly an extremely valuable corroborative test for general paresis. In cases undergoing treatment it usually diminishes in intensity if the other pathological changes are clearing up. But sometimes it may remain even after the fluid has become otherwise normal.

In tabes, cerebrospinal syphilis, and congenital syphilis an entirely different reaction is obtained. Either no reduction occurs, or a reduction of varying intensity in the mid or luetic zone. The resulting curve can be differentiated at a glance from that typical of general paresis. It is this power of differentiation which gives the colloidal gold test its value.

\section{JUVENILE GENERAL PARESIS}

In this condition the cerebrospinal fluid shows the same pathological changes as in the adult form of the disease. The four reactions and the Lange test are all positive.

In practice general paresis has to be differentiated from a number of clinical conditions. In the majority of these the laboratory examination of the cerebrospinal fluid is of the greatest value, and at once serves to clinch the diagnosis. The only real difficulty lies in distinguishing between general paresis and cerebrospinal syphilis. In both of these the Wassermann reaction in the blood is positive, and the spinal fluid shows a pleocytosis and a globulin increase. The Wassermann reaction in the fluid in general paresis, however, is always positive, whereas it is negative in at least 70 per cent. of cases of cerebrospinal syphilis with 0.2 c.c. of fluid. When larger quantities of fluid up to I.O c.c. or 2.0 c.c. are used the figures may be brought up as high as in general paresis. Even when a positive result is obtained with 0.2 c.c. of fluid in cerebrospinal syphilis the reaction is not so marked as in 
paresis. If to this difference is added the very different behavior of the collodial gold reaction in the two conditions, and the equally different response to specific treatment, it will be found that the information furnished by the laboratory will enable the clinician in practically every case to arrive at a correct diagnosis.

The various reactions in those forms of syphilis which affect the nervous system are shown in the following table. The plus signs indicate that a positive result is obtained in nearly every case. The Wassermann reaction in the fluid is reckoned on the assumption that 0.2 c.c. are used.

\begin{tabular}{|c|c|c|c|c|}
\hline & $\begin{array}{l}\text { Secondary } \\
\text { Syphilis }\end{array}$ & $\begin{array}{l}\text { Cerebro- } \\
\text { spinal } \\
\text { Syphilis }\end{array}$ & $\begin{array}{l}\text { Tabes } \\
\text { Dorsalis }\end{array}$ & $\begin{array}{l}\text { General } \\
\text { Paresis }\end{array}$ \\
\hline $\begin{array}{l}\text { Wassermann in } \\
\text { blood } \ldots \ldots \ldots \ldots\end{array}$ & + & + & $70 \%$ & + \\
\hline $\begin{array}{l}\text { Wassermann in } \\
\text { fluid } \ldots \ldots \ldots \ldots .\end{array}$ & - & $30 \%$ & $60 \%$ & + \\
\hline Pleocytosis ...... & $50 \%$ & + & + & + \\
\hline Globulin $\ldots \ldots \ldots$ & - & + & + & + \\
\hline $\begin{array}{l}\text { Lange (paretic } \\
\text { curve) } \ldots . . . . .\end{array}$ & - & - & 一 & + \\
\hline
\end{tabular}

\section{REFERENCES}

Boyd, W.: The cerebrospinal fluid in certain mental conditions. Jour. Med. Sc., 1912, LXVIII, p. 203.

Dreyfus: Die Bedeutung der modernen Untersuchungs und Bedhandlungs methoden für die Beurteilung isolierter Pupillenstorungen nach vorensgangenerer Lues. Münch. med. Woch., 1912, p. I647.

Fruhwald, R. and Zaloziecki, A.: Uber die Infectiostat des Liquor cerebrospinalis bei Syphilis. Berlin. klin. Woch., I9I7, LIII, No. I.

Gregory and Karpas: A case of cerebral syphilis occurring six months after the initial lesion. Rev. of Neurol. and Psych., May, I9I3.

Kaplan: Serology of Nervous and Mental Diseases. 1914, W. B. Saunders Co.

Levaditi, C., Marie, A:, and Bankowski, L.: Le tréponème dans 
le cerveau des paralytiques généraux. Ann. de l'Inst. Pasteur, I913, XXVII, p. 576 .

Noguchi, H., and Moore, J. W.: A demonstration of treponema pallidum in the brain in cases of general paralysis. Jour. Exper. Med., I9I3, XVII, p. 232.

Nonne, M.: Syphilis und Nervensystem, Berlin, 1902.

Plaut, Rehm, and Schottmüller: Leitfaden zur Untersuchung der Cerebrospinalfüssigkeit, 1913, Fischer, Jena.

Wile, U. J.: The spirochetal content of the spinal fluid of tabes, general paresis and cerebrospinal syphilis. Am. Jour. Syphilis, 1917, I, p. 84 .

Wile, U. J. and Stokes, J. H.: Involvement of the nervous system during the primary stage of syphilis. Jour. Am. Med. Assoc., I9I 5, LXIX, p. 979. 


\section{CHAPTER XVI \\ ORGANIC DISEASE OF THE BRAIN}

\section{CEREBRAL TUMOR}

The pressure of the cerebrospinal fluid is raised sometines to such an enormous extent that the fluid shoots right across the bed when the needle is introduced. In these cases the minimum amount of fluid should be withdrawn - not more than 2 or 3 c.c.- and the foot of the bed should be kept raised for some time. The mechanism of the accidents which sometimes occur in lumbar puncturing these cases has already been discussed.

The cell count as a rule is normal, but may be increased, especially in tumors involving the meninges. In one case of tumor of the pituitary body there was a very marked pleocytosis. In this case the somewhat rare condition of cerebrospinal rhinorrhœa was present, for a communication existed - owing to the destructive action of the new growth - between the cranial and the nasal cavities, and whenever the patient sat up cerebrospinal fluid dripped from the nose In gumma of the brain a considerable lymphocytosis may be present.

The protein content varies much as the cell count. As a rule it is not increased. It is more likely to be raised if the tumor is a gumma. In the pituitary case above mentioned there was an enormous increase.

Rehm records the presence of cholesterin crystals and fat needles in a case of cholesteatoma of the base of the skull, and I have found cholesterin ester crystals in a case of tumor of the optic chiasma.

In echinococcus disease of the brain it may be possible to demonstrate the presence of hooklets and fragments of membrane in the spinal fluid. 


\section{CEREBRAL ABSCESS}

Abscess of the brain may present a difficult problem in diagnosis. The onset may be so insidious and the symptomatology so indeterminate that great difficulty may be experienced in arriving at a decision. The spinal fluid findings may be helpful or may be misleading. They will not mislead, however, if it is borne in mind that a cerebral abscess may coexist with a perfectly normal fluid. Indeed it is often the absence of pathological change in the fluid which is the determining factor in the diagnosis.

The chief difficulty lies in distinguishing between abscess of the brain and septic meningitis. In the latter condition the fluid is purulent and presents the usual characters seen in meningitis. If the brain abscess communicates with the surface its contents will be discharged into the subarachnoid space, a purulent meningitis will result, and there will be no difference in the cerebrospinal fluid in the two conditions. If, however, the abscess be deep seated the spinal fluid may be perfectly normal. If in a case with symptoms of acute cerebral irritation and pressure, a moderate degree of pyrexia, and a leucocytosis in the blood, there are no changes in the spinal fluid, the strong presumption is that the condition is one of cerebral abscess. Thus a negative finding may be of more value than a positive one.

It has already been seen, however, that even in a deep seated abscess in which the autopsy may reveal no evidence of meningitis changes may be present in the fluid in the shape of a cellular and globulin increase. This is apparently due to the diffusion of toxins from the abscess causing a certain amount of meningeal irritation.

The commonest source of a cerebral abscess is the middle ear. Infection may readily spread through the tegmen tympani and give rise to an abscess in the temporo-sphenoidal lobe. It is remarkable, however, in how many instances no meningitis results from this spread, although the infection must have traversed the subarachnoid space. This immunity of the men- 
inges is due to the walling off of the area of infection by adhesions, which provide an efficient protection when the process is not too acute.

The condition of the cerebrospinal fluid may change during the course of a cerebral abscess, so that if a preliminary puncture reveals a normal fluid it may be well to make another examination a day or two later. The following case illustrates this in a remarkable way.

The patient when first seen complained of headache and dimness of vision. Two years before he had suffered from severe headaches and a left hemiplegia which were syphilitic in origin and which completely disappeared under anti-syphilitic treatment. The present attack of headache and loss of sight had lasted five days, during which time he had largely lost the use of his left arm. The cerebrospinal fluid contained I Io lymphocytes per c. mm. The evident diagnosis appeared to be one of return of the syphilitic cerebral affection, but anti-syphilitic treatment was without effect. The sight failed rapidly, the left arm became paralyzed, and the patient sank into a condition of coma, which terminated in a few days in death. On the day before he died lumbar puncture was again performed, and to my surprise I found that the fluid was now turbid, and contained large numbers of polymorphonuclear leucocytes. The chronic syphilitic condition had apparently been replaced by an acute suppurative one.

A visit to the autopsy, room provided the explanation. In the right motor area were the remains of a syphilitic gumme, to which were due the hemiplegia of two years ago, and the lymphocytosis which still persisted. In addition, however, two acute abscesses were present, one in the right motor area, the other in the occipital lobe. The pus from the latter had made its way into the ventricles, and thence to the base of the brain through the locus perforatus posticus. The abscesses were the cause of the recent hemiplegia and the loss of vision. The change in the character of the spinal fluid was due to a real change in the infection, but the relationship was not recognized, and an unavailing line of treatment was the result. 


\section{CEREBRAL H IEMORRHAGE}

In many cases of cerebral hæmorrhage the spinal fluid is quite normal. In a few there may be a moderate lymphocytosis and a slight globulin increase. Should the arterial disease be syphilitic, the fluid will show corresponding changes, although it must be remembered that the purely arterial form of cerebral syphilis leaves fewer traces in the fluid than any other variety.

If the hæmorrhage is near the surface or leaks into the ventricles, red blood cells will be found in the fluid in large numbers.

Subarachnoid hæmorrhage may thus be due to an original hæmorrhage in the brain. A much more frequent cause, however, is hæmorrhage from a meningeal vessel. This is usually due to injury to the skull, but may occur from other causes. In one case there was a history of the patient lifting heavy boxes, with the onset in a couple of hours of symptoms of cerebral compression. The behavior of the cerebrospinal fluid in this case may be taken as typical of the whole class. On the day following the onset the fluid was under moderate pressure, and presented the appearance of pure blood. On being centrifuged a thick layer of red cells collected at the bottom of the tube, the supernatant fluid showing an almost imperceptible yellowish tinge. A couple of days later there was still an abundance of red cells, but considerable hæmolysis had taken place, and the fluid was of a canary yellow color. At the end of a week the red cells had largely disappeared, but their place was taken by large numbers of polymorphonuclear leucocytes, together with a small portion of lymphocytes. It was not possible to follow this case further, but in similar cases it is common to find numbers of large phagocytic cells showing numerous cell inclusions in the later stages of the condition. Lymphocytes and large mononuclear cells have been found a considerable time after the occurrence of the hæmorrhage.

Reference may here be made to certain changes which have 
been observed in the brain and spinal fluid in cases of shell shock. The bursting of a large high explosive shell in the immediate vicinity may produce neurological phenomena bewildering in their variety, and sometimes strongly suggesting a functional basis. It has been found, however, that if the spinal fluid of such cases is examined shortly after the injury blood will be very constantly observed. Mott and others have further demonstrated that if such patients die from other injuries numerous petechial hæmorrhages may be found scattered throughout the brain and spinal cord.

\section{CEREBRAL THROMBOSIS}

In thrombosis of the cerebral vessels proper the spinal fluid may present no abnormality. In syphilitic cases there will probably be a lymphocytosis and a globulin increase. A positive Wassermann reaction in the spinal fluid will settle the etiology of the condition.

Rehm has described marked changes in sinus thrombosis. This usually involves the lateral sinus, most commonly in inflammatory conditions of the middle ear, but any of the sinuses may be affected from either local or general causes. The fluid may be clear, of normal pressure, and contain no abnormal constituents. On the other hand the pressure may be considerably raised, and the fluid may be of a yellow color and contain large numbers of red blood corpuscles. In some cases the fluid is cloudy, shows a marked leucocytosis and contains large quantities of albumen. Occasionally a definite network of fibrin forms in the fluid.

\section{ENCEPHALITIS}

Encephalitis or diffuse inflammation of the brain may occur as a complication in such conditions as acute meningitis and cerebral abscess. The most important and interesting form in which it occurs, however, is as encephalitis lethargica, a disease characterized by lethargy, cranial nerve disturbances, and foci of inflammation scattered throughout the brain, more especially in the mid-brain and medulla. The condition of the spinal 
fluid varies greatly in different cases. In a series of over 40 cases seen in Winnipeg at the end of 1919 the pressure was almost invariably raised, but there was no other constant change. In the majority the cells and globulin were normal. In a small proportion there was a moderate increase up to $3^{0}$, and in two the count was 152 and 210 . The increase in globulin was not proportionate; there being never more than a trace present. The sugar was normal. No bacteria were found in culture.

\section{HYDROCEPHALUS}

The condition of hydrocephalus has been known to medical science since the days when Hippocrates with a master's sure insight first tapped the hydrocephalic ventricle. In the centuries which have elapsed since then little or nothing has been added to our knowledge of the subject, and as Magendie has remarked, we merely cloak our ignorance in words when we apply the high sounding term hydrocephalus to the condition known to every layman as "water on the brain." It was Magendie himself who first recognized that obstruction of the aqueduct of Sylvius was followed by dilatation of the lateral ventricles, but he was unable to explain the phenomenon, as he was unaware that the fluid was produced in the lateral ventricles. With increased knowledge regarding the physiology of the fluid, however, and with some little insight into the factors governing its production and absorption, there is hope that an understanding of the condition may yet be attained which will give us the power of grappling with a disease that has hitherto baffled the best surgical effort.

The most exhaustive work on the subject is that of Dandy and Blackfan, who, in addition to clearing up many doubtful points, introduced new methods of investigation which give promise of bearing very fruitful results. They produced extreme degrees of hydrocephalus experimentally by introducing a pledget of cotton wool into the aqueduct of Sylvius. They were also able to produce lesser degress of hydrocephalus by ligating the vein of Galen or the straight sinus. By injecting 
phenolsulphonephthalein into the ventricles and spinal canal they were able to determine that some cases of hydrocephalus were due to obstruction of the aqueduct of Sylvius, but that in others the aqueduct was open and the defect appeared to be one in the mechanism of absorption. In a number of cases where a diagnosis was made of obstruction to the aqueduct of Sylvius on the basis of these tests, very striking evidence was furnished by the autopsy. Thus in one case there was congenital absence of the aqueduct.

Frazier suggests that the condition be divided into obstructive, non-absorptive, and hypersecretive types. In the first variety the obstruction may be due to a congenital defect, such as absence of the aqueduct of Sylvius, or, much more commonly, to post-inflammatory adhesions around the roof of the fourth ventricle. The non-absorptive variety is due to some interference with the mechanism of absorption. This may be due to an abnormal condition of the arachnoid villi or the cerebral veins, or there may be toxic substances in the fluid which prevent its absorption. At present these are mere matters of conjecture, but recognition of the variety is important that proper treatment may be instituted.

Finally, there is the third type in which there is hypersecretion of the fluid, due probably to over-activity of the epithelium of the choroid plexus, the result of the action of toxins in the blood. Many cases of meningismus and meningitis serosa are probably of this nature. Quincke describes what he calls an angioneurotic condition of the choroid plexus with excessive production of fluid, which he considers may be the basis of the headaches so common in chlorosis and other blood conditions.

Frazier also has employed the phenolsulphonephthalein test as a means of differentiating between these different types. This is based on the following facts. If I c.c. of the dye is injected into the lateral ventricle it should appear in the fluid withdrawn by lumbar puncture in from 3 to 8 minutes. Under normal conditions 60 per cent. of the dye should be excreted in the urine in the first two hours. As none of the 
fluid is absorbed within the ventricles, the appearance of the dye in the urine indicates that there has been a free escape from the ventricles to the subarachnoid space. Finally if I c.c. of the dye be injected by lumbar puncture, normally a trace of the dye should appear in the urine in ten minutes, and the entire amount be excreted in two hours. In the obstructive type - the so-called internal hydrocephalus - there will be a normal absorption from the subarachnoid space, but the intraventricular dye will appear neither in the spinal fluid nor in the urine. In the non-absorptive type, on the other hand, the appearance of the dye in the urine, whether injected into the ventricle or the spinal canal, will be greatly delayed, and the total amount excreted will be very small.

In performing the tests a neutral solution of the dye should be used, as the commonly employed slightly alkaline solution acts as an irritant to the brain and cord. Lumbar puncture is done and I c.c. of fluid is allowed to escape. A 2 c.c. syringe containing I c.c. of neutral phenolsulphonephthalein is then attached to the needle and the syringe is filled with spinal fluid. The diluted dye is slowly injected, and the urine tested in 5 minutes for the appearance of the dye. The total amount excreted in two hours is estimated.

Next day I c.c. of the dye is injected into the lateral ventricle. In infants this may readily be done through the lateral part of the anterior fontanelle. Lumbar puncture is done, and the spinal fluid examined for dye every five minutes. The urine is examined as above, both for first appearance of the dye and for the total amount excreted in two hours. In estimating this latter quantity the amount of dye lost by lumbar puncture must be taken into consideration.

The obstructive form of hydrocephalus is best treated by puncture of the corpus callosum. In the non-absorptive form endeavors should be made to drain the subarachnoid space into some convenient receptacle such as the pleural cavity. For the hypersecretive variety Frazier recommends the use of thyroid feeding, for he found that thyroid gland was the only substance which invariably acted as a depressor to the choroid 
plexus, as shown by diminution in the quantity of cerebrospinal fluid produced.

\section{CONCUSSION}

Concussion of the brain or commotio cerebri is a condition the pathology of which is still far from thoroughly understood. It is of importance not so much for its immediate as for its later effects. Months or even years after the original injury the patient may suffer from headaches of varying severity. Many of these cases are doubtless pure neuroses, having their basis in the accident with which the condition originated. In other cases, however, the condition has a true organic foundation.

Lumbar puncture forms a valuable means of differentiating between these two classes. The functional type shows no abnormality, but in the organic type there is invariably heightened pressure and an increased volume of fluid. In the early stages the fluid may be of a yellowish or red color, and may show an increase of cells and globulin. In the chronic stage it is normal in composition.

The condition of shell shock may be considered in this connection. It was at first thought that this was a purely functional affection, due to the extreme shock to which the nervous system was subjected from the explosion of a great shell close at hand. Ravaut, however, examined a series of cerebrospinal fluids from such cases, and in a considerable number he found blood or a cellular or globulin increase. Post-mortem observations of Mott and others have confirmed the view that the condition has a definite histological basis, for in many of these cases minute hæmorrhages have been demonstrated in the brain and spinal cord.

\section{OEDEMA OF THE BRAIN}

Although cerebral œdema can hardly be described as a disease in itself, but rather as a complication occurring in other diseases, yet its effects are of such importance that it deserves separate consideration. 
A moderate degree of œdema in most parts of the body is not usually of much importance in itself, nor does it cause grave inconvenience to the patient. In the case of the brain, however, we are dealing with an organ confined in a rigid non-expandible bony chamber, and the effects of even a slight increase in volume are disproportionately great. A moderate degree of œdema is accompanied by headache of varying degrees of intensity, and marked œdema may be followed by still more serious symptoms. There is reason to believe that one of the important factors in the convulsions and coma of uræmia is cerebral œelema, and in such purely cerebral affections as cerebral tumor and hamorrhage the presence of an accompanying œdema will greatly aggravate the symptoms.

The conditions in which œdema of the brain is liable to occur are those with which we are accustomed to associate odema in other parts of the body, namely cardiac failure, various forms of anæmia, and renal disease. The headaches so characteristic of chlorosis probably have their basis in cerebral œdema. The importance of recognizing the œedematous element in these conditions is that simple lumbar puncture may afford a degree of relief which is as remarkable to the physician as it is gratifying to the paticnt.

\section{REFERENCES}

Boyd, W.: A case of tumor of the pituitary body. Lancet, rgro, II, p. 1129 .

Boyd, W.: The Winnipeg epidemic of encephalitis lethargica. Jour. Can. Med. Assoc., 1920, X, No. 2.

Dandy, W. E., and Blackfan, K. D.: Internal hydrocephalıs; an experimental, clinical and pathological study. Am. Jour. Dis. Child., I9I4, VIII, p. 406.

Frazier, C. H. and Peet, M. H.: Factors of influence in the origin and circulation of the cerebrospinal fluid. Am. Jour. of Physiol., 19I4, XXXV. p. 3.

Frazier, C. H.: Types of hydrocephalus - their differentiation and treatment. Am. Jour. Dis. Child., 1916, XI, p. 95.

Mott, F. W.: The effects of high explosives upon the central nervous system. Lancet, I9 6 , I, p.p. 33I, 44I, and 545 . 


\section{CHAPTER XVII}

\section{ORGANIC DISEASES OF THE SPINAL CORD}

\section{TUMOR OF THE SPINAL CORD}

In tumors of the cord the cerebrospinal fluid may present very varying appearances. It may be quite normal, in which case the examination has no diagnostic value. On the other hand it may present appearances so characteristic that a positive diagnosis of pressure on the cord can be made on the pathological findings alone.

These significant findings about to be described are characteristic not of all cord tumors, but of those producing pressure on the cord with a resulting division of the canal into two segments, a large upper one in free communication with the remainder of the subarachnoid space, and a small lower one in which there is complete stagnation of the contained fluid. The pressure may be due to intra- or extra-medullary tumors of the cord, or to tuberculous or malignant disease of the spine. If an intra-medullary tumor fails to produce this subdivision of the spinal canal, the fluid will fail to show characteristic changes.

Two syndromes have been described in this connection. In 1903 Froin described 3 fluids which showed marked xanthochromia, high protein content, and spontaneous coagulation on standing, owing to the large amount of fibrin present. In 1908 Nonne pointed out that certain cases of spinal cord tumor were associated with a marked increase in globulin without a corresponding increase in cells. It is now recognized that the Nonne syndrome is an early stage of the Froin syndrome, and may develop into it. It is perhaps best to describe the condition as the Nonne-Froin syndrome. The complete picture comprises xanthochromia, spontaneous coagulation, increase of protein, and absence of lymphocytosis. 
It is quite unnecessary, however, that all of these should be present in order that a diagnosis of cord compression should be made. The most characteristic feature is the great protein increase without an increase of cells. This in itself, without any coloration or spontaneous coagulation of the fluid, is sufficient for a positive diagnosis, for in no other known condition does so remarkable a dissociation occur. Of the two cases which have come under my own observation, in one there was a clear fluid with very large protein excess but no pleocytosis and in the other there was in addition a typical xanthochromia.

According to Mestrezat a yellow coloration of the spinal fluid may be met with in icterus, in meningeal inflammation with intense vascular congestion, in minute meningeal hremorrhage of at least three days' duration, and in xanthochromia with massive coagulation.

Although characteristically absent it by no means follows that a lymphocytosis may not be met with. In syphilitic conditions or where there is some inflammation of the membranes of the cord there may be a cellular increase, but the protein will still probably be greatly in excess, and if massive coagulation and xanthochromia are present confusion will not arise.

That the Nonne-Froin syndrome is not confined to cases of tumor of the cord is shown by the observations, amongst others, of Sicard and Froin who published a series of observations on the spinal fluid in cases of active Pott's disease. In all of these the characteristic dissociation was present.

Babes has described a curious finding in certain cardiac cases whom he classifies as asystolique - patients in whom the heart is unable to contract in full systole. In Io such cases he found a marked yellow coloration of the fluid without other changes. There was no trace of bile in the fluid. He considered the condition to be due to stagnation of the blood and transudation of blood pigment through the vessel walls. He also found a similar coloration in some acute infections such as pneumonia and appendicitis, which he ascribes to a 
condition of abnormal permeability of the choroid plexus with consequent hæemolysis of red blood corpuscles.

The mechanism of the phenomenon has already been discussed. The prevalent view is that the color is due to blood pigment from multiple small hæmorrhages. It appears much more probable, however, that the condition is one of transudation of serum into the spinal cul-de-sac owing to pressure on the meningeal venous plexus. The composition of the fluid bears a close resemblance to that of a mechanical effusion into such a sac as the pleural cavity.

\section{SYRINGOMYELIA}

Kaplan states that in this condition there may be a marked protein increase without a pleocytosis. He mentions one case in which there was some degree of xanthochromia. These findings indicative of cord pressure are only what one would expect. In four other cases the fluid was normal.

\section{ACUTE MYELITIS}

Very few observations on the condition of the spinal fluid in this condition have been recorded. In one case of typical transverse myelitis under my observation there appeared to be a very small amount of fluid present, although punctures were made on several occasions. The fluid presented no other abnormality. A second case gave a very marked globulin reaction, with 30 cells per c. nm. The Wassermann reaction was negative. In both of these cases the fluid was sterile. Rehm describes similar findings in one case.

\section{ACUTE ANTERIOR POLIOMYELITIS}

Descriptions of the spinal fluid in poliomyelitis anterior acuta which have appeared in the past have varied in a somewhat surprising degree. One of the chief reasons for the divergence of opinion has probably been the different stages at which the cases have been examined, for the condition of the fluid changes very rapidly as the disease advances. The recent American epidemics have offered unrivaled opportuni- 
ties for investigating the disease in every stage, and a very considerable extension of our knowledge of the subject has been the result.

The fluid is usually under distinctly increased pressure. The pressure may, however, be normal. It is clear, and may show a good fibrin network on standing. In rare cases it may be slightly cloudy.

The cellular changes vary with the stage of the disease. In the earliest stage, that is to say before the onset of paralysis, there is usually a high cell count, consisting of polymorphonuclear cells and lymphocytes in varying proportions. The earlier the stage the higher is the percentage of polymorphs, which in some cases may reach to 80 or 90 . Cases with turbid fluid give a very high polymorph count. Large mononuclear or endothelial cells are sometimes present in considerable numbers, a finding always suggestive of poliomyelitis: In the prodromal stage Peabody, whose work on poliomyelitis is the most thorough and valuable contribution to the subject which we possess, found that the lowest cell count was 34 , the highest I980. Batten has pointed out that cases with meningeal symptoms give the largest cell counts.

As the disease progresses the cell count rapidly falls, so by the time that paralytic symptoms are well developed - at which time the fluid is most likely to be examined - the pleocytosis may be moderate or only very slight. A coincident change in the type of cell takes place, the polymorphs being almost entirely replaced by lymphocytes. By the end of the third week the cell count may have returned to normal.

A globulin increase is present which is in inverse ratio to the increase in cells. In the early stages it is slight, but increases with the progress of the disease, until it reaches a maximum by the third or fourth week. In no case, however, does the increase become excessive. It is almost always less than that found in tuberculous meningitis, the condition which most resembles poliomyelitis as regards the condition of the cerebrospinal fluid.

Josephine Neal has described two rare occurrences in 
poliomyelitis, namely true hæmorrhage in the fluid and the existence of the Froin syndrome. These probably indicate a very virulent and acute infection.

The fluid gives a well marked Fehling reduction. This is a point of very considerable importance in differential diagnosis, for the meningitic affections with which poliomyelitis is most likely to be confused show a diminution in glucose which is often very characteristic. Wollstein and other observers have investigated the question as to whether specific antibodies can be demonstrated in the fluid, but in no case has any trace of such antibodies been found.

An important recent contribution to the subject is that of Felton and Maxey on the colloidal gold reaction in the cerebrospinal fluid. These observers have found that the fluid gave a very constant reduction in the second or luetic zone, that is to say in dilutions of from $I$ in 40 to I in I6o. The reaction is most marked in the first week. In the second and third weeks it shows some tendency to weaken, but in many cases is still well marked. After the fourth week it diminishes and finally disappears.

In reviewing our knowledge of the changes in the cerebrospinal fluid in acute poliomyelitis it is evident that there is no one pathognomonic feature comparable with the presence of the meningococcus or the Wassermann reaction. The changes can in no sense be described as specific. And yet it would be a great mistake to think that an examination of the fluid is not of immense value in the practical task of arriving at a diagnosis. There is a modern tendency to demand too much from the laboratory. After all, in a large number of cases laboratory results do not give information which is absolutely specific, but merely afford an indication to the clinician which enables him to use his powers of discrimination and judgment in arriving at a correct diagnosis. A high leucocytosis in the blood may be met with in an immense variety of conditions, but that fact does not lessen its value as a means of differentiating between colic and acute appendicitis.

Acute poliomyelitis has to be differentiated from meningitic 
and non-meningitic conditions. The early prodromal stage before the onset of the paralysis is the time when it is most important to make a correct diagnosis. At this stage the disease may bear a close resemblance to a number of febrile conditions, in which, however, there is absolutely no involvement of the central nervous system. The age of the patient, the mode of onset, or still more the prevalence at the time of an epidemic of poliomyelitis may suggest to the physician the possibility of the disease. A lumbar puncture will at once settle the question, for the non-meningitic affection will show a normal fluid, whereas in every case of poliomyelitis at this early stage there will be pathological changes present.

The differentiation between poliomyelitis and acute meningitis is, however, a much more difficult task, in so far at least as the condition of the cerebrospinal fluid is concerned. The most valuable single point is the presence in meningitis of the causative organism. The meningococcus, pneumococcus, streptococcus, or tubercle bacillus can usually be demonstrated to the exclusion of poliomyelitis. These organisms, however, cannot always be found. In such cases the general character of the fluid must be taken into consideration. In meningitis due to the pyogenic organisms the fluid is almost always more or less turbid or purulent, and the cell count and protein increase are very much higher than in poliomyelitis. The proportion of polymorphs is always very high, which is never the case in poliomyelitis after the first two or three days. The Fehling reducing power of the fluid is commonly decreased or entirely lost in purtulent meningitis, whercas it is unaffected in poliomyelitis.

The difficulty of differentiation is perhaps greatest in the case of tuberculous meningitis, on account of the insidious nature of the onset, the frequent difficulty of detecting the tubercle bacillus, and the similarity between the fluids in the two conditions. In tuberculous meningitis the pressure is likely to be higher, the globulin reaction to be more marked in the early stages, and the Fehling reducing power to be diminished. A considerable number of polymorphs after the 
third or fourth day suggests meningitis. The presence of endothelial or large mononuclear cells in appreciable numbers, on the other hand, is fairly strong evidence, according to Abramson, of poliomyelitis as these cells are rarely met with in tuberculous meningitis.

The colloidal gold test usually gives a well marked reaction in all forms of meningitis in Zone 3 , that is to say, with dilutions higher than I-I6o. In poliomyelitis on the other hand, the reaction occurs in Zone 2 with dilutions between $\mathrm{I}-40$ and I-I6o. Tuberculous meningitis is again likely to prove the greatest stumbling block, for in this condition the maximum change tends to occur nearer the second zone than in the other forms of meningitis. In a series of comparative tests carried out by Jeans and Johnston, however, the poliomyelitis fluids gave a reaction with distinctly lower dilutions than did those from tuberculous meningitis.

It will be seen that although there is no single point in the chemical and cystological examination of the fluid of the same diagnostic value as the discovery of the tubercle bacillus, yet a reasoned consideration of the various facts disclosed will usually enable the physician to arrive at a correct conclusion. It is in the early preparalytic stage that the clinical signs are indeterminate, and fortunately this is the stage in which the laboratory evidence is most characteristic and convincing. $\mathrm{Up}_{\mathrm{p}}$ to the present it has not been possible to base the prognosis on the condition of the cerebrospinal fluid, for there may be no difference between the fluid of the cases which are going to terminate fatally and those which will make a good recovery.

The bacteriology of poliomyelitis is still in a very unsettled state, and it is impossible as yet to draw any definite conclusions from the work which has been done. Two main views have been advanced. Flexner and his co-workers at the Rockefeller Institute hold that the "globoid bodies" which they have isolated from the brain and corcl of cases of poliomyelitis are the causal agent of the disease. This organism has been ișolated in culture, and animal inoculations 
have reproduced in monkeys lesions which are said to be characteristic of the condition.

Mathers, Rosenow, Nazum and Herzog, and others have isolated a streptococcus from the central nervous system which, according to them, is capable of reproducing the disease in monkeys. Nazum described the presence of this organism in the cerebrospinal fluid of cases of poliomyelitis. The most recent work of Rosenow and Towne offers a suggested explanation of the differences in the results of the two sets of workers. The streptococci isolated from the spinal cord maintain the form of diplococci under ordinary aërobic conditions. With a medium containing ascitic fluid and fresh sterile tissue, however, they gradually diminish in size by transverse fission, and in the course of ten days a pure growth of globoid bodies may be obtained. Rosenow and Towne are of the opinion that the globoid bodies of the Rockefeller Institute workers are in all cases the result of the breaking down of large diplococci. More cannot be said on the subject until further work has confirmed or disproved the results of the different investigators.

\section{SUBACUTE COMBINED DEGENERATION}

Very few observations on the cerebrospinal fluid in this interesting condition are on record. I have only had the opportunity of examining two cases. The blood and neurological pictures were quite typical, but the spinal fluid showed little change. There was a very slight increase of globulin, but the cell count was normal. Kaplan, however, describes three cases in which the changes resembled those seen in compression of the cord - very marked globulin increase with no pleocytosis.

Cases of pernicious anæmia with cord changes which often bear so close a resemblance to subacute combined degeneration that it is difficult to know where to draw the line of distinction, present a perfectly normal fluid. That is to say, our present methods fail to detect any abnormality. It is almost inconceivable, however, that in a condition where toxins 
must certainly be acting upon the cord the fluid which bathes the cord is in reality normal.

\section{MULTIPLE SCLEROSIS}

In a series of I 8 cases which I examined no constant pathognomonic change was found. The fluid was clear and under normal pressure. In about a quarter of the cases it showed no change. In most of the cases, however, there was a slight to moderate lymphocytosis, never exceeding 30 cells per c. mm. The globulin showed a slight increase, but to a somewhat lesser extent. Multiple sclerosis is such a characteristically toxic disease that it is desirable that inoculation and other experiments should be performed in as many cases as possible, and at different stages of the disease. Bullock succeeded in producing suggestive lesions in a rabbit by the injection of cerebrospinal fluid from a case of multiple sclerosis.

\section{HERPES ZOSTER}

The pathological basis of herpes zoster bears a very close resemblance to that of anterior poliomyelitis, and this relationship is reflected in the condition of the cerebrospinal fluid. In true herpes zoster and in herpes due to inflammation of the ganglia on the cranial nerves there is a well marked cellular increase, the average number of cells being as a rule about 50 per c. mm. The cells are mainly small lymphocytes, but in some cases a considerable number of large lymphocytes are found. The pleocytosis may last for several weeks after the herpetic eruption has completely disappeared. The globulin may show a slight increase but the fluid in other respects appears to be normal.

\section{REFERENCES}

Amoss, H. L.: The cultivation and immunologic reactions of the globoid bodies in poliomyelitis. Jour. Exper. Med., I9I7, XXV, p. 545 .

Abramson, H. L.: The spinal fluid in poliomyelitis and its differentiation from fluids of other infections. Am. Jour. Dis. Child. 19I5, p. 344 . 
Babes: La xanthochromie du liquide céphalo-rachidien chez les asystoliques. Rend. Soc. de biol. I9I4, LXXVI, p. 313.

Babes: La xanthochromie du liquide céphalo-rachidien dans d'autres maladies que les hemorragies cérébrales, les affections du névraxes et l'ictère. Comp. rend. Soc. de biol. I9I4, LXXVI, p. 67 .

Batten, F. G.: Acute poliomyelitis. Lumleian Lectures, Lancet, I9I6, I, p. 8I I.

Bromer, R. S.: The syndromes of coagulation massive et xanthochromie occurring in a case of tuberculosis of the cervical spine. Amer. Jour. Med. Sc., I916, CLI, p. 378.

Felton, L. D. and Maxey, K. F.: The colloidal gold reaction of the cerebrospinal fluid in acute poliomyelitis. Jour. Am. Med. Assoc., I9I7, LXVIII, p. $75^{2}$.

Flexner, S. and Noguchi, H.: Experiments on the cultivation of the microörganism causing epidemic poliomyelitis. Jour. Exper. Med., I913, XVIIII, p. 46I.

Jeans, P. C. and Johnston, M. R.: The cerebrospinal fluid in poliomyelitis with special reference to the Lange reaction. Amer. Jour. Dis. Child., 19I7, XIII, p. 239.

Kaplan: Serology of Nervous and Mental Diseases.

Mathers, G.: Some bacteriologic observations on epidemic poliomyelitis. Jour. Am. Med. Assoc., 1916, LXVOO, p. Iorg. Jour. Infect. Dis., I9I7, XX, p. II3.

Neal, J. B.: Laboratory aids in the diagnosis of poliomyelitis. Arch. of Pediatries, 1916, XXXIII, p. 595.

Nuzum, J. W.: Bacteriologic findings in cerebrospinal fluid in poliomyelitis. Jour. Am. Med. Assoc., I916, LXVII, p. 1437.

Peabody, F. W.: The cerebrospinal fluid in poliomyelitis. Jour. of Nervous and Mental Diseases, Feb. I917.

Peabody, F. W., Draper, G., and Dochez, A. R.: A clinical study of acute poliomyelitis. Monographs of the Rockefeller Institute, No. 4, 1912.

Rosenow, E. C. and Wheeler, G. W.: The etiology of epidemic poliomyelitis. Jour. Am. Med. Assoc., 1916, LXVII, p. I202.

Rosenow, E. C. and Towne, E. B.: Bacteriological observations in experimental poliomyelitis of monkeys. Jour. Med. Research, 1917, XXXVI, p. I75.

Sicard and Froin: Dissociation albumino-cytologique au cours des compressions rachidiennes. Presse med., I9I4, XX, p. Ior3.

Wollstein, M.: A biological study of the cerebrospinal fluid in anterior poliomyelitis. Jour. Exper. Med., 1908, X, p. 476. 


\section{CHAPTER XVIII}

\section{MENTAL DISEASES}

The blood shows so many changes in various pathological conditions affecting the body that it might be confidently supposed that the cerebrospinal fluid which bathes the inmost recesses of the brain would show similar changes in mental disease. And yet, with the exception of those forms of insanity due to syphilis, the results have been distinctly disappointing. This is all the more remarkable because in some of the acute psychoses the evidence of an acute irritant being at work is in many cases very striking. The temperature is raised, the tongue coated, and the blood shows in many cases a well marked leucocytosis. Under these circumstances it might be supposed that, as the most striking symptoms are those indicative of the action of an irritant on the brain, some corresponding change would be found in the fluid which subserves the function of the lymph of the brain.

\section{MANIC-DEPRESSIVE INSANITY}

In a long series of cases of manic-depressive insanity, I uniformly failed to find any change in the spinal fluid, even during attacks of the greatest excitement. Other workers have obtained similar results. I cannot but feel that the explanation of these negative results lies in the coarseness of the methods at our disposal. If there is not a cellular or a globulin increase we conclude that the fluid is normal. The future, however, is certain to give us methods of greater refinement, and when these are employed it is more than likely that important changes will be found in the spinal fluid in the toxic psychoses. 


\section{EPILEPSY}

Epilepsy is one of those convenient all-embracing terms in which medicine still abounds, which can be made to include an indefinite number of different conditions. It is only natural, therefore, that some difference of opinion should exist concerning the condition of the cerebrospinal fluid. A number of cases of epileptic convulsions are undoubtedly. syphilitic. The majority of cases, however, must still be classed as idiopathic. In these it is the rule to find no changes in the spinal fluid. In five such cases, however, I found a moderate lymphocytosis, ranging from twenty to forty, together with a corresponding increase in globulin. One of these cases was sufficiently interesting to merit a brief description. The patient was a man of fifty-three years, whis was admitted in a restless excited condition, with marked delusions and hallucinations. His cerebrospinal fluid on admission showed no increase in cells, and those present were all small lymphocytes. He settled down and became quiet and rational. Six months later he had a severe epileptic fit and became excited, with vivid visual and auditory hallucinations. The cerebrospinal fluid was examined and found to contain 39 cells of which 68 per cent. were small lymphocytes and 32 per cent. large lymphocytes. The fluid was examined on five successive days, and each time time a marked lymphocytosis was present, the number on the last occasion being 8o. The most probable explanation is that both the fit and the lymphocytosis had a common toxic origin.

\section{DEMENTIA PRAECOX}

In dementia precox the spinal fluid is not supposed to show pathological changes, and certainly in the katatonic and paranoid forms this is usually the case. In Io cases of the hehephrenic type, however, there was a marked lymphocytosis together with some globulin increase. These cases were mostly young adults who had sunk into a dull, phlegmatic, lethargic condition in which the chief feature wạ an almost 
entire loss to emotional response. They knew neither joy nor grief, and all emotional contact with the outer world seemed to be severed. These cases were examined on several occasions, and each time the cell count was above normal.

\section{ALCOHOLISM}

In chronic alcoholic insanity the fluid is quite normal, a point of great value in the differentiation from general paresis. Alcoholic neuritis also gives a normal fluid, in marked distinction to tabes dorsalis, with which it may sometimes be confused. In acute alcoholism Schottmüller and Schumm have demonstrated the presence of alcohol in the spinal fluid by means of the iodoform test. Acetone and diacetic acid have been described as occurring in the fluid in delirium tremens.

\section{IDIOCY AND IMBECILITY}

The application of the Wassermann test to the blood and spinal fluid in these conditions has shown that a considerable proportion are syphilitic in origin. Such cases show the usual syphilitic changes in the spinal fluid. Non-syphilitic cases present an absolutely normal fluid.

Other forms of mental disease, as far as is known, present no abnormalities in the spinal fluid.

\section{REFERENCES}

Boyd, W.: The cerebrospinal fluid in certain mental conditions. Jour. Mental Sc., I9I2, LXVIII, p. 203.

Schottmïller and Schumm: Nachweis von Alkohol in der Spinalflussigkeit von Saufern. Neurolog. Centralblatt, August, I912. 


\section{CHAPTER XIX \\ GENERAL DISEASES}

\section{DIABETES}

In diabetes mellitus the sugar content of the spinal fluid closely parallels that of the blood. It thus differs, as Hopkins has pointed out, from the condition found in acute infectious hyperglycæmia without any accompanying increase in the cerebrospinal sugar. In diabetic coma the increase is usually very marked and as much as 0.5 per cent. of glucose may be found in the fluid. A very high sugar content is of great diagnostic and prognostic importance. It is not an invariable rule, however, that cases in which coma is threatened should show this great increase in sugar and its absence is not sufficient evidence for a negative diagnosis, although it would be one point against it. The presence of sugar in the fluid depends not only upon a condition of hyperglycæmia but also upon interference with the selective action of the choroid plexus.

More important is the appearance of acetone in the fluid. This is never present except in cases of coma or unless coma is impending. In obscure cases of coma in which a sample of the urine cannot be obtained very great assistance may therefore be afforded by the examination of the cerebrospinal fluid. Diacetic acid is found more rarely, and its presence is always an indication of the extreme gravity of the case.

\section{UREMIA}

In uræmic convulsions and in eclampsia the cerebrospinal pressure is raised and the amount of fluid increased. Even in uræmia without convulsions the pressure is often above normal. In a number of cases of uræmic convulsions a con- 
siderable lymphocytosis has been found, but this is not a constant feature.

In all uræmic states, whether accompanied by convulsions or not, an estimation of the urea content of the cerebrospinal fluid is of the greatest value both in diagnosis and prognosis. It parallels in a remarkable way the urea content of the blood, but while the estimation of the latter is a matter of some difficulty demanding refined methods of chemical analysis, that of the former can be carried out with the greatest ease. An examination of the cerebrospinal fluid thus affords a ready method of estimating the degree of urea retention in the body.

The normal urea content of the cerebrospinal fluid varies from 0.01 to 0.05 or 0.06 per cent. Anything above this must be regarded as indicating some degree of urea retention. According to Mestrezat cases of renal impermeability to urea without any symptoms of uræmia may show a urea content up to o.I per cent. In true uræmia the urea content may be anything from o.I to o.6 per cent. The variations in the amount of urea closely correspond with those of the blood. In practice it is often found that cases of cardio-vascular disease show signs and symptoms highly suggestive of true uræmia, but in such cases, as Canti has pointed out, the urea content of the spinal fluid remains normal. An estimation of the cerebrospinal urea is therefore a valuable aid in diagnosis, and in cases which are seen for the first time in a state of coma it may be the only method available.

Nor is it of any less value in questions of prognosis. All the work which has been done so far tends to prove that the higher the urea content the graver is the prognosis. The critical figure may be taken as 0.3 per cent. According to Mestrezat cases which exceed that figure are almost invariably fatal, whereas those below that figure may be regarded as curable, and many of them recover. Soper and Grant arrived at somewhat similar conclusions. They consider that if the urea content only reaches o.I per cent. no prognostic conclusions can be drawn. Between o. I and 0.2 per cent. 
many of the cases proved fatal. Above 0.2 per cent. all the cases showed severe uræmia and ran a speedy course.

The estimation of the urea is conveniently carried out by the hypobromite method. To 5 c.c. of cerebrospinal fluid are added 25 c.c. of 40 per cent. potassium hydrate and 2.2 c.c. of bromine, and the result is read in a Doremus ureometer.

Wells, using the more delicate urease method as modified by Van Slyke, found that there was a close relation between the urea nitrogen and the total non-protein nitrogen both in the blood and the spinal fluid.

The retention of chlorides in the body so characteristic of uramia is reflected in the cerebrospinal fluid. The normal chloride content of the fluid is 0.73 per cent. In uræmia and eclampsia this may be increased to 0.8 or more.

After eclamptic seizures considerable quantities of lactic acid may be present in the fluid, as much as 4 per cent. having been recorded. In the normal fluid there is either none present or only the merest trace. The Uffelmann test is not suitable for demonstrating the presence of lactic acid in the spinal fluid, and that of Reichmann should be used. At least Io c.c. of spinal fluid are treated with 5 c.c. of $9^{6}$ per cent. alcohol, and filtered after an interval of i 2 hours. The filtrate is washed, treated with hot alcohol, and dried. The residue is placed in a test tube to which are added 3 drops of decinormal $\mathrm{H}_{2} \mathrm{SO}_{4}$ and then Io c.c. of ether, the whole being well shaken. A dilute solution of ferric chloride is placed in two test tubes, to one of which is added the etherial extract. A pale golden color, which can be compared with the control tube, indicates the presence of lactic acid.

\section{CHOREA}

The etiology of chorea is still uncertain. It certainly appears to bear a close relationship to acute articular rheumatism. Several attempts have been made to associate chorea with syphilis. In order to try to settle these points several small series of observations have been made on the spinal fluid.

Such observations conclusively prove that syphilis bears 
no etiological relationship to the disease. Koplik examined the spinal fluids in Io cases, and in all the Wassermann reaction was negative. Marie and Chatelin in I9I2 and Comby in 19 I 5 had already obtained similar results.

In many cases of chorea, however, there is some evidence of the action of an irritant on the central nervous system as shown by the presence of a leucocytosis. A number of French observers - Thomas and Tinel, Claude, and others - have described the occurrence of a marked lymphocytosis. No extensive series of cases has been reported, however. In a small series of 7 cases I found the fluid perfectly normal, except that in one case there was a slight lymphocytosis of 17 per c. mm. In a series of Io cases Morse and Floyd had three with counts of 18,24 , and 25 .

Many observations have been made on the bacteriology of the fluid during life, but with negative results. Poynton and Paine succeeded in isolating the organism which they term the diplococcus rheumaticus from the spinal fuid post-mortem in three cases which died of acute rheumatism complicated by chorea. They figure these organisms together with the cellular exudate in their paper.

\section{MUMPS}

It might be thought that mumps was hardly the type of disease in which changes in the cerebrospinal fluid might be expected. And yet in a considerable number of cases meningeal complications may occur. These vary in intensity from restlessness with signs of cerebral irritation to delirium and paralysis of cranial nerves. It is but natural that the cases with cerebral complications are the only ones in which a systematic examination of the cerebrospinal fluid has been conducted, but in these cases a very constant change has been observed, namely a great increase in the number of lymphocytes without a corresponding increase in the globulin. There may be several thousand cells per c. mm., over 90 per cent. of which are lymphocytes. These changes have been described by a number of French writers such as Dopter and 
Sicard as occurring in cases of involvement of the cranial nerves with an accompanying herpes. Feiling has pointed out that a lymphocytosis may occur in mumps where there has been no evidence of an organic lesion of the nervous system. Some experiments by M. H. Gordon serve to illustrate the distinct affinity which the virus of mumps has for the meninges. Patients suffering from parotitis were made to gargle their mouths with saline solution. The saline was passed through a Berkefeld filter and was found to be sterile. It was then injected into the brains of monkeys. Half the monkeys injected developed meningitis, and in one the fluid during life contained I,500 cells per c.mm., of which 82 per cent. were lymphocytes.

In I9I3 Gordon described four fatal cases of illness occurring in children, in which the chief feature was symptoms of marked cerebral irritation. All of the cases showed acute interstitial parotitis, but they were in no way typical examples of mumps, for the glandular tissue proper appeared to have entirely escaped. The cerebrospinal fluid was examined and showed a very marked lymphocytosis, in one case there being 6,800 cells per c. mm. The pia mater showed slight congestion, and a variable degree of lymphocytic infiltration, but no definite evidence of meningitis. There were no lesions suggestive of poliomyelitis in the brain or cord. The foci in the parotids consisted of dense infiltration of lymphocytes, so marked that in places the glands closely resembled a lymph node. In spite of this, however, there were no clinical signs of parotitis during life. Gordon is of the opinion that either the condition was the result of an unusual action of the virus of mumps, or that it was a form of a disease which has not hitherto been recognized. The marked cerebrospinal lymphocytosis occurring apart from mumps was a very striking feature, and the possibility of other cases of this disease being encountered should be borne in mind. In such cases, of course, tuberculous meningitis must be first excluded. 


\section{PNEUMONIA}

Few observations have been made on the spinal fluid in pneumonia apart from those cases which show evidence of developing pneumococcal meningitis. Rohdenburg and Vander Veer made a series of observations on the condition of the fluid in all cases of pneumonia admitted to hospital, whether these manifested symptoms of meningeal irritation or not. The only case of the series which showed meningeal symptoms was the only one with a turbid spinal fluid. The remaining cases, however, showed various pathological changes in a remarkable number of instances. The observers considered that these changes were of distinct prognostic value. Should further work confirm these results it may furnish the clinician with an additional means of arriving at a correct prognosis in a disease in which prognosis is always difficult.

Pneumococci were found on culturing the fluid in a much higher proportion of the fatal cases than in those which recovered. Of the fatal cases 87 per cent. showed pneumococci in the fluid, whereas those which recovered only gave I3 per cent. The average cell count of those who died was 212; that of those recovering was 50 . In the sterile fluid the count was much lower. There is need for further observations of this nature on other series of cases.

\section{SLEEPING SICKNESS}

Of all the observations on the cerebrospinal fluid none have been of greater importance than those in sleeping sickness. For it is now known that sleeping sickness is but one manifestation of that very widely spread tropical disease, trypanosomiasis, and that the fatal symptoms do not make their appearance until the trypanosomes have succeeded in passing from the blood to the cerebrospinal fluid.

In many ways the disease bears a close resemblance to general paresis. In both conditions the nervous lesions may be preceded for a long time by a systemic infection. In both, one of the chief features is a lymphocytic infiltration of the 
meninges and the perivascular lymphatic sheaths. In both a lymphocytosis occurs in the cerebrospinal fluid.

The ordinary worker rarely has the opportunity of observing such a case, but it appears that the cytological picture in the fluid is similar to that of general paresis. The most characteristic feature, however, is the presence in the spinal fluid of Trypanosoma gambiense.

\section{TRICHINOSIS}

The absolute diagnosis of trichinosis is not usually a simple matter. The general symptoms and especially the characteristic eosinophilia in the blood may point strongly to the probability of an infection with Trichina spiralis, but unless a piece of muscle be excised and the larvæ demonstrated, absolute certainty can hardly be attained.

It has lately been discovered that in a number of cases an early infection of the cerebrospinal fluid occurs. Strange though it may appear, the larvæ have the power of making their way into the spinal fluid, and can be demonstrated there with ease. Linty reports three cases in which several motile embryos were present in every field of the centrifuged deposit, although there was no increase of the cells or globulin. If further work shows that this cerebrcspinal invasion is an early and constant feature, a new and valuable means of diagnosis will have been placed in the hands of the clinician.

Although eosinophils are so numerous in the blood in this condition, they have not been reported as occurring in the cerebrospinal fluid. Occasionally, however, the spinal fluid may respond in this way to infection by animal parasites. Two cases of infection of the brain by Cysticercus cellulose were accompanied by a marked eosinophilia in the cerebrospinal fluid as well as in the blood. Such a condition may be taken as pathognomonic of animal parasitic infection of the central nervous system. 


\section{REFERENCES}

Canti, R. G.: The urea content of the cerebrospinal fluid, with special reference to the diagnosis of uræmia. Lancet, I9I6, I, p. 366.

Claude, H.: Deux cas de Ehorée persistante avec signes de lesions anatomiques legères de systc̀me nerveux. Rev. neurol., I909, XVII, p. 93 I.

Dopter. Paralysie faciale ourlienne; lymphocytose du liquide céphalo-rachidien. Bull. et mém. Soc. méd. d. hôp. de Paris, 1904, XXI, p. 9I2.

Feiling, A.: The blood and the cerebrospinal fluid in mumps. Lancet, I9I3, II, p. 7I.

Feiling, A. Mumps: a critical review. Quart. Jour. Med., 1915, VIII, 255.

Gordon, M. H.: A fatal illness in children associated with acute interstitial parotitis. Lancet, 19I3, II, p. 275.

Gordon, M. H.: Reports Local Government Board, New Series, No. 96, 1914.

Hopkins, A. H.: The sugar content of the spinal fluid in meningitis and other diseases. Am. Jour. Med. Sc. I915, CL, p. 827.

Koplik, N.: The etiological relationship of syphilis to the chorea of Sydenham. Arch. Pediat., 1915, XXXII, p. 378.

Linty, W.: Trichinosis and the cerebrospinal fluid. Jour. An. Med. Assoc., I9I6, LXVI, p. I856.

Marie, P. and Chatelin, C.: Sur les effets favourables des injections intra-veineuses de salvarsan dans 25 cas de Chorée de Sydenham. Bull. de l'Acad. de méd., Paris, I9I2, LXVIII, p. 507.

Morse, J. L. and Floyd, C.: A study of the etiology of chorea: Am. Jour. Dis. Child., I9I6, XII, p. 6r.

Poynton, F. J. and Paine, A: Some observations on the nervous manifestations of acute rheumatism. Lancet, I905, II, p. I760.

Reichmann: Zur Physiologie und Patologie des Liquor cerebrospinalis. Deutsche Zeitschr. f. Nervenheilkunde Bd. 42, H. 1 u. 2.

Rohdenburgh, E. L. and Vander Veer, A.: The spinal fluid in pneumonia. Jour. Am. Med. Assoc. I915, LXIV, I227.

Sicard. J. A.: Un ces d'oreillous, avec zona du trijumeau et lymphocytose rachidienne. Bull. et mém. Soc. Med. d'hôp de Paris, I905, XXII, p. 135 .

Van Slyke and Cullen: A permanent preparation of urease and its use in the determination of urea. Jour. Biol. Chem. I9I6, XIX, p. 22I.

Soper, W. B. and Grant, S,: The urea content of the spinal fluid 
with special reference to its diagnostic and prognostic significance. Arch. Int. Med., I9I2, XIII, p. I3I.

Thomas and Tinel: Hemichorée et signes de lesion organique du système nerveux central. Lymphocytose du liquide céphalo-rachidien. Rev. Neurol., 1909, XVII, p. 638.

Waterhouse, R.: Cysticercus cellulosæ in the central nervous system. Quart. Jour. Med., 1913, VI, 469.

Wells, A. C.: Studies of nitrogen partition in the blood and spinal fluid. Arch. Int. Med., I915, XVI, p. 577.

Zweifal: Zur Anklarung der Eklampsie: Archiv. f. Gyn., 1905, 76. (Quoted by Kaplan.) 


\section{CHAPTER XX}

\section{THERAPEUTICS}

Lumbar puncture was originally introduced by Quincke with the object of relieving intracranial pressure. In the 25 years which have elapsed since then interest has been mainly centered on the diagnostic possibilities of the examination of the cerebrospinal fluid. Recently, however, therapeutics have again claimed attention, and a number of important advances in this direction have been made.

\section{LUMBAR PUNCTURE}

The original conception of lowering intracranial pressure by lumbar puncture has been widened and applied to a variety of conditions. At the same time it is recognized that the operation is not devoid of danger, and that certain precautions must be observed. The possibility of accidents occurring during the withdrawal of fluid in cases of cerebral tumor has already been discussed.

In a large number of diseases symptoms of increased intracranial tension may appear, and in many cases relief of these symptoms may be afforded by lumbar puncture. It is only possible to give the briefest summary of such cases.

The value of lumbar puncture in uræmic coma and eclampsia has already been commented on. Many cases have been reported in which brilliant results have followed this simple operation. Thus Wilson described two cases of puerperal eclampsia which had each had more than 20 convulsions. The patients were in a very serious condition and were rapidly passing into a state of coma. All methods of treatment had been tried, but without avail. The withdrawal of 40 c.c. by lumbar puncture was followed by speedy relief, the con- 
vulsions ceased, the threatened coma passed off, and both patients made a good recovery. I have seen a similar result in a case of commencing uramic coma, and the method is well worthy of trial in every case in which there is reason to believe that a condition of cerebral œedema may exist.

The persistent headaches which sometimes constitute so troublesome an accompaniment of anæmia may be greatly relieved by lumbar puncture. From 5 to io c.c. of fluid may be withdrawn at intervals, relieving the tension within the skull and allowing the intracranial conditions to return to a state of normal equilibrium. The headaches of newrasthenia and other nervous conditions may be benefited by similar treatment.

A not uncommon manifestation of disturbed intracranial tension is disturbance of the auditory mechanism. Deafness, tinnitus, and auditory vertigo may be associated with high cerebrospinal pressure, and the symptoms may be wonderfully relieved by a series of lumbar punctures. Babinski describes one case, aged 35, who had been a deaf mute for over two years, but who could hear a voice at $20 \mathrm{c} . \mathrm{m}$. after three lumbar punctures. In this case I5 c.c. of fluid were withdrawn on each occasion. The most promising cases are those of persistent tinnitus. An intimate relationship exists between the pressure of the cerebrospinal fluid and that of the perilymph and endolymph of the labyrinthine canal, and some cases of tinnitus and vertigo are undoubtedly due to disturbance of this relationship. Typhus fever may sometimes be accompanied by deafness, which is uswally greatly relieved by lumbar puncture.

Convulsions in children, of which the etiology is frequently so indeterminate, may often be more quickly relieved by lumbar puncture than by any other therapeutic measure. In one case of convulsions in an infant the paticnt was almost moribund as the result of a long series of fits. The fontanelle showed marked bulging and the intracranial pressure was evidently considerably increased. Withdrawal of a clear and apparently normal fluid under pressure prevented the child 
from having any more fits for a week. At the end of that time they returned, and the fontanelle was again found to be bulging. A second withdrawal was again successful for another week. Once more the fits returned, but the third puncture effected a complete cure, and the child has remained well ever since. Apparently a disturbance in the intracranial equilibrium had occurred which was purcly temporary, and when the immediate danger had been tided over the disturbed balance returned to normal. It is probable that these disturbances may readily occur in children, and in lumbar puncture we have a really valuable means of dealing with the emergency. They are examples of a mild form of what has already been described as hypersecretive hydrocephalus.

In rare cases it may happen that although there are marked signs of high intracranial tension lumbar puncture affords no relief and the pressure of the spinal fluid does not appear to be raised. In such cases, which are really examples of internal or obstructive hydrocephalus, it may be permissible to puncture the lateral ventricle through the anterior fontanelle. Fischer has described a case of very severe convulsions following whooping cough in a baby of 8 months. All forms of treatment including lumbar puncture were of no avail, but the withdrawal of 22 c.c. of clear cerebrospinal fluid from the right ventricle of the brain was followed by an immediate cessation of the convulsions and the complete recovery of the patient. The needle was introduced downwards and towards the middle line to a depth of $\mathrm{I} .8$ inches at an angle of 20 degrees.

The question of the advisability of lowering intracranial pressure by lumbar puncture in cases of cerebral tumor is a debatable one. It has already been emphasized that this is the one condition in which the greatest caution must be exercised. Tumors in the posterior fossa should not be decompressed in this way. The danger is too great, and in any case only a very small quantity of fluid could be withdrawn. In tumors situated in the anterior and middle cranial fossa, however, a spinal decompression sometimes provides a useful 
and simple means of relieving the headache and the optic neuritis. A large quantity of fluid should not be withdrawn at once, but a number of small amounts on frequent occasions.

Lumbar puncture has proved a useful measure in a variety of war injuries. Many cases of hernia cerebri have derived benefit from repeated tappings, but great caution must be used, as there is a distinct danger that localized pockets of pus may become disseminated if the pressure is suddenly lowered. In concussion and shell shock the cerebrospinal pressure may be markedly increased, and in such cases lumbar puncture will be found of great value.

A curious and interesting example of the diverse uses to which lumbar puncture may be put is afforded by a case recently published by Costa. The case was one of podalic extraction with central placenta previa. The head of the child could not be delivered, so lumbar puncture was performed. As the head passed through the inlet fluid gushed from the needle and ceased when the head emerged. It is estimated that the diameter of the head can be diminished 0.5 c.m. by this means.

\section{THE SERUM TREATMENT OF MENINGITIS}

The mortality from meningococcal meningitis used to average about 80 per cent. Both in the American and in the English epidemics it was seldom that the death rate fell below 75 per cent. In 1907, however, Simon Flexner introduced the intraspinal use of antimeningococcal serum, and the mortality at once showed a marked and sudden drop. In most recent epidemics the figure has ranged between 25 and 30 per cent.

In the winter of I9r4-I5 at the outbreak of the war there were a large number of cases of epidemic meningitis owing to the great bodies of men collected in barracks and camps. These cases were treated by the injection of serum, but the results were very unsatisfactory. The same was true for the cases which came under my observation in Belgium. In these latter cases we got quite as good results by frequent lumbar 
puncture as by the use of serum. It was considered at the time that the disappointing results were probably due to the strains of meningococci which caused the disease being different from those with which the serum was prepared. Now, however, it appears certain that the serum used was of poor quality. Fresh samples of serum were obtained, and the mortality again fell to below 30 per cent.

Much depends on the promptness with which the serum is administered. The earlier in the disease it is given the better are the results. It is well to go to a suspected case armed with serum, a microscope, and the means for preparing a film. A diagnosis can be made at the bedside, and if the meningococcus is found the serum can be given on the spot. Even if laboratory facilities are not available the serum should be taken, and injected if the fluid is at all turbid, or if it fails to reduce Fehling's solution.

The technic is very simple. A large-sized lumbar puncture needle is introduced into the subarachnoid space, and as much or more fluid withdrawn as it is intended to inject. This is absolutely cssential, and in itself is a measure of proved therapeutic value. A sterile glass funnel or cylinder the barrel of a 20 c.c. syringe will do perfectly - and a rubber tube about $\mathrm{I} \delta$ inches in length are attached to the needle by a metal connection, and the serum, heated to body temperature, is run in by gravity. The inflow may be fast or slow, but however slow the temptation to use pressure with a syringe should be resisted. If not, the consequences may be disastrous. If the proper amount of spinal fluid has been withdrawn, sufficient patience exercised, and the patient directed to take deep breaths, no pressure need ever be used. A general anæsthetic may be necessary, especially in children. Each case must be decided on its own merits.

The usual dose of serum is 30 c.c. In children half that quantity may be used. If a large amount of fluid can be withdrawn the dose may be increased in very serious cases. The question of how often the serum should be given is an important one. It should certainly be continued until definite 
clinical improvement has taken place. It must be remembered that an apparent improvement may occur about the second or third day, followed by a relapse. It is therefore advisable to give the serum for at least three days. In severe cases a much larger number of doses will be required. The bacteriological content of the fluid is not very reliable as a guide in prognosis, and it must be borne in mind that the ventricular fluid may be swarming with meningococci, although none can be found in the spinal fluid. Acute meningitis is no longer regarded as merely an infection of the meninges; it is rather a local manifestation of a general blood infection. It is good practice, therefore, to combine intravenous with intraspinal injections, using for that purpose 30 c.c. or more of the serum.

The bacteria rapidly degenerate and disintegrate so that after the first injection it is not usually possible to obtain a culture, and after the second or third the organisms lose their staining reaction. The cytology of the fluid, however, affords more valuable indications as to the success of the treatment, and it is most interesting to watch day by day the cell count gradually dropping, and the polymorphs being replaced by lymphocytes. The turbidity at the same time progressively diminishes.

Occasionally the serum may produce an inflammatory reaction which it may be difficult to distinguish from a true relapse. The fluicl again becomes turbid, and large numbers of polymorphs make their appearance. In such cases the estimation of the sugar is of great value. As the patient improves the Fehling-reducing power of the fluid gradually returns. In a true relapse it promptly disappears owing to the renewed activity of the sugar-splitting organisms. In the pseudo-relapse due to the irritation of the serum, on the other hand, the Fehling-reducing power is unaffected.

It may happen that no serum is available for treatment. In such cases lumbar puncture should be done every day, at least 30 c.c. being withdrawn. The physician is often too timid in the amount of fluid which he withdraws. I have 
drawn off 70 c.c. of fluid from a boy of 12 on three successive days, and the only effect was the most marked relief of the headache and other clinical symptoms. It is somewhat remarkable that the more abnormal the fluid the less disturbance does its withdrawal produce. It is in the normal person that the withdrawal of even small quantities of fluid is apt to produce unpleasant results of some severity. The withdrawal of large quantities of purulent material is a sound physiological and surgical procedure. It is simply opening an abscess, draining thoroughly, lowering the pressure, and allowing fresh serum containing antibodies to pour in from the blood. It is obviously not sufficient to do this once, any more than it is enough to dress a septic wound once. The procedure must be repeated daily. Even when serum treatment has been discontinued it is well to continue the spinal drainage till the fluid has returned to a fairly normal condition.

After the administration of each dose of serum it is well to raise the foot of the bed on blocks so that the serum may the more readily reach the brain.

It occasionally happens that the clinical signs point conclusively to the existence of an obstruction to the outflow of the ventricular fluid. In such cases lumbar puncture and intraspinal administration of serum are useless. The lateral ventricle must be drained and serum given by that route. This operation is not so difficult as might be imagined. In the case of children in whom the fontanelle is still open the needle is introduced at the lateral angle of the fontanelle, and passed downwards and inwards for $1 \mathrm{I} / 2$ inches. If the fontanelle is closed a trepine opening is made at a point a little behind it and to one side of the middle line, so as to miss the superior longitudinal sinus.

The injection of a variety of antiseptic substances has been tried in the treatment of meningitis, but none have given any satisfaction. Pneumococcal and streptococcal cases should be treated by repeated spinal drainage. As the former is such a fatal illness it may be well to mention a case reported by 
Wolff and Lehmann, in which typical pneumococcal meningitis was treated by injections of optochin (ethylhydrocuprein), which has a specific action on the pneumococcus. The drug was injected into the spinal canal, the ventricles and under the skin. The patient made a good recovery. The intraspinal dose was 0.03 grams.

\section{TUBERCULOUS MENINGITIS}

The treatment of tuberculous meningitis has been in the past one of masterly inactivity. Frequent lumbar punctures may relieve the headache, but fail to affect the course of the disease. Any new method is, therefore, worthy of trial. Bacigalupo treated three cases, in which tubercle bacilli were present in the spinal fluid, by intraspinal injections of tuberculin. The first was a hopeless case, for it was complicated by general miliary tuberculosis, and the patient could hardly have been expected to recover. Of the other two cases, one received two and the other three injections, and in the course of 20 days they both made a good recovery. The usual dosage of tuberculin is employed, depending largely upon the age of the paticnt.

\section{POLIOMYELITIS}

The serum treatment of poliomyelitis may be considered here. It is an unfortunate fact that it has not so far been possible to produce an efficient antipoliomyelitic serum from the horse. Flexner found, however, that the intraspinal injection into an ape of the serum of another ape which had recovered from the disease had a distinctly curative value. He has applied the principle to man, with encouraging results. The serum should be obtained if possible from a patient who has recovered from the disease within the last 5 years, but the antibodies remain in the blood for a considerably longer time. From 5 to Io c.c. should be injected into the spinal canal every day for 8 days. The serum should be given if possible in the prodromal stage of the disease. 


\section{THE INTRA-SPINAL TREATMENT OF NEURO-SYPHILIS}

For purposes of treatment the classification of nervous syphilis into interstitial and parenchymatous is one of great value. The former, the so-called cerebrospinal syphilis, has always been recognized as being amenable to treatment. Long before the days of salvarsan and intraspinous injections it was a delight to watch a syphilitic ocular palsy clear up under mercury and potassium iodide. The intravenous administration of salvarsan has rendered the treatment of this condition still more satisfactory. But the treatment of parenchymatous nervous syphilis - general paresis, tabes dorsalis - has long been the despair and the opprobrium of the neurologist.

Our increased knowledge of the relation of the neural clements to the cerebrospinal fluid offers some explanation for the inadequacy of treatment. Spirochætes in the walls of the blood vessels and in the meninges can be readily reached by drugs circulating in the blood. But the nerve cells are peculiarly isolated from the blood stream. They are bathed by the fluid of the perineuronic lymph spaces, which in its turn communicates directly with that of the perivascular spaces and with the main body of the cerebrospinal fluid. The epithelium of the blood vessels and that covering the choroid plexus exerts a peculiar selective action which prevents toxic substances passing out of the blood stream and injuring the delicate nervous elements. Unfortunately this selective and protective mechanism proves the greatest obstacle to the therapeutist, for it frustrates all his efforts to reach the nervous tissue from the blood stream. As a matter of fact even in cases of salvarsan poisoning only the most infinitesimal quantities of arsenic have been found in the cerebrospinal fluid.

In order to overcome this difficulty Swift and Ellis devised the method which is known by their name, the object of which is to circumvent the obstacle presented by the choroid plexus by introducing the drug directly into the subarachnoid space. It was considered undesirable to inject the drug in the pure form into the lumbar sac, as the results of some French in- 
vestigators along this line had not been encouraging. It was therefore decided to give the drug intravenously, and after a certain interval had elapsed to withdraw the serum thus salvarsanized and use it for lumbar injection. The advantage of this method is that the serum withdrawn contains many antibodies which may have been produced by the body in response to the action of the salvarsan on the spirochæetes. Its disadvantage is that it is impossible to be certain how much salvarsan is being injected intraspinally.

The details of the method are as follows. . The patient is given an intravenous injection of 0.5 or $0.6 \mathrm{gm}$. of salvarsan, or a corresponding quantity of neosalvarsan or diarsenol. In an hour's time $6 \mathrm{oz}$. of blood are withdrawn. Swift and Ellis concluded from their experimental work that an hour was the interval which provided the greatest concentration of antibodies in the blood. The blood is allowed to stand overnight and clot. The serum is separated and centrifuged thoroughly until it is absolutely clear from red corpuscles. This is of great importance, as the presence of hremoglobin in the injected serum may produce a violent reaction. The serum is carefully pipetted off, placed in a water bath at $56^{\circ} \mathrm{C}$. for half an hour, and is then ready for injection. Swift and Ellis recommend that it should be diluted with twice the quantity of saline solution, but I have not found this of any advantage. They diluted Io c.c. of serum with 20 c.c. of normal saline, but 20 c.c. of pure serum may be used without producing an undue reaction. Should the patient be specially sensitive to the action of the drug, I 5 c.c. of serum may be diluted with I 5 c.c. of saline. Lumbar puncture is now performed, and a quantity of fluid larger than the amount of serum to be injected is drawn off. The serum is warmed to body temperature, and allowed to run into the subarachnoid space by gravity exactly as in the administration of antimeningitic serum. During the operation the patient should be in the recumbent posture, and when it is over the foot of the bed should be raised on blocks so as to encourage the flow of serum.

The obvious objection to the Swift-Ellis method is that an 
unknown amount of arsenic is being injected into the spinal canal. This objection, however, is probably more apparent than real, for the results suggest that very much the same quantity of the drug is used each time. A more serious objection is that the patient cannot have an intraspinal dose unless he first receives an intravenous injection. In cases where intensive treatment is being used it may be possible to give injections at more frequent intervals by the intraspinal than by the intravenous route.

Ogilvie accordingly introduced a modification of the treatment, by which the salvarsan is added to the serum outside instead of inside the body. Blood is withdrawn from a vein as before and the serum separated. To io c.c. of serum is added from $0.25 \mathrm{mg}$. to $0.5 \mathrm{mg}$. of salvarsan, which has been dissolved in a small quantity of distilled water and neutralized. The serum is inactivated for half an hour at $56^{\circ} \mathrm{C}$., and is administered in the usual way. Salvarsan should also be given intravenously every ten days or two weeks. From the point of view of convenience in private work when there are only one or two cases to treat the Swift-Ellis method is the most satisfactory. In a hospital clinic, however, in which there may be a dozen or more cases the Ogilvie method is very convenient, for the salvarsanized serum can be made up in bulk and given rapidly. As regards results statistics up to the present do not show any striking differences. Byrnes of the Johns Hopkins Hospital has introduced still another method, in which he substitutes mercury for salvarsan. It has the great advantage of cheapness. When an inorganic salt of mercury comes in contact with albumen, an albuminate of mercury is formed. This albuminate is insoluble in small quantities of serum, but soluble in excess. It was found that 6 c.c. of serum would hold $0.02 \mathrm{gm}$. in solution. A safe dose for intraspinous injection is 0.00I $3 \mathrm{grm}$. which is dissolved in the patient's own serum. Enough blood is withdrawn to yield $I_{5}$ c.c. of serum, and the serum removed by centrifuging in the usual way. In I c.c. of distilled water is dissolved o.oor3 grm. mercuric chloride, and the whole 
added to 12 c.c. of serum, which is heated at $56^{\circ} \mathrm{C}$. for half an hour. The mercurialized serum is injected into the spinal canal just as before.

All of the above are intraspinal methods. It has already been pointed out, however, that although the flow of fluid is from the spinal canal to the base of the brain it is also from the cortex to the base. Little flow apparently takes place from below to above the tentorium. As the chief seat of the disease in paresis is the cerebral cortex various methods have been devised for bringing the drug into more direct relation with the cortex. Ballance, after making a trephine opening, has punctured the corpus callosum and injected the salvarsanized serum directly into the lateral ventricle. Wardner, on the other hand, makes a small opening into the cerebral subarachnoid space, withdraws 30 c.c. of cerebrospinal fluid, and then injects the salvarsanized serum. On theoretical grounds this would seem to be the most promising method. As for results, time must be allowed to tell its tale.

If the intraventricular method should come into vogue it will afford an excellent opportunity for comparing the composition of the ventricular and the spinal fluids. A few observations have already been made along this line, and it has been found that the spinal fuid contains more cells and globulin than the ventricular. Indeed these tests may be positive in the former but negative in the latter. The Wassermann and colloidal gold reactions may be very weak in the ventricular but quite intense in the spinal fluids. Further observations on differences in the two fluids occurring in various forms of disease are greatly to be desired.

In judging the effects of treatment upon a case of neurosyphilis attention must be paid ( $\mathrm{I}$ ) to the clinical condition of the patient and (2) to the pathological changes in the spinal fluid. It is important to bear in mind; however, that spontaneous remissions may occur in the clinical course both of tabes and paresis. It is well known that a case of paresis may occasionally show an extraordinary temporary improvement 
in his mental and physical condition. Such remissions may last from several months to a year. Similar inexplicable periods of improvement may also occur in tabes. If the spinal fluid be examined during these intervals it will never be found to have returned to normal. Mitchell, Darling, and Newcomb, however, found from repeated observations on selected cases that the cell count may fluctuate to a remarkable degree. In several of their untreated cases of paresis the cell count varied on different occasions from I to over roo. These various facts must be borne in mind in forming a critical judgment of the effects of treatment in neuro-syphilis, for sometimes the spontaneous improvement both clinical and cytological would deceive the very elect.

Even when the subject is approached in this critical mood, however, the results of the new methods of treatment are in many cases calculated to make the most skeptical enthusiastic. The results in cerebrospinal or interstitial syphilis are brilliant, as was to be expected. Walker records a case of syphilitic meningitis in which the cell count dropped from 9,80o to I 26 after three intraspinal injections. In the early stages of cerebrospinal syphilis it may appear hardly necessary to resort to intraspinal medication, for by intravenous treatment alone the symptoms may be completely relieved, the cell count return to normal, and the Wassermann reaction no longer be obtained even with I c.c. of fluid. It is always wise, however, to give a few intraspinal injections. Chronic and long standing cases may show some symptomatic improvement with intravenous treatment, but the spinal fluid is not affected until the intravenous are combined with intraspinal injections. The cell count is the first of the pathological conditions to be affected, and it can be watched dropping week by week until it reaches normal. As Walker has pointed out, it is the endothelial cells which are the first to go, followed, at a short interval, by the small lymphocytes. The globulin is more difficult to influence. After repeated injections, however, it also can usually be reduced to normal. The Wassermann is the most obsti- 
nate of the changes. In some cases it will be found impossible to abolish it. As a rule, however, treatment will result in a fluid which will give a negative reaction with I c.c.

But it is with regard to its success in the parenchymatous forms of neuro-syphilis that any new treatment must stand or fall. What hope has the new therapy to offer to the victims of paresis and tabes? Not a certainty of cure. That was hardly to be hoped for, and certainly never claimed. But at least the strong probability that the symptoms will be to some extent alleviated, the course of the disease stayed, and the possibility that in favorable cases an actual cure may be achieved. And can more than this be done in diseases of the heart, kidney or pancreas? Once the parenchymatous tissue of an organ has been replaced by interstitial tissue no power on earth can make that organ normal again. If, however, the injurious agent be removed or destroyed further downward progress may be arrested.

No one who has looked at the brain of an advanced paretic or at the posterior columns of a tabetic cord will expect patients suffering from these diseases to be restored to a normal condition. Everything depends on the stage of the disease at which treatment is commenced. As Cotton remarks, the varying results obtained by those practicing the treatment depend rather on the stage of the disease than on the modification of treatment used. Cases seen in private or in a neurological clinic will naturally give very different results from inmates of asylums who are passing into a state of dementia.

The question of the very earliest diagnosis of paresis and tabes is therefore of incalculable importance, for it is in the very early stage that there is a chance of completely arresting the course of the disease and restoring the patient to health. The results have been most satisfactory in tabes, considerably less so in paresis. Even in the latter, however, astonishing improvement sometimes results. Thus Cotton records the case of a German woman suffering from paresis who was admitted to the asylum in a state of acute excitement. The four reactions of Nonne were positive. On admission she was un- 
able to speak a word of English. After a course of intraspinal treatment she made a good recovery, learned English, and when she was discharged she was able to converse fluently in that language.

Tabetics may confidentially expect to receive very great symptomatic relief. The severe pains which are so distressing a feature of the disease are usually relieved in a remarkable degree and often completely abolished. The gastric crises, attacks of giddiness, headaches, bladder disorders and other troubles are often greatly improved. Even the ataxia may become considerably less.

The spinal fluid is-more resistent to treatment than in the case of cerebrospinal syphilis, but if the treatment be persisted in it will ultimately respond. In early cases the cell count and globulin can be reduced to normal, and in some instances the Wassermann reaction may become negative with I c.c. Cases of longer standing will cause more trouble, and it may be impossible to abolish the positive Wassermann. Usually, however, it can be greatly diminished in intensity. The cases which respond best to treatment are those in which the cell count is highest, indicating probably that a marked meningeal element is present. In such cases the rapid fall in the number of cells is generally accompanied by a corresponding improvement in the clinical condition.

It is in paresis, as was to be expected, that the greatest difficulties are experienced. Nothing can be hoped for in advanced cases. It is to the early cases - indeed the very earliest possible cases - that we must look if we wish to stay the course of the disease. In these cases results have already been obtain which indicate that the future of the paretic is not now as hopeless as it has been in the past. And even in cases which have passed this earliest stage a long series of injections should certainly be tried, for both the mental and physical condition may occasionally show astonishing improvement. The tremors may disappear, the handwriting may change from an illegible scrawl to an example of good penmanship, and the mental improvement may be so great that 
the patient is able to return to his home life, and perhaps even resume his civil occupation. In short, the combined intraspinal and intravenous salvarsan treatment has accomplished for general paresis what no other form of treatment has ever done before. It is, however, very necessary still to preserve a critical attitude towards the whole matter, for the introduction of any new therapeutic measure has always been followed by reports of many successful cases. It is only later that we hear of the failures.

It is difficult to say how long the treatment should be continued. Everything depends on the individual case, the improvement in the clinical condition, and the response of the spinal fluid. Just as a physician nowadays should not feel satisfied with his treatment of a case of diabetes until he gets the urine completely sugar free, so in the treatment of neurosyphilis it should be the ambition of the doctor to get the cerebrospinal fluid cell free, globulin free, and if possible with a negative Wassermann.

Occasionally it may happen that treatment is too energetic and intense, with the result that a meningeal reaction is produced. The patient develops severe headache and other signis of meningitis, and the spinal fluid shows a very marked pleocytosis, most of the cells being polymorphs. These changes, however, are only transient and are merely an indication that the treatment must be pursued with less energy.

\section{TETANUS}

There is still no specific curative treatment for tetanus. All that we can do is to try to control the convulsions, and tide the patient over the immediate danger of respiratory paralysis. For this purpose our most efficient remedy is the intraspinal injection of magnesium sulphate. A 25 per cent. solution of magnesium sulphate is prepared and warmed to body temperaturc. Of this solution I c.c. is used for every 20 lbs. of body weight. The patient is put under a general anæsthetic and a quantity of cerebrospinal fluid withdrawn equal in bulk to the amount of solution which it is intended 
to inject. Relief, evidenced by complete relaxation which may last for 24 hours, is often obtained at once, owing to the depressant action of the magnesium sulphate on the lower motor centers in the cord. If the symptoms recur a second but smaller dose should be given, 0.8 c.c. for every $20 \mathrm{lbs}$. The chief danger is respiratory paralysis. If this occurs a large quantity of cerebrospinal fluid should at once be withdrawn, and the subarachnoid sac washed out with normal saline, the head being kept well elevated.

It will be seen that at present the therapeutics of the cerebrospinal fluid fall under two headings: (I) drainage of the fluid and (2) injection of certain sera and drugs. Excellent results have been obtained in certain conditions and the outlook is very bright. The method of intraspinal injection in particular is capable of great expansion, and the therapeutic possibilities are extremely encouraging. Before the full benefits of this measure can be reaped, however, it is necessary that our knowledge of the origin and destination, the ebb and flow, the streams and channels, and the course of circulation of the fluid should be still more extended and systematized.

\section{REFERENCES}

Babinski, J.: Sur le traitement des affections de l'oreille et en particulaire du vertige auriculaire par la rachicentèse. Ann. des Mal. de l'oreille., 1904, XXX, p. ror.

Bacigalupo, J.: Eine neue Behandlungsmethode der Tuberkulosen Meningitis. Münch. med. Wchnschr., I915, LXII, p. 222.

Ballance, C. A.: A method by means of which remedial agents may be mingled with the cerebrospinal fluid. Lancet, 1914, I, p. 1525 .

Byrnes, C. M.: The intra-dural administration of mercurialized serum in the treatment of cerebrospinal syphilis. Jour. Am. Med. Assoc., 1914, LXVII, p. 2182.

Costa, R.: Punctura Lombare nel feto duranto l'estrazione podalica nell' interesse della vita del feto stesso. Gazette degli. Ospedali a delle Clinicke, Milan, Sept. 3, 1916, XXXVII.

Cotton. The treatment of paresis and tabes dorsalis by salvarsanized serum. Amer. Jour. Insanity, I915, LXXII, pp. 125, 35.5 , and 485 . 
Fischer, L.: Convulsions during pertussis. New York Med. Jour., I9I4, C. p. I054.

Mitchell, H. W., Darling, A., and Newcomb, P. B.: Observation upon spinal fluid cell counts in untreated cases of cerebrospinal syphilis. Jour. Nerv. and Mental Dis., I914, XLI, p. 686.

Ogilvie, H. V.: The intraspinal treatment of syphilis of the cen-. tral nervous system with salvarsanized serum of standard strength. Jour. Am. Med. Assoc., I9I4, LXIII, p. 22.

Ogilvie, H. S.: The treatment of general paresis. Am. Jour. Syphilis, I9I7. I, p. 509.

Swift, H. F. and Ellis, A. W. M.: The direct treatment of syphilitic diseases of the central nervous system. New York Med. Jour., I912, XCVI, p. 53.

Swift, H. F.: Observations on types of response in treatment of syphilis of the central nervous system. Amer. Jour. Syphilis, 1917, I, p. 524 .

Walker, I. C. and Haller, D. A.: The treatment of syphilis of the central nervous system with intravenous salvarsan alone, with intravenous salvarsan and intraspinal salvarsanized serum together, and with intraspinal salvarsanized serum alone. Arch. Int. Med., 1916, XVIII, p. 376.

Wardner, D. M.: A report of 5 cases of the intracranial injection of autosero salvarsan. Am. Jour. Insanity, 19I5, LXXI, p. 459.

Wilson, W. T.: Lumbar puncture for the relief of convulsions in puerperal eclampsia. Jour. Am. Med. Assoc., I9I6, LXVII, p. 742.

Wolff, S. and Lehmann, W.: Uber einen durch intralumbale und intraventriculare Aethylhydrocuprein-Injektionen geheilten Fall von Pneumokokkenmeningitis Deut. med. Wchnschr., I9I3, XXXIX, p. 2509. 


\section{ADDITIONAL REFERENCES}

Ayer, J. B.: Lumbar puncture and examination of the spinal fluid in affections of the eye. Arch. of Ophthalmology, 19I6, XLV, No. I.

Ayer, J. B. and Viets, H. R.: Spinal fluid findings characteristic of cord compression. Jour. Am. Med. Assoc. 1916, LXVII, p. 1707.

Barbet, F. H.: Finding of arsenic in the cerebrospinal fluid following intravenous administration of neosalvarsan. Calif. State Jour. of Medicine. I9I6, XIV, No. II.

Baumel, J.; La ponction lombaire dans les commotions nerveuses et les traumatismes due crâne par projectiles de guerre. Lyon. chir. I9I5, XII, p. 27 I.

Bloch, L.: The value of spinal puncture in the etiologic diagnosis of cardiovascular diseases. Jour. Am. Med. Assoc. I917, LXVIII, p. 69 I.

Bronstein, Boris: Acute syphilitic meningitis. International Clinics, I9I6, Vol. IV, p. 23.

Church, A.: Some modern views of syphilis of the nervous system. Jour. Am. Med. Assoc., 1916, LXVI, p. I596.

Collins, J.: Pathognomonic alterations of the cerebrospinal fluid in syphilis of the nervous system. An. Jour. Med. Sc., I916, CLI, p. 222.

Dana, C. L.: Puncture headache. Jour. Am. Med. Assoc., 1917, LXVIII, p. IоI7.

Demole, V.: Coagulation and xanthochromia in compression of the spine by a tumor. Rev. neurol., r9I5, XXII, p. 649.

Dercum, F. X.: Metabolism in insanity. Jour. Am. Med. Assoc., 1916, LXVI, p. I 186.

Dinar, J.: Observations on the cerebrospinal fluid in poliomyelitis. Med. Times, 19r6, XLIV, p. 287.

Donaldson, R.: An improved type of needle for lumbar puncture. Lancet, I9I6, CXCI, p. 982.

Elser, W. J. and Huntoon, F. M.: Studies on meningitis. Jour. Med. Research, I909, XX, p. 37 I.

Gilpin, S. F. and Earley, T. B.: Drainage of cerebrospinal fluid as a factor in the treatment of nervous syphilis. Jour. Am. Med. Assoc., I916, LXVI, p. 260.

Golla, F. L. and Symes, W. L.: Simultaneous records of cerebrospinal pressure and of respiratory movements. Jour. Phys., I9I6, L, No. 5 .

Halverson, J. O. and Bergeim, O.: The calcium content of the 
cerebrospinal fluid particularly in tabes dorsalis. Jour. Biol. Chem., 19I6, XXIX, p. 337.

Hort, E. C.: The meningococcus of Weichselbaum. Brit. Med. Jour., I9I7, II, p. 377.

Kafka, V.: Ueber den heutigen stand der Liquordiagnostik. Münch. med. Woch. I9I5, LXII, p. 105.

Kahn, R. L.: Folin and Denis' method of nitrogen determinations by direct Nesslerization and its application to spinal fluids. Jour. Biol. Chem., I9I6, XXVIII, p. 203.

Labbé, Zislin, and Cavaillon: Les méningites cérébrospinales et leur traitement par la trépanation et l'injection de serum intraventriculaire. Bull. de l'Acad. de Méd., I9ı6, LXXV, No. II.

Leopold, J. S. and Bernhard, A.: Chemistry of spinal fluid in children. Am. Jour. Dis. Child., I9I7, XIII, p. 34.

Levinson, A.: A uniform method for collection of spinal fluid into test tubes. Med. Record, 1916, LXXXIX, No. 17.

Meltzer, S. J.: Inhibitory properties of magnesium sulphate and their therapeutic application in tetanus. Jour. Am. Med. Assoc., 1916, LXVI, p. 933.

Nobel, E.: Untersuchung tuberkulös meningitischer. Punktionsflüssigkeiten mit Hilfe der Ninhydrinreaktion. Münch. med. Woch., 1915, No. 52.

Reece, R. J.: Anthrax simulating cerebrospinal fever. Lancet, I9I7, CXCII, p. 406.

Schloss, O. M. and Schroeder, L. C.: Nature and quantitative determination of the reducing substance in normal and pathologic cerebrospinal fluid. Am. Jour. Dis. Child., I9I6, XI, p. I.

Simon, G.: Zur Untersuchung der Liquor cerebrospinalis nach Mayerhofer. Wein. klin. Woch, I9II, XXIV, p. 94.

Stern, C.: Verleichende Untersuchungen über die ThomaZeiss'sche und Fuchs-Rosenthal'sche Zählkammer bei Liquoruntersuchungen. Münch. med. Woch., 1916, LXIII, No. 3.

Stevens H. C.: The spinal fluid in Mongolian idiocy. Jour. Am. Med. Assoc. 1916, LXVI, p. 1373.

Stoddard and Cutler: Torula infection in man. Monographs of the Rockefeller Institute. No. 6, 1916.

Taylor, F. E.: The antibody content in meningeal infections. Lancet, I9I7, CXCII, p. 418.

Torrey, R. G.: Influenzal meningitis. Am. Jour. Med. Sc., 1916, ClII, p. 403.

Weston, Paul G.: Reaction of the cerebrospinal fluid in the psychoses. Jour. Med. Research, I9I7, XXXV, p. 367. 


\section{INDEX}

Absorption of cerebrospinal fluid, I8

Acetone in cerebrospinal fluid, $\mathrm{I} 46$

Alcoholism, 145

Ammonium sulphate test for globulin, 5I

Arachnoid villi, 9, 20

Bacteriology of cerebrospinal fluid, 86

Blood in cerebrospinal fluid, $4 \mathrm{r}$

Carbon dioxide as stimulant to flow of cerebrospinal fluid, 25

Cerebral abscess, 124

Cerebral hæmorrhage, I26

Cerebral thrombosis, 127

Cerebral tumor, I23

Cerebrospinal rhinorrhœa, 18

Cells, differentiation of, by Alzheimer's method, $65^{\circ}$ methods of counting, 60 origin of, 70 varieties of, 67

Chorea, 148

Choroid plexus, 12

Circulation of cerebrospinal fluid, 23

Colloidal gold reaction, 79 in cerebrospinal syphilis, II4 in general paresis, II9 in acute poliomyelitis, 137

Composition of cerebrospinal fluid, 49

Concussion, I3I

Counting chamber, Fuchs-Rosenthal, 62

Cytology of cerebrospinal fluid, 60

Dementia præcox, 144

Diabetes mellitus, 146
Echinococcus cyst of brain, 123

Electrical conductivity, 46

Encephalitis lethargica, I27

Epilepsy, I44

Erythrochromia, 43

Freezing point, 45

Function of cerebrospinal fluid, 29

General paresis, II7 juvenile form, 120

Globulin, 50 in acute poliomyelitis, 136 in general paresis, 118 in meningococcal meningitis, 95 in tabes dorsalis, 116 in tuberculous meningitis, I07 tests for, 5I

Gold reaction of Lange, 79

Herpes zoster, I4I

Hydrocephalus, treatment of, 130 varieties of, 129

Hydrogen-ion concentration, 46

Idiocy, 145

Insanity, 143

Jaundice, 45

Lange's colloidal gold reaction, 79

Lumbar puncture as therapeutic measure, 155 after effects, 38

Lymphocytosis in acute poliomyelitis, 136

in general paresis, 117

in mumps, 149

in tabes dorsalis, 115

in turberculous meningitis, 102 
Manic-depressive insanity, 143

Mastic test, $\mathbf{8 4}$

Meningitis, meningococcal, 92

pneumococcal, 97

serous, 105

serum treatment of, 158

staphylococcal, I04

streptococcal, 99

typhoid, 104

tuberculous, 100

Meningococci, methods of culture, 94

Multiple sclerosis, I4I

Mumps, 149

Myelitis, acute, I35

Nature of cerebrospinal fluid, 3I

Noguchi test for globulin, 52

Nonne-Froin syndrome, 133

Nonne test for globulin, 5I

Edema of brain, 131

Origin of cerebrospinal fluid, 14

Pacchionian bodies, 7

Pandy test for globulin, 52

Permeability of meninges, 26

Physical properties of cerebrospinal fluid, 4 I

Pituitary gland, secretion of posterior lobe, 18

Pneumonia, cerebrospinal fluid in, I5I

Poliomyelitis, acute anterior, I3I

Potassium permanganate index, 53

Pressure, methods of determining, 34

Protein content, 50

Reaction, 46

Sleeping sickness, $15 \mathrm{I}$

Specific gravity, 46
Spinal cord tumor, 133

Subacute combined degeneration 140

Subarachnoid space, anatomy of, 6

Sugar, 55

in acute poliomyelitis, 137

in diabetes mellitus, 146

in general paresis, $\mathrm{II}_{7}$

in meningococcal meningitis, 95

in tuberculous meningitis, IOI

Swift-Ellis method of treatment, 163

Syphilis, cerebrospinal, II 3 early III

Syphilis of the nervous system, treatment of, ${ }^{6} 63$

Syringomyelia, I35

Tabes dorsalis, II4

Tetanus, treatment of, I7o

Trichiniasis, 152

Tuberculous meningitis, 100 treatment of, I62

Tubercle bacilli, demonstration of, 102

Turbidity, 45

Urea, 58 estimation of, 148

Uremia, 146

Urotropin, excretion of, in cerebrospinal fluid, 26

Ventricles, anatomy of, 12

Wassermann reaction, 73 in cerebrospinal syphilis, $\mathrm{II}_{3}$ in early syphilis, II 2 in general paresis, II9 in tabes dorsalis, II6

Xanthochromia, 43 in tumor of spinal cord, 133 



UNIVERSITY OF CALIFORNIA LIBRARY

\section{Los Angeles}

This book is DUE on the last date stamped below.

DEC 28 \$96.

DEC 17 RECD

MAR 301966

MAR 18 RECD

OCT 191966

OCT 20 REC'D

DBIQMEA: CIB. $+B=$

SEP 18 RECT

SEP 18 REC 


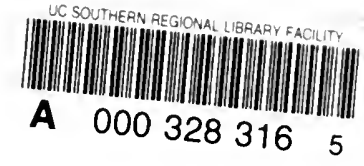

\section{in 203 B692p 1920 \\ Domedieal \\ Litrug}

$a^{-1}$ 

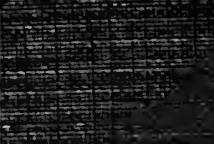

至

intitis

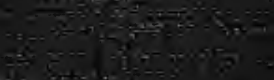

$\left.x^{2}=1^{2}\right)^{2}$

$x$

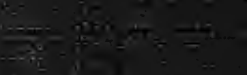

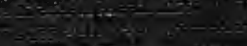

